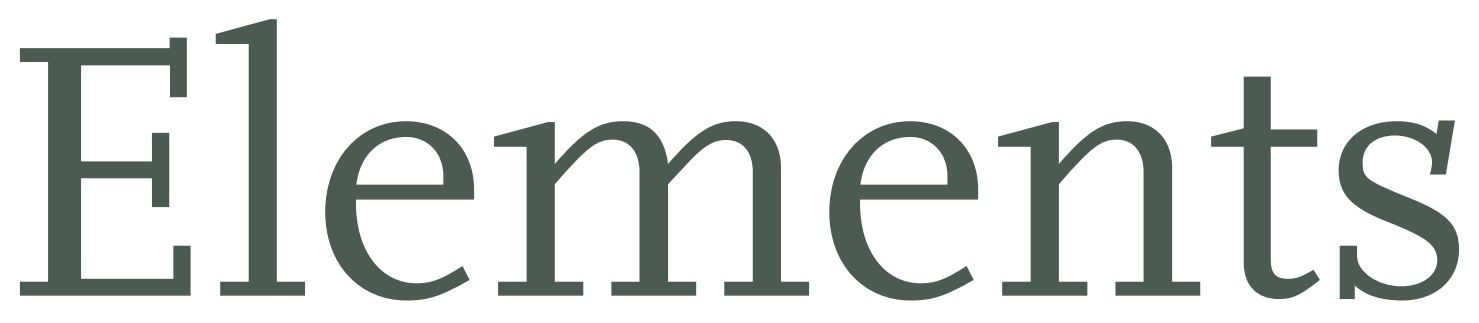

Fall 20II

00000000000000000000000000000000000000

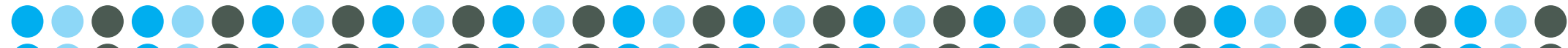

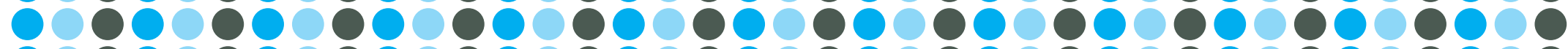
00000000000000000000000000000000000000 000000000000000000000000000000000000000 000000000000000000000000000000000000000 000000000000000000000000000000000000000 00000000000000000000000000000000000000 000000000000000000000000000000000000000 000000000000000000000000000000000000000

Volume $7::$ Issue 2 


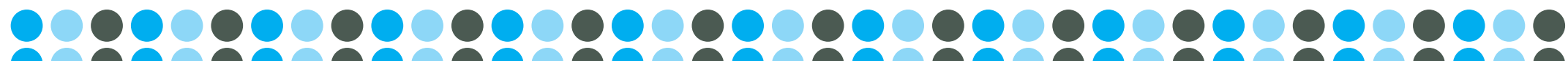
. ○०8

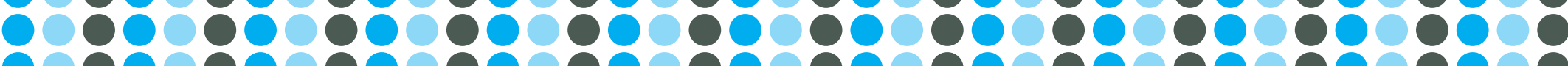

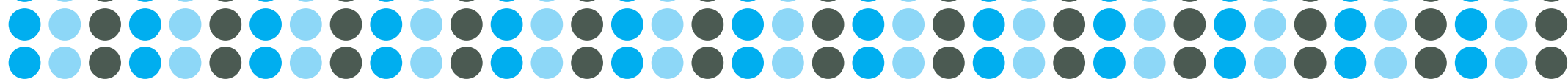

HANK YOU

\section{LEMENTS STAFF}

EDITOR-IN-CHIE

W ts and the Office of the Dean for the College of Arts and Sciences

for the financial support that makes this issue possible. We would also

permission to print Frank Lloyd Wright's work in this issue.

QUESTIONS \& CONTRIBUTIONS

NICK COCHRAN-CACGAN

ALI MCDONALD

lements@ @bc.edu. The next deadline is Friday, November 4, 20II. All our website at www.bc.edu/elements for updates and further information

Frontal temporal dementia

Zephyr / Photo Researchers, Inc.

PERIODICITY

Elements is published twice an academic year in the fall and spring

The information provided by our contributors is not independently verifed by Elements. The materials presented represent the personal opinions of the individual authors and do
not necessarily represent the views of Elements or the Boston College community.

Elements, The Undergaduate Research Journal of Boston College
volume 7 , Issue 2 , all 2011 .

Volume 7 , Issue 2, Fall 201

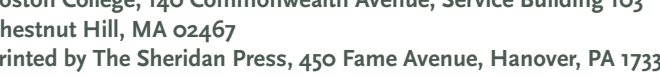

Copyright $\odot 2011$ by the Trustees of Boston College
HUMANITIES

SAM BARON, Editior

SARAH COLLIER, Edito
MiKE HENRY, Editor

BRENDAN KELLY, Edito
ALI MCDONAL, Editor

DAN SOLOCGUREN, Editor

SCIENCES

ADI ASHOK, Senior Editor

S. EVAN COOPER, Editor

CHRIS GACNE, Editor

CHRISTINA HAN, Edito

ALEXANDER TINGLE, Editor

WEB DESIGN

DAN SOLOCUREN, Ser
SAM BARON, Editor

FACULTY ADVISOR

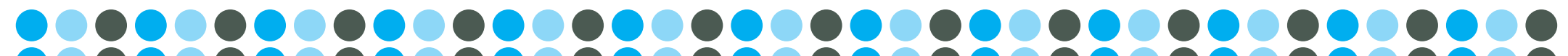

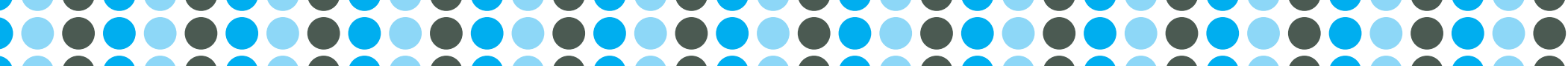
0888080808 00800800800800800800800800800800800800

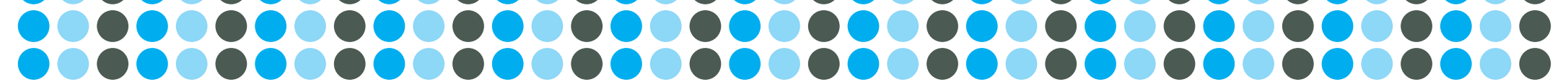

\section{EDITOR'S NOTE}

The photo on the cover of this issue shows one of the clearest physiological ground information and context for the research presented in Elements. effects detectable in frontal lobe dementia: a whole area of the diseased These reviews will hopefully allow our readers to get the most out of every
brain displays decreased activity indicated in this picture by a lack of color
article we publish. As an added benefit seventeen authors are featured in in the part of the brain directly behind the forehead. Though frontal lobe this issue, twice as many as Elements usually publishes.

disease are extremely prevalent, levying a burden of \$70 billion in U.S. Ultimately, the "Perspectives" section provides an outlet for authors to wishes of a patient, taken in combination with the professional advice of a deavors and the Western cultural tradition that we all share. I am confident though-out ethical framework. perpetually opposed concepts but by a certain "chiasm" - a blending that
builds bridges both within the academy and beyond the academy. Thank As with Orr's article, the other articles in this issue share this spirit of you for taking part in our project. sngle piece of art in a larger historical context or by sketching a philosophical way of understanding nature, the authors in this issue contribute wo that broadens the horizon of work in their field. Indeed, I take this keen a conversation-to be one of the hallmarks of scholarship at Boston College. Undergraduate scholarship at Boston College is expanding, and so is Ele ments. As Elements expands, I hope that it mirrors Boston College's ethos
in research, public service, and personal development. To that end, this latest issue of Elements introduces a new segment labeled "Perspectives." A ter years of only solichids substions tor peer revew and selection for the research articles. These small, invited reviews of literature provide back-
P. Brian Pracz

\section{sincely}




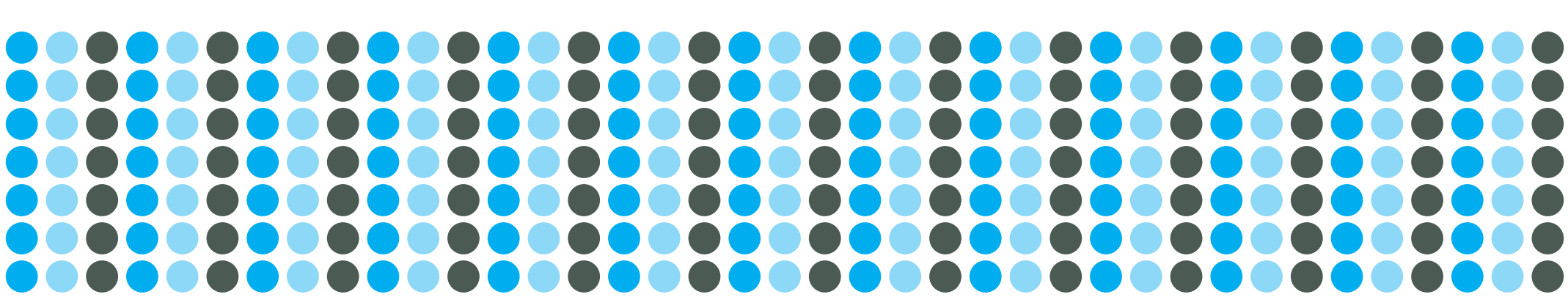

CONTENTS

6 PERSPECTIVES

A new, minature review segment of the journal in which undergraduate experts from a variety of fields provide an academic context for the articles featured in this issue of Elements.

I3 THE "NOW PATIENT" AND THE "THEN SELF": CONFLICTING VIEWS IN THE ETHICS OF DEMENTIA CARE

Andrew Or

Investigating the ethical dilemmas surrounding the consideration of dementia patients' wishes, including weighing the desires of the "then" patient against the current happiness of the "now" self.

25 COPING IN JORDAN: THE PLIGHT OF IRAQI-FEMALE-HEADED HOUSEHOLDS Sophia Moradian

Interviewing displaced Iraqi women to understand the economic coping mechanisms of female-headed-households in Jordan.

35 THE MYSTERY OF MITHRAS: ANALYZING RELIGIOUS PRACTICES IN DURAEUROPOS

Jenna Howarth

Unearthing the unique cult of Mithras to understand the relationships between religions in the ancient city of Dura-Europos

43 CULTURE IN CONFLICT: REMEMBERING THE VIETNAM WAR THROUGH CINEMA

Rosa Maribel Colorado

Reflecting upon the con war culture and "The American Hero."

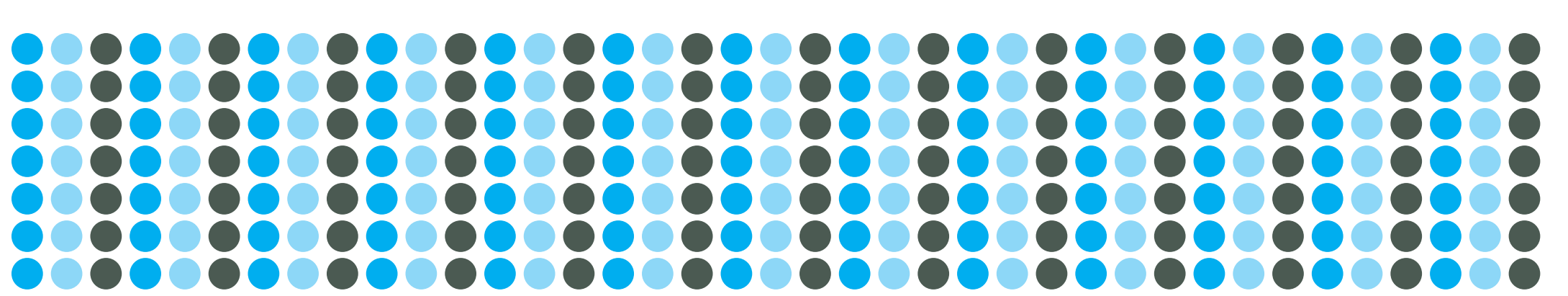

33 THE VIRGIN OF JEANNE D'EVREUX: AN AFFECTIONATE MOTHER IN AN UNAFFECTIONATE ERA

Brian D. Varian

Gilding the virgin of Jeanne d Evreux, revealing its origins while uncovering its position as a reflection of transformative style and enduring iconography.

6 I A VIABLE OPTION: ORGAN PROCUREMENT IN THE FACE OF A NATIONAL SHORTAGE

Zachary T. Martin

Examining the significance of altering policy to allow for the procurement of organs from non-heart-beating cadavers.

73 FRANK LLOYD WRIGHT: THE POWER OF ILLUMINATION IN ARCHITECTURE Tiphaine Leverrier

Illuminating the interplay of shadows and light in Frank Lloyd Wright's architectural designs

8 I TRANSCENDENTAL GEOLOGY: TOWARDS A PHENOMENOLOGY OF NATURE AND HISTORY

Karen Kovaka

Reframing the philosophy of nature by providing a phenomenologically nuanced account of work by MerleauPonty, Dilthey, and Husserl.

92 AUTHOR BIOGRAPHIES

9. LIST OF ARTWORK 


\section{Perspectives}

GOING GREEN: SOURCES IN ARCHITECTURE

by Natalie Thomas

With increasing awareness of "going green" campaigns and alternative en ergy sources, the word "organic" has become synonymous with popular
culture. In a sense, words like "sustainable" and "organic" derive their power and influence from the human desire to return to nature. Though these words have infiltrated headlines predominantly in the last decade, concern
of how we as a society relate to our environment are not unique to our genof how we
eration.

Frank Lloyd Wright discusses architecture as a reflection of societal concerns and values when he states, "All fine architectural values are huma Itth and the beginning of the 2 oth centuries, Wright asserts that our work, dwelling, and leisure spaces should mirror our values as a noble society. H was heavily influenced by the writings of Henry David Thoreau and Ralph
Waldo Emerson, and believed that the best society is one that respects its roots in nature and works with its forces in a symbiotic relationship; thus
his architecture was termed "organic.". His design for Fallingwater, a home for the Kaufmann family in Mill Run Pennsylvania, presents a marriage of nature's elements to architectural forms as he incorporates the rocks of the
hill into the hearth of the home. The hearth is commonly symbolic as the hill into the hearth of the home. The hearth is commonly symbolic as the
heart of the home therefore, it may be that Wrights emphasis on nature in this particular place is a reflection of the family as the natural nucleus of
society 3 Wright's architectural school of thought became known as the society. Wright's architectural school of thought became known as the
Prairie School Movement in which architects strove to incorporate the mor Prairie School Movement in which architects strove to incorporate the most
basic elements of nature including water, light, and heat as sources for "nasic elements of nature including wate,
new indigenous American architecture."

Today architects continue to work towards organically derived forms and functions. Renzo Piano, a contemporary Italian architect, is known for his innovative designs in which form follows function. His Living Roof of the
California Academy of Sciences is covered completely with vegetation not only mirroring the building's purpose as a science center but also servin the environment by regulating temperature, reducing storm water runofff
and creating a natural habitat that filters pollutants and carbon dioxide. Piano's architecture presents a contemporary vision of Wright's Prairie
School. His architecture is not just a reflection of society's cerent cerns, but also has undertones that render interest in the environment and greenn; thus, todays cony
back to almost a century

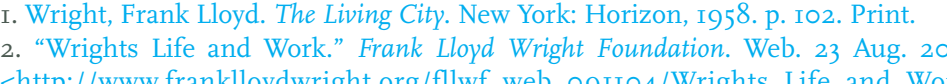
intp://www franklloydwright.org ffllwf web ogrou/Wrights_Life_and_Work.

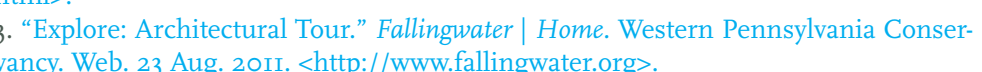

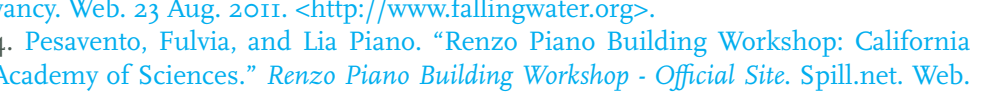
23 Aug. 20II. ¿http://www.rpbw.com/s.

'HE MADONNA AND THE HUNDRED YEARS' WAR

by Theresa Cunningham

The endless battles of the Hundred Years War plagued fourteenth centur France, bringing with it intermittent violence which punctuated daily lif
for over a century. Actually a series of several wars, the conflict known he Hundred Years War was not the first dispute between France and England. The two nations had engaged in sporadic power struggles since the Norman invasion. Yet, as war raged on, culture flourished and Gothic a most notably in France. Throughout the decades of political turmoil and uncertainty, art focused that which remained constant, the Church. Religious imagery dominated the subject matter of Gothic art, in lofty catheoralizing messages devotional objects aiding in prayerful contemplis and reliquaries containing the venerable remains of saints. Of religious images, the Virgin and Child was one of the most widespread.

The social changes of this transitional era, including the rising prominence mission luxury goods for religious worship. ${ }^{2}$ In 13339 , at the onset of the Hundred Years War, a silver-gilt sculpture was completed for Jeanne Devreux, the wife of the then deceased French King Charles IV. ${ }^{3}$ The statue
peaks to the unrest in which it was created. Although commissioned the viewed by the public as a devotional aid. The chaos of the Hundred Years War did not go unnoticed by any member of French society, yet the statute nown as the Virgin of Jeanne d'Evreux exudes a calm and tenderness to

The Virgin of Jean d'Evreux is merely one example, albeit a highly regarded one, of the humanity that entered the art of the period, especially depiction

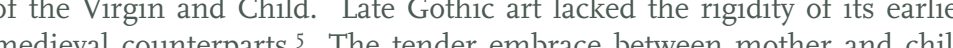
seen in the Virgin of Jeanne d'Evreux, and other works like it, was no doub comforting to those who came to St. Denis for worship. It brought into re lgious iconography, a human element not previously seen in mediev
imes. ${ }^{6}$ While the world outside the church walls was ever changing, for those living in fourteenth century France, (nearly all of whom were practiing Christians) the tender image of the Vir
reminder of the consistency of their faith.

I. Anne Curry, "France and the Hundred Years War, 1337 - I4533," in France in the

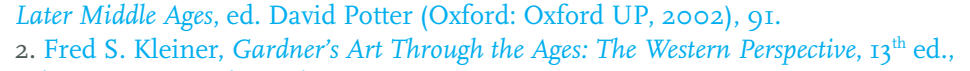

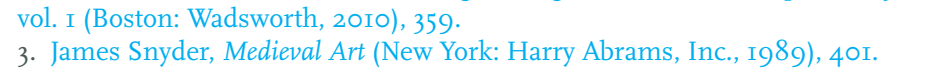
4. Curry, "France and the Hundred Years War," 93; Kleiner, Gardner's Art Through 5. Gombrich, 2

6. Emilie Male, Religious Art in France: The Late Middle Ages (Princeton: Princeton
UP, 1987 ), 137 .

MITHRAISM

by Corey Yarochowicz

As the name might imply, the mystery cults of the ancient world were secre
tive religious fraternities that tive religious fraternities that offered triumph over death by way of their
esoteric dogmata. Despite the fact that scholars understandably lack primary sources to study the mysteries acutely, they are of great importance
and intricue to Classicists because they are crucial for establishing an curate historical reconstruction of religious developments in antiguity

The Cult of Mithras is particularly intriguing for scholars. Though no liter ary sources from the cult survive save for a few wall graffitit, the cult was a forerunner in Romes increasingly popular religious cults, with practitio-
ners worshipping alongside more long-lived religious traditions of Christanity and Judaism. In spite of the lack of Mithraic literature, a number of Mithrea-houses of worship for the adherents of Mithraism, the Mithraic equivalents of churches or synagogues-survive. Excavations on the know
Mithrea suggest that the cult worshipped a central deity Mithros his rel tionship with the Sol Invictus, and his ceremonious slaughter of a bull (the so-called "tauroctony"). Reliefs of Mithras near sprouting plants suggest the
adherents connected him with harvest and life. Though the central narraadherents connected him with harvest and life. Though the central narra-
tives of the Mithraic cult remain mysterious and out of context, the archaeological record has provided important information about the cult, including the extent of its popularity with the Roman military, the cult's use of easter motifs, and the general popularity of the cult in the empire.

In the I920's, the excavation of a Roman Mithraeum in Dura Europos, eastern frontier, allowed scholars to drastically expand the archaeologic record. Attacked by Sasanian invaders in the middle of the third century C. serving a religious function along thed city's western wall in a failed fortif serving a religious function, along the city's western wall in a failed fortifi-
cation effort. This effectively sealed the city's Mithraeum, Christian baptistery, and synagogue, among numerous other buildings significant to pagan
worship, and permitted an unbelievally well preserved archaeological re cord for the city. The Mithraeum alone finds a well-preserved floor plan, paintings, bas-reliefs, and numerous graffiti that substantially increased

Dura is unique in that the study of the city's remains not only strengthens scholars' understanding of Christianity, Judaism, Mithraism, and pagan
worship in third century Rome, but also allows an in-depth study into the relationship between these religions; most of Dura's religious buildings existed side by side on the same street, suggesting a fairly tolerant religious outlook in a time when the literary record counts polemics and schism as ropos, and scholarly discussion on Mithraism; its record entertains questions about the nature and ethnographic make up of the cult's membership, its prac-

THE WAR OF A GENERATION

by Benjamin Mayer

The Vietnam War seared the American consciousness with scenes of brutal from napalm burns, of antiwar dem. Be it footage of children suffering

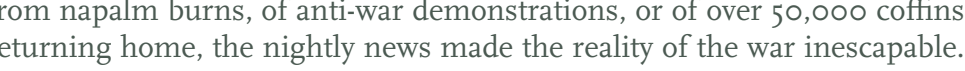
In light of this, tis no great surprise that the primary medium for exploring three decades, American flmmakers have used their own images to grap. ple with the implications of the war. "Culture in Conflict" explores the way that the images of Vietnam have evolved, highlighting essential themes jis by diser directed by Michael Cimino.

The Deer Hunter, starring Robert Di Nero, Myrell Streep, John Cazale and

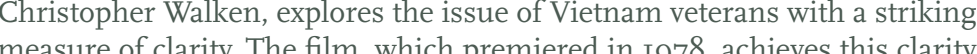
by showing a traumatic transformation in its characters that occurs because of their experience in the war. Beginning in a small steel town in Indiana, Simino attempts to portray archetypal immigrant working class characters. Walken and Stanley played by Cozale, work at the steel mill and are eager to go through the traditional rites of passage, including marriage and military service. The second act of the film cuts straight to brutal battle scenes in Vietnam and eventually a North-Vietnamese prison camp, where the charof sadistic guards. The last act of the film is dedicated to showing the drastic change in Di Nero's, Walken's, and Cazale's characters. At the end of the film, Nick and Stanley are broken men. Nick becomes a drug addict in Saigon and pays for his habit by participating in Russian roulette in a gambling
den. Stanley is confined to bed because of his wounds and atempts to isolate himself from his friends and family. Michael tries, but fails, to help his friends, ultimately remaining a mere shell of his former self. 
Although Cimino has been widely criticized for historical errors in the film such as present in the Russian roulette scenes and in his caricature of
North-Vietnamese brutality, his film holds a valuable place in the history of Vietnam War film because its primary focus is not the larger implications of the war, but rather the effects that it had on American soldiers. It was one
of the first major Hollywood films to show the difficulty Veterans incurred upon returning home. Cimino explores in depth the alienation, depres. sion, and addiction experienced by many veterans. Given that just a few years before the film premiered it was not uncommon to have soldiers recant statement It was an attempt to force the American people to reconsider the way that they had treated their veterans.

Vietnam was a watershed event in American history. Militarily it humbled America's pride as a superpower. Culturally it forced Americans to questio
their self-perceived moral exceptionalism. Socially it caused a generation Americans to doubt the judgment of their government. Through a study of
the films about the Vietnam War, one can begin to understand how these

MIGRATION: A POLITICAL AND ECONOMIC REALITY

by Samuel Hocking

The plight of international migrants and refugees is a well documented
phenomenon. In addition to struggling with the hardship of the initial dis phenomenon. In addition to struggling with the hardship of the initial dis-
location, refugees confront the difficulty of finding a place to relocate and must ensure they will be able to subsist upon arriving. Perilous endeavors,
border crossings are often fraught with encounters with militias and corrupt officials demanding outrageous bribes to guarantee safe passage.
When victims of conflict flee their home country in search of greater safety When victims of conflict flee their home country in search of greater safety and stability, they commonly encounter hostility from the native popula-
tion. They are often barred access to the formal economy, leaving them to piece together a sparse life for their families.

Along with the normal raft of concerns that accompany a large influx of
cross-border refugees the specter of terrovism also haunts displaced po cross-border refugees, the specter of terrorism also haunts displaced peo-
ples in the politically troubled Middle East. Given the porous borders of most nations in the region and the international nature of radical groups like Al Qaeda and Hezbollah, regimes pay careful attention to flows of
goods and people. Yet as economies have decayed and governments doubled down in the face of the Arab Spring, people have fled in large numbers from countries like Syria, Yemen, and Libya.

Still, this recent surge in the volume of political refugees pales in compari-
son with the number of displaced persons harbored in the Kingdom of Jorson with the number of displaced persons harbored in the Kingdom of Jor
dan. With historic and ethnic ties to the people of Palestine, Jordan houses dan. Wit historic and ethnic ties to the people of Palestine, Jordan houses
almost two million Palestinian refugees, nearly a third of the country's total population. A political broker between the United States and neighbors
countries, Jordan's King Abdullah is a moderate pragmatist who values his countries, Jordan's King Abdullah is a moderate pragmatist who values his
country's strategic position. As a consequence of its deep economic ties to country's strategic position. As a consequence of its deep economic ties to
the United States, Jordanian policy towards displaced persons tends to be more forgiving than that of most developing nations. Jordan provides refu-

Questions of displacement and flight therefore require understanding of aid funds received from family and friends in foreign nations co vital source of income for Iraqi FHHs. Altogether, remittances to developing countries totaled $\$_{325}$ in 2010. .' Given the scale of these transfers, their risen that the "brain drain" effect the exodus of capable people from deve. ances, in the unique case of refugees (who flee violence and ultimately aim contribute materially to the

This paper adds valuable anecdotal evidence to help advance the understanding of conditions endured by refugees, especially those in female ing means by which refugees cope economically the to monitor the evolmost of these measures are only temporary fixes. Despite its efficacy aid remains a crude instrument in international policy; efforts to support Iraa efugees in Jordan have been befuddled by false estimates about their numbers and diversion of funds for projects which benefit few Iraqis. ${ }^{2}$ More (designed to return the refugees to their country of origin) or a path to lega residency

The first of these solutions heavily depends on the state of Iraq. So far, depite policies designed to encourage return, many Iraqis prefer to live in Iraqis have returned home. ${ }^{3}$ Among the returnees, many cite insufficient aid and lingering violence as reasons for dissatisfaction, leading some to golicy thao few leaders have dared to broach. From the Gulf $\$$ Stesents North America, immigrants remain a scapegoat for economic problem despite contrary evidence upholding their importance to the economy.t. Given the level of education and skills possessed by many Iraqi refugees, vy: coupled with their high productivity their tax receips and denor Jordanian goods would constitute a major boo

Migration is a difficult issue. It imposes hard choices not only on host counries, but also on the millions of people uprooted from their homes an NGOs supply invaluable relief and are a necessary crutch for families transition. However, as the case of Iraqiis in Jordan proves, aid is no substiate for resettlement at home or abroad-the focus $\mathrm{m}$.

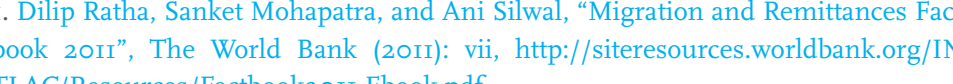

2. Nicholas Seeley, "Why Millions In US Aid May Help Few Iraqi Refugees In The End," The Christian Science Monitor (3) January 2or1)

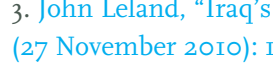

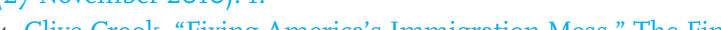
20IIl): 9. . 5. Thler Cower 2010$): 6$.

APPROACHES TO BIOETHICS

by Michele Kelley

Over the course of less than a century bioethics has quickly progressed an diversified into an academic disciple addressing a broad range of issues in-
cluding end-offlife care, reproductive technologies, genetic enhancement neuroethics, global health, synthetic biology, and nanotechnology - just to
name a few. The realities and perspectives that a bioethicist must analyze name a few. The realities and perspectives that a bioethicist must analyze
and weigh against one another in evaluating any one of these issues are and weigh against one another in evaluating any one of these issues are
often paradoxical at best. Furthermore, the moral theories applied to resolve the issues are numerous, which can make finding an objectively "right"
answer seem ineffable. One who favors a utilitarian approach will often answer seem ineffable. One who favors a utilitarian approach will orten
prefer a completely different resolution to the issue than one who favors prefer a completely different resolution to the issue than one who favors
deontological approach, and she in turn will differ from one who favors the use of natural law or situational ethics.

A very useful moral resource that arose in the late I970's is the Georgetown
Mantra of Bioethics. Applicable within many applied moral theories, the Mantra of Bioethics. Applicable within many applied moral theories, the cence and justice. The practice of bioethics is by no means reduced to these four principles, but they tend to be applied on a consistent basis in cases of
medical ethics and are often good starting points for ethical evaluation. The principle of autonomy calls for the respect of an individual's right to probably the most important to wrestle with in respect to dementia ethics The principles of beneficence, acting to promote the wellbeing of the other,
and non-maleficence, to do no harm, are typically the responsibility of the
healthcare providers. When physicians make a difficult decision that goes healthcare providers. When physicians make a dficult decision that goes
against what the patient may want it is called paternalism The bioethicist Richard McCormick, S.J., observes that medical ethics in the United States is in a state of an "absolutization of autonomy," where the rightness or
wrongness of a choice is left only in the individual's hands and which re wrongness of a choice is left only in the individual's hands and which re-
sults in an impoverishment of morality.2 sess the facts pertaining to medical coses of a similar ethical issue and to often determine which principle should prevail in determining the course of care. In the issue of dementia ethics, the conflict between respecting the
patient's autonomy and exercising paternalism for the best interest of the patient's autonomy and exercising paternalism for the best interest of the
patient is difficult to mediate. This is why communication and obtaining
patient consent is so important in the physician-patient relationship.

The principle of justice extends beyond the application of the previous three
principles because justice concerns itself with the fair distribution of health care to all people. The structure of medicine has progressively evolved into a business model, and bioethics has found itself responding to the call for a enter the hospital seeking the best medical treatment possible. I I say "pos-
sible" sense of what tour society and itsindividuls can aford in medicate in the The question of justice and equitable distribution of medical treatment is certainly important to consider given the problem of organ donation today. The shortage of available organs for transplantation brings on the search to be taken to assure that organ procurement is performed in a just way without violating the rights or the dignity of human beings.

The two issues of dementia ethics and organ donation continue to incite tilluminate the extremely challenging ethical decisions being made everyday, for example, to a patient with increasing stages of Alzheimer's and is orgetting to eat, or a patient at the bottom of a long recipient's list who is about to die unless she recelves a liver transplant. The role of bioethics is to offer some guidance for healthcare providers, the patients and their families and to perhaps even negotiate the murky waters of establishing health are policies that offer universal guidelines for the majority of ethical cases

Sally Satel, “The Limits of Bioethics," 20ro, The Hoover Institution, Stanford Unie/5354>. Sept 20II, chttp://www.hoover.org/publications/policy-review/arthRichard A. McCormick, S.J., “Bioethics: A Moral Vaccum?", America, I80.I5

THE PHENOMENOLOGICAL METHOD

Chris Sheridan

Phenomenology is an exciting philosophical discipline that aims to phenomenology - which is by no means exclusive of of other disciplines begins with conscious, lived-through experience (static phenomenology) experiences (genetic phenomenology). It is the particular stance and method prescribed by phenomenology that sets the discipline apart.

The roots of phenomenology run deep in the philosophical tradition, but the gathering of these roots into a coherent discipline is generally attributed to the phenomenoloopher Edmund Husserl (1859-1938), Bet is important to stress the goal of a phenomenological investigation.

ust as the geometer would aim to describe the essential features of a triangle, the phenomenologist aims to describe the essential features of a
type of conscious experience (e.g., perception).'. Descriptions of individual 
product of his work is a derivative set of articulated features that both specify and transcend any particular instance of a triangle. The geometer'
ultimate currency is that of axioms, their possible interactions, and their logical consequences. Likewise, the end product of a phenomenological
investigation of perception is not a set of detailed descriptions of instances investigation of perception is not a set of detailed descriptions of instances
of perception, but a thematization apprehending the essential features of

Traditionally, two types of reduction are commonly used to arrive at such and the eidetic reduction. The phenomenological reduction is a term for change in attitude toward the world that puts the activities of consciousness into high relief.2.3 In our normal commerce with the world, we pay no a table as a alass. We see instead a world affording particular a abject on reflecting only on our thirst. This natural attitude- - that is, attention to the natural motivations and assumptions driving our experiential economy-
must be suspended so that the activities which set the glass before us might must be suspended so that the activities which set the glass before us might
come to light. The phenomenological reduction "slackens the intentiona
threads which attach us to the world and brings them to our notice.".

Once we have adopted an attitude that exposes conscious activity, then the work of identitying the indispensible features of a given conscious
phenomenon can begin. This eidetic reduction of a phenomenon proceed by means of eidetic variation, a method for critically yxaminining descriptions
of subjective experience in order to home in on its essential aspects. of subjective experience in order to home in on its essential aspects.
Sticking with the example of perception, a phenomenologist first describes his own perceptual experiences as accurately as possible, taking carefu perception. That glass on the table, for example, affords a visual experience and a tactile experience, both stretching out toward the same object, but a glass on the table, my visual and tactile experiences apprehend a different respectively.

From a critical mass of these descriptions, the phenomenologist abstracts With this thematized structure in hand, a series of thought experiments is conducted, varying, adding, or subtracting discrete elements of the structure and checking the accuracy of result against the original descriptions. the thematized structure are identified as essential to the phenomen of I cannot remove objects from perceptual experience: I cannot, strictly speaking, see or touch a glass if there is no glass before me. But I do not need to pertense color to perceve his glass. A subjects dependence on it (Ig08-I96I) point out-or a sense of the object's persistence in space and time might also be examples of essential structural elements of perceptu experien phenomenologist passes from static to genetic phenomenology when e begins asking questions like: What conditions must an object meet in

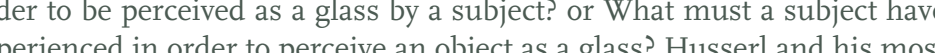
otable student, Martin Heidegger (I889-I976), disagreed vehemently over ow to make progress on these genetic questions.

The two diverged over the question of being. Husserl insisted that-like the thot sciences take for granted the material reality of their subject matter nomena generally excluding their ontological status from consideration east by means of the phenomenological method). ${ }^{6}$ Heidegger, on the other and, defended the question of being as the central question of phenom pology, asserthing that the conditions which underwrite the regularitities of for subjects and objects in the world. 7 What is now called continental phlosophy flourished in the space opened up by these two towering figures of 2oth century philosophy. The generation of Hench philosophers including Ronty was heavily infuenced Husserl and Heideger's phil, and Mete

"Transcendental Geology" addresses the concepts of nature and history from a phenomenological perspective, and situates itself firmly in the late by neo-Kantian philosophers like Wilhelm Dithey demonstrates the ontinuity of phenomenology with previous lines of philosophical inquiry "Transcendental Geology" illustrates the evolution of phenomenologic thinking from an intuition in Dilthey, through a methodologic shed out by That tradition still exercises considerable influence in contemporary philosophy. Today, cutting edge investigations into subjectivity with philosophers in the analytic tradition, as well as interdisciplinatry dialogue with those areas of the natural sciences and medicine concerne with consciousness. In place of vague talk of "what-1-1-1-s-like" or outrigh insmissals of subjective experience, phenomenology provides genera uniqueness and bridge the gap between those unique subjectivities and ations in biological term

Husserl ofien used the comparison with geometry to bring out the character foundations of ogogy. Towarty the end of his life, he explored the significance of the
foul

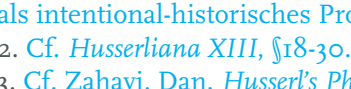

.

2003. pp. 43-78. Merleau-Ponty, Maurice. Phenomenology of Perception. Trans. Kegan Paul.

5. C. Soldek Now Yowki, Robert. Introduction to Phenomenology. Cambridge University
Press: New York, 2000. p. $177-184$.
6. Cf. Husserl, Edmund. Psychological and Transsendental Phenomenenology and the
Confroutation with Heidegger (1927-1931). Trans. T. Sheehan and R. Palmer. Kluwer Dordrecht, I997. pp. 485-50\%

RECORDING THE VIETNAM WAR

By Hilary Chas

From All Quiet On The Western Front in I930 to the Hurt Locker in 2009, the alike. Themes explored in these films include combat, survivor and escape stories, tales of gallant sacrifice and struggle, studies of the futility and inof the moral issues. ${ }^{I}$ Combat films can generally be classified into subpicting, from World War I to Vietnam to the modern wars in the Middle East.

In addition to being artistic expressions, war films have a greater respons bility than other genres in that they can shape social perceptions about wa-
fare, both positively and negatively. During World War II, the Office of Wa Information mobilized the Hollywood studio system to create films to kee up morale at home and motivate draftees.

The films that Hollywood produced at this time, including Sands of Iwo Jima and Bataam, softened the realities of war by emphasizing tales of herrectors were able to discuss the moral clarity of Hollywood's World War II involvement in the war effort With this new freedom of expression, the involvement in the war efrort. With this new freedom
films began to exhibit a greater sense of disillusionment.

Before too long, the generation that had been raised on the image of the glorious soldier in World War If films was shipped to Vietnam, and, with
them, this enlisted generation brought a glamorized Hollywood image to
the battlefield that did not really apply. When they returned home, Hollywood was given the challenge of creating an entirely new message for the
war films it produced while remaining true to the conventions of the genre. "Culture in Conflict" focuses on the three eras of Vietnam War films: those made during the War, those made in the decade following the War, and history. The examples selected run the gamut from comedies (MASH) to

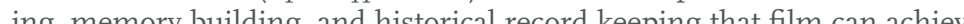
The article shows how the films made about the Vietnam War mark a turning point in the Combat film genre, the moment where the lines between moral and In the 200os, as the nation grapples with two major overseas wars and
other military entanglements all over the world, Hollywood has had plenty of fodder for the combat film genre. The films made in the past decades have built upon the revolutionary conventions created by the auteurs of the Vietnam War era cinema; indeed, recent films such as Jarh
Locker would not have been made without this influence.

1" “The War Film.” Turner Classic Movies Online. Accessed Sept. Io, 201 .

2. “The Combat Film," American Cinema. PBS: 1995 
THE “NOW PATIENT" AND THE “THEN SELF” Conflicting Views in the Ethics of Dementia Care

"Until the advent of drugs that slow, stop, or reverse the syndrome that gradually steals its victims' most intimate thoughts and threatens the cores of their identities, society's interests are best served by a policy that protects these vulnerable individuals."

ALZHEIMER'S DISEASE IS A NEURODEGENERATIVE CONDITION THAT TYPICALLY AFFECTS THE EL-

DERLY AND GRADUALLY CONSUMES A PATIENT, DESTROYING THE CONNECTION BETWEEN BODY

AND MIND IN THE PROCESS. DUE TO THE AGING OF THE BABY-BOOM GENERATION, ALZHEIMER'S

DISEASE IS EXPECTED TO SUBSTANTIALLY INCREASE IN PREVALENCE IN THE COMING YEARS. DE-

SPITE THIS EPIDEMIOLOGICAL PROBABILITY, PUBLIC POLICY REGARDING TREATMENT OF PATIENTS

WITH THE ILLNESS REMAINS PIECEMEAL. CONTROVERSY POLICY STEMS FROM THE FACT THAT, IN

MANY CASES, A SEVERELY DEMENTED PATIENT'S WISHES FOR TREATMENT DIFFER FROM THE WISH.

ES HE OR SHE EXPRESSED IN THE EARLIER STAGES OF DISEASE. WHEN CONSIDERING WHOSE PERSPECTIVE-THAT OF THE COMPETENT, “THEN" VERSION OF THE PATIENT OR THAT OF THE DE-

MENTED “NOW" VERSION OF THE PATIENT-SHOULD TAKE PRECEDENCE, THE GUIDING PRINCIPLE SHOULD BE RESPECT FOR OVERALL DIGNITY. FROM THIS PERSPECTIVE, HONORING THE AUTONOMY OF THE "THEN" SELF IS THE MOST VIABLE OPTION AND SHOULD SERVE AS THE BASIS FOR FUTURE POLICY DECISIONS REGARDING THE TREATMENT OF ALZHEIMER'S DISEASE. 
INTRODUCTION

Memory, the valuable information that connects past and
present, and higher-level cognition, the uniquely human the

elements of the human condition. Dementia, an all-en-

tating neurodegenerative illnesses, strikes these two pil

with profound social, medical, and legal consequences. A

least seventy-five different diseases can present as dementia.' It is a disorder affecting 6-8\% of individuals over sixty-
five and is characterized by marked cognitive decline and (distinct elements of intellectors

processing." ${ }^{34}$ While conditions such as multiple sclerosis
Pick's disease, or stroke may precipitate dementia, Al zheimer's disease, which comprises more than half of al primarily on Alzheimer's-induced dementis.

"With the rapidly increasing elderly population in the United States, the number of persons affected by Alzheimer's disease is projected to reach 13.2 million by mid-century." Discovered in the early twentieth century, Alzheimer's dis
ease accounts for $60-80 \%$ of dementias in the elderly. Ac cording to various studies, it affects $20-40 \%$ of people over ignature pathology of neuritic phe cus" in combing with neurofibrillary tangles, ${ }^{8}$ the underlying cause of thes bnormalities remains unknown. The development of such trademark brain lesions makes diagnosis seem lechnology makes diagnosis rather difficult in the early stages of the disease, On average, Alzheimer's disease pa- ients live eight to ten years after being diagnosed, which

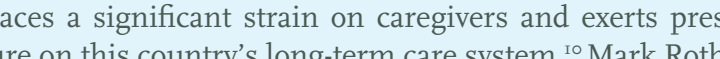
tein estimates the annual cost of caring for a patient with "moderate Alzheimer's disease" to be $\$_{30,096}$ while the billion " Data from 2008 show that at that to roughly $\$ 50$ er's disease affected approximately 5.2 million people
With the rapidly increasing elderly population in the United States, the number of persons affected by Alzheimer's

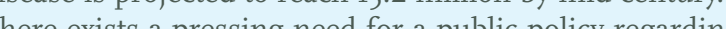
Alzheimer's disease to contain healthcare costs and to help protect some of society's most vulnerable persons. This article will address the myriad issues surrounding demeny the syndrome as well as the resulting perspective on the viability of advance directives for making treatment decisions. It will contest aspects of certain arguments that favor the privileging of the patient in late stage dementia policy suggestions for the future designed to create a more fective treatment plan for patients with dementia. THEORIES OF PERSONHOOD IN DEMENTIA Significance and Implications

The reasoning behind many decisions regarding dement ies of personhood presented by the progression of de mentia: the theory of the "now" self or the theory of the "then" self.'s Stephen Post articulates the difference in his Current geroto tween the 'then' self that existed prior to severe Alzheimer dis ease and the 'now' self that lives almost entirely in the presen
with little if lthough a middle ground does exist between these two dichotomous views, because the loss of decisional capacity gradual, one's basic understanding of the issue informs earch particioation for dementis pand of consent to re mentia can be summarized by a central question: at what point, if ever, does the "now" self take precedence over the
"then" self?
Privileging the "Now" Self

Rebecca Dresser presents an argument for valuing the home, even if he or she has become senile, as opposed hese that a tary factor in treatmest fumped by beneficence when it is lost. ${ }^{6}$ Additionally, Dosy favores, hyt at the root of precedent autonomy, the (n) invalidates the position.". Her reasoning suggests that p
tients in the early stages of dementia cannot provide in formed consent through advance directives because the they are providing instructions. Conversely by the time the patients acquire the necessary experience to execute a informed treatment decision, they are no longer compe fully endorsing the "now' self and che gnoring advance directives that refuse treatment in to continue the life of the severely demented patient. S states:

Many mildly or moderately demented patients do appear to 0 作 benefits may seem small to us, we must evaluate them from the patients' perspectives... Given their limits, then, patien who can relate to the people and objects surrounding then
typically have lives that for them are significantly better than no Ife at all.,

Dresser rejects the notion that demented patients are ters that an external, compared to an introspes and courpersonhood is more suitable under these circumstances. In doing so, however, she disregards the earlier wishes of the patient on the basis of her presumed knowledge of the value of life for someone with dementia. Her relationa tient also leads to an acceptance of extramarital intimate relationships between dementia patients in nursing homes. This controversial situation frequently arises distorted reality mistakes another resident for a spouse or due to Alzheimer's disease, experiences less inhibitio and expresses aggressive sexual desires. Perhaps the mo

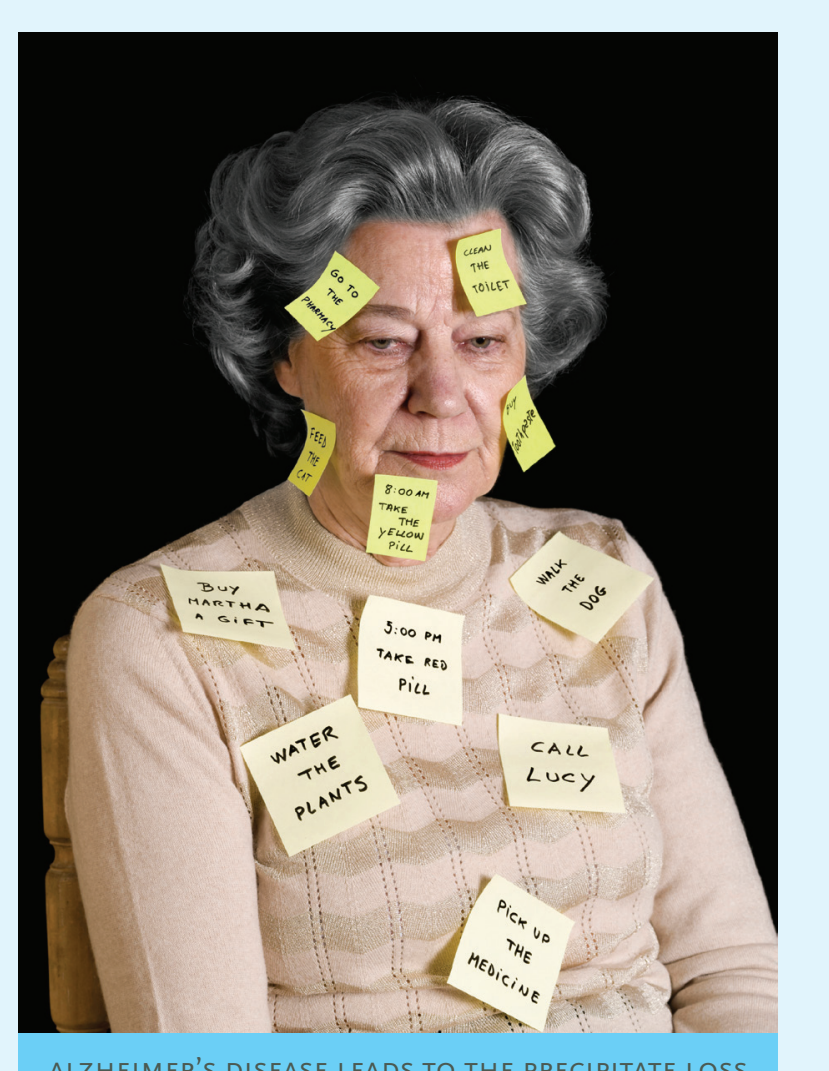

OF MEMORY, HINDERING THE VICTIM'S DALYY ROUTINES. well known incidence of cohabitation between dene 'Connor permitted her husband, who was in the late stages of Alzheimer's disease, to have a romance with anwith Dresser's aroument, privileged current happiness hrough a relationship over the objections that her hus位

Another implication of this view of personhood can be sead of substituted judgment in courtordered treatment decisions. ${ }^{2}$ Indeed, this objective approach was utilized in he cases of Barber v. Superior Court and In re Conroy. In nng cardio-respiratory arrest after a successful surgery, and
his family successfully petitions the physicians to remove the feeding tubes. ${ }^{22}$ The court in Barber did not find the physicians guilty of murder and, of the current approac 
involves the determination of whether the proposed treat-
ment is proportionate or disproportionate in terms of the Alzheimer disease should be permitted to de exert controf of necessarily determining what the patient would have over the future through the implementation of precedent wanted, the court suggests that a logical balancing of cur- sion, including the dual desires on behalf of the person

"Seemingly, being human involves on its deepest level some element, free from the constraints of time, akin to a soul that prevents infants and dementia patients from being empty shells even in the absence of cognition."

ent benefits and burdens will yield the optimal treatment decision. In Conroy, the nephew of Claire Conroy, an in-
competent, demented patient, also seeks permission emove a naso-gastric feeding tube from his aunt.24 The New Jersey court in this case explicitly proposed both
limited objective test and a pure objective test, under which treatment can be ceased provided that the "net bur dens of the patient's life with treatment ... clearly and markedly outweigh the benetive that the patient derives the "now" self, a basic problem with this method is the fat that a subjective judgment is still being made regarding the value that the patient derives from life. Surely no pertent herself, whose opinion would be extensively in a substituted judgment analysis. The mat er, then, returns to whether it is more appropriate to bass the value in question on the objective benefit to the incomwhile competent? At this point the argument for the "then" self enters the picture.

Preserving the Integrity of the "Then" Self

Proponents of the "then" self favor a treatment plan in which caregivers honor the wishes of the competent $\mathrm{pa}$
tient while simultaneously fulfilling the reasonable need of the "now" self. Post epitomizes this position when he manner can and bente whe an be amply expessed in a ronmental, and relational support rather than by efforts to extend life." "26 Post also supports Ronald Dworkin's arguthe former self even when the individual is no longer

with dementia not to be subjected to unwanted medical chnologies and not to exhaust the financial resources of
is or her family.8

As Nancy Rhoden argued, mere consciousness, like biological life, is not a morally significant end in itself. Instead, it is a necessary condition for achieving the ends that are of moral
value to us-thought, emotion, pleasure, and relationships

This argument implies that severely demented patients lacking relational abilities need not be kept alive "for their own good" if it is against the wishes of their former, com-

One potential danger of such an argument lies in applying this "empty shell'130 principle to all people whose ability to from moderate impairments. This selfffulfilling "empty ural tradition, and, specifically, by John Locke, who argued hat self-reflection is requisite for being considered human..$^{3}$ However, complications arise with this formulation they have even less mental faculties than do elderly de mentia patients.32 Seemingly, being human involves on its deepest level some element, free from the constraints of ients from being empty shells even in the absenestia panition. As such, respect for the "now" self is preserved in the theory of the "then" self, as Post demonstrates with the case of Mrs. A, an incompetent dementia patient who, as gery in the later stages of her disease.33 Unfortunately, she
develops a painful tumor, and, despite her previous wish, Post recommends surgery to reduce the size of the tucomforting the "now" self and suggesting a policy in which pain treatment is primary and life prolongation is merely a secondary effect. In this way, demented persons are nat
viewed as empty shells, memory is not overvalued, and the feelings and needs of dementia patients are noted and re
sponded to using compassionate standards of care.35 With respect to former Justice O'Connor's ethical dilem.

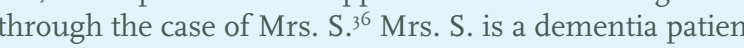
who brings daily gifts to another resident, Mr. R, whom she mistakenly believes is her deceased spouse. One day tion with Mrs. S for a night However. Mrs. S's daughter objects to what she deems a violation of the integrity of he mother's "then" self.37 Here, Post, quoting Erik Erikson

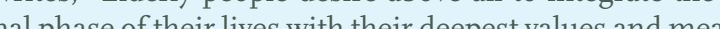
ings." ${ }^{38}$ Although refusing to enter Mrs. S's reality completely and thus denying her a certain degree of happiness is objectionable from Dresser's standpoint, another examer the case of a J Jehorah's Witness in the late stages of $A$ zheimer's disease. This patient's consistently expressed religious values while competent will assure that he or sh is not subjected to blood transfusions even when in a state should not be violated simply because she is incompetent Discovering and integrating the "then" self into the "now" self appears to be the ideal treatment goal whenever pos

ADVANCE DIRECTIVES Mental Health Advance Directives

Whether one privileges the "then" self or the "now" self validity of advance directives for dementia patients. On specific type of advance directive for those with mental il(MHAD), though its efficiency for patients with dementia is a disputed. An MHAD allows drafters to express a statement of core values and explicitly provides the opportunity vulsive therapy (ECT), psychotronic medication, and ad- mission to mentat health facility for up to three days. ${ }^{\circ} \mathrm{Th}$ was prompted by cases such as Guardianship of Roe, which involved the utilization of substituted judgment to force onally the case of Lurille Ansacitated patients who refused ECT, medication, nutrition, and hydration, court approval to have her mother's wishes honored, tri gered a reactionary movement in Illinois to ena

The argument for MHADs generally consists of an appreciation of the medical benefits that the directives offer as well as a positive evaluation of their utility as a planning
instrument. Concerning the medical benefits, MHADs provide the opportunity for patients to avoid the seriou side effects of potentially hazardous therapies such as
CTT which include from onfusion include fractures, additional memory loss rugs, which have been known to cause dyskinesia, dry mouth, dizziness, and depression, among other symptoms." In addition to these physical benefits, the option to pares a patiant's family or caregivers significant guilt in the event that the patient becomes violent and gut $n$ such a facility regardless of opinion tated earlier. Admittedly, though, this benefit of Menta peal competency and incompetency and for whom the direc ives were orignally designed 44 Nevertheless ment health conditions such as delusion, depression, and hallucination often accompany Alzheimer's disease and justify highly predictable nature of the progression of Alzheim-
er's disease, according to Lisa Brodoff " "givels individuals a real opportunity to anticipate and plan."34 Indeed, additional benefits of MHADs arise mainly from the process of future planning initiated by the directives. The resulting
discussion often explicitly informs family members and caretakers of the patient's core values, cultural care preferences, and financial plans, as well as illuminates the pa-

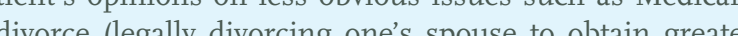
Medicaid benefits) entering future intimate relationship while demented, and consent for research.4 If nothing else, MHADs provide the opportunity to educate one's surogate about on
is not respected. 
Those who oppose MHADs take issue with the very pos-
sibility that the directive may not be honored. Specificallythe lack of a uniform competency standard plagues these directives, which may be appropriately revoked if a patien is deemed competent but can only be invoked if a patien is incompetent..$^{8} \mathrm{Few}$ patients fall clearly into one category or the olter, whe most display varying degrees of cognithat, although Alzheimer's disease may last eight to ten years, most directives expire after only three years.49 Cur-
rently, a man or woman in an early stage of Alzheimer's rently, a man or woman in an early stage of Alzheimer's
disease may order an MHAD only to have it expire in three years' time when they are no longer competent to sign
new one. Additionally, the presence of both a "Ulysses clause," stating that the patient's order should still be insion for a surrogate decision-maker within the and a provbe inherently confusing for caregivers and thus problematic for the incompetent patient..$^{\circ}$ Yet another risk with MHADs, notes Brodoff, is that patients may request "bad" sician's professional judgment SII In these situations, statutes that "allow physicians to override treatment requess they deem inappropriate"sis cause Elizabeth Ann Rosen Faldse in her article "Mental Heathe Advance Directives: A tion," to argue that MHADs, in select ways, actually protect health care providers more than patients.53 The directives grant physicians immunity regardless of whether the

Further, managed care organizations may provide financial incentives for physicians to order preventive tests and essarily follow the MHAD 55 This conflict of interest is the first of several that work to diminish the power of these directives. Ignoring MHADs is also permissible when a contradictory court order is issued, an emergency situation state has significant interest in preserving mainst hat the ues by preventing the patient from refusing "life-prolong.
ing" medical treatment. . $^{\circ}$ Rosenfield worries that the qual. fications for an "emergency situation" can easily be manipulated for broad application and that the state's $\mathrm{p}$ the implementation of MHADs is that, due to either lack of knowledge or initiative, "most people with mental il-"

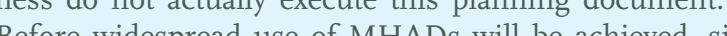

nificant efforts to educate the target population and fortify
protection of the "then" self by attaching more gravity

While MHADs specify treatment preferences during a pa fent's intermediate years with dementia, living wills an
durable powers of attorney aim to direct end-oflife care for patients. Brodoff writes,

A living will is a written document wherein a person states his
or her preferences for treatment or more likely the refusasa of scious condition or terminally ill where death is reasonably i imminent.s.

ichard Beresford describes the durable power of attorney as an advance directive that "appoints an agent to act on petent." ${ }^{\prime 60}$ Arguments for advance directives are loosely vacy as well as Fist An wicent rights to hrough treatment choices and, arguably the freedom of hought to decide treatment options. ${ }^{6}$ Legal developmen in the area of advance directives burgeoned after the $\mathrm{Cr}$ -

The appropriateness of end-oflife advance directives for
dementia patients has been a subiect of much debate in ecent literature because these individuals maintain con nent wishes frequently change as the disease takes firmer
hold. Privileging the "now" self precludes the use of this ype of advance directive for persons with dementia on the rounds that the reality of the decisionally-incapacitate tient. Other arguments against advance directives, however, are based primarily on a lack of portability. Currently the health care system lacks "one central registry for these instruments, and this leads to problems in locating and directives from one health care provider to the next or lo ating advance directives in emergency situations may cuse a patient's wishes to be inadvertently disregarded. A study by Thomas Finucane et al. provides evidence that supports the use of advance directives for persons with de
mentia. ${ }^{64}$ The study measured decisional capacity and the burden of discussing end-of-life treatment options for
seven patients with Alzheimer's disease. The level of dementia for each patient was determined using the MiniMental State Examination (MMSE), in which scores lower
than twenty-four are associated with dementia and worse than twenty-four are associated with dementia and wors
scores indicate greater degrees of impairment. . $^{5}$ The re search subjects had a mean MMSE score of seventeen, i the group, yet the study showed that three of the seven
subiects acknowledged memory problems and expected subjects acknowledged memory problems and expected
their condition to worsen, which suggests that early-stage their condition to worsen, which suggests that early-stage
Alzheimer's disease patients are capable of awareness of tients, on a meaningful and consistent basis, were likely respond that they would refuse life-sustaining therapy i i study found "no measurable adverse effects" on the sub. 'ects' psyche or health from discussing future treatment options..$^{68}$ The results of this study indicate that advance directives for patients with Alzherer's disease do not incertain patients in early stages of the disease.

Respecting the "then" self through advance directives does not seem an unreasonable burden for caregivers of de dementia should possess the same rights as the mentally healthy individual to refuse feeding tubes, ventilators, and cardiopulmonary resuscitation. The policy regarding feed ing tubes, in particular, has generated controversy because
some advocates of the "now" self argue that the withdrase of artificial nutrition betrays the demented patient's fundmental interest in continued life. While percutaneous endoscopic gastrostomy (PEG) tubes were once common-
place in treatment of late stage dementia patients who have lost the ability to swallow food, new evidence sug. gests that the tubes may not be medically indicated. Dr. Muriel Gillick, in a study published by the New England
Journal of Medicine, suggests rethinking the consensus on Journal of Medicine, suggests rethinking the consensus on
feeding tubes for these patients: "Because of problems with diarrhea, clogging of the tubes, and the tendency of
wats patients with dementia to pull out the tubes, nutritional
status offen does not improve with the use of feeding tubes." tric contents and the aspiration of saliva"mo rather than the act of eating that feeding tubes are designed to replace.
Finally end-stage cancer ptients who have described the Finally, end-stage cancer patients who have described their
experience after the removal of gastrostomy tubes "do no experience more than transient hunger, and any the be assuaged by ice chips and mouth swabs." ${ }^{\prime \prime 2}$ These find hat PEG tubes, along with other medical treatments with for aus efficacies, should not necessarilly be mandator If refusal of nutrition and hydess explicicitly requesthough, how far do the rights of dementia patients hough, how far do the rivan
advance directives extend?

Euthanasia and Physician-Assisted Suicide

At present, a critical debate in the Netherlands centered o his very question raises the notion of the viability of ad-
anced directives for euthanasia of dementia patients. Cees Hertogh distinguishes between negative advance dipositive advance directives, which request specifc treat ments, the most common of which being euthanasia, for patients in the Netherlands. ${ }^{2}$ Although advance directives physicianasian (ADDs) are legal in the Netherlands, the physician can never be obliged to follow them.73 These
rules of due care include physician satisfaction that the patient's request was "voluntary and well considered," physician satisfaction that the patient has experienced "unbear the situation and its prospects," patient and physicin satisfaction that there is "no reasonable alternative solution, examination by at least one other independent phy. sician that verifies the above standards, and professional
ivecution of the life termination process 74 Despite egality these directives have generally been avoided for number of reasons, primary among them the question of which criteria must be met before a request for euthanasia criterion for euthenesia is not necessanily a spouse as sure because the patient's ability may vary day by day or perhaps the demented individual always perceives the pouse on a level that is not apparent to outside observers ing cognitive tests as criteria because "tests results often of the individual." "rs Additionally, the task of providing euthanasia for a demented patient who is currently assenting argument to that if the "now" self is, in fact, different from the "then" self, then an AED "would in effect be a contract for murder. The complex dilemmas betind the issuance of 
practical in the Netherlands, the United States, and any-
where else.

that enhance quality of life for those who grow old., ${ }^{84}$ An-
other element to this debate is the fact that physician-as is for the United States revolves around the acceptability of physician-assisted suicide (PAS) in patients with early
stage Alzheimer's disease. The Dutch refer to the ravages

20 of dementia as "entluistering," or effacement, and the Dutch government permits its citizens to seek physician-
assisted suicide as a means to avoid this slow, debilitating process..$^{7}$ Five cases of PAS in the Netherlands have bee headlines in the United States when she enlisted the help

"Therefore, the authority of the 'then' self, while it should be restricted from ordering euthanasia and

PAS, must otherwise be held paramount in an effort to prevent PAS and mercy killing."

of Dr. Kevorkian and became the first dementia patient in
he United States to participate in physician-assisted sulcide.7.980 Post relates the suicide drive in early stage de mentia patients to a legitimate fear that the wishes of the
"then" self will not be honored: "Assisted suicide becomes a very attractive alternative for many of us if our 'then'
selves are not to be allowed to control the destiny of our now' selves." "Weak sanctions on doctors and hospital for failing to co
this problem.

Post advocates an increase in palliative care and tightening tients from both PAS and pleas for mercy killing ${ }^{8}$ Pos $_{3}$ Post also presents as an argument against these controversia topics his "incompatibility hypothesis," which suggests that if PAS and euthanasta are allowed, there will be dthan six months to live, and Alzheimer's disease leaves an
indeterminate amount of time between diagnosis and death. ${ }^{85} \mathrm{~A}$ related, albeit weaker, argument holds that in cian-assisted suicide, a treatment or even a cure for $\mathrm{Al}$ heimer's disease may become avallable. The stronges rgument against PAS may be that of the slippery slope
policy scenario. Already in the Netherlands, one case of physician-assisted suicide for dementia patients has gar nered massive criticism because the patient involved never officially received a diagnosis of Alzheimer's disease be
fore engaging in PAS Critics believe that his sym to

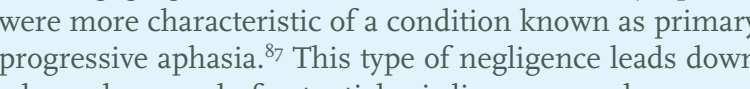
a hazardous road of potential misdiagnoses and unneces sary deaths due to the difficulty of diagnosing Alzheimer's
disease in an early stage. More troubling still is the idea that if PAS is made legal, the slippery slope may lead to world of "obligatory altruistic suicide," in which demented individuals who elect not to engage in PAS are viewed as thority of the "then" self, while it should be restricted from ordering euthanasia and PAS, must otherwise be held paramount in an effort to prevent PAS and mercy killing. Public Polic

Bruce Jennings suggests three policy models to shape the the of dementia care: the public health model, the or public safety in terms of protecting third parties from ehaviors of dementia patients who are deleterious to socinodel, however, is that dementia patients injure a relatively low number of people annually.90 Additionally, conconfidential health information to state agencies such a state departments for motor vehicles to alert the state as to seking physcian guidance out of fear of a los of tiving llunt, and impractical" and, as such, unlikely to be effec he years of life forfeited by the patient who opts for physquiring physicins to release their dementia pan re the conditions of these individuals." A law such as this privileges. Finally, action taken by the state will be "costly,
Protection of the demented individual from harm defines pragmatic than state intervention because it involves the use of specific caregivers, this model is by no means per-
fect 93 Decision-making tapacity from the perspective fectars Decision-making capacity from the perspective of
guardianship is viewed as all-or-nothing by the caregive instead of as the continuum that it actually is. ${ }^{94}$ The inhe-of guardianship also plays a maior role in limiting patient autonomy, and this use of excessive
tion can limit rather than foster the ward's growth 95

Jennings calls the third and perhaps most appropriate "sustaining agency and capacity" of the demented individstate of transitions rather than decline, and therapy rouas a human being.97 Minor illnesses and conditions a immediately treated to prevent accompanying further mental deterioration. .8 $^{98}$ The best treatment options involve educating the care staff 99 Caregivers emphasize the patient's remaining abilities and build upon them as encouragement while simultaneously finding acceptable subst tutes for activities that can no longer be performed.oo honored and maintained deep into disease progression.

CONCLUSION

Since cases of dementia are expected to more than triple in the coming years, public policy governing the vast realm of dementia ethics will become an important factor in the fuvare of the United States hed hare system. Until the adgradually steals its victims' most intimate thoughts and threatens the cores of their identities, society's interes are best served by a policy that protects these vulnerablo fer results from respecting the precedent antont of of "then" self. Although arguments for the "now" self uphold the essential dignity of mankind, their roots in beneficence for an imagined best interest of the severely demented inagnosed with early Alzheimer's disease to seek physicinassisted suicide or euthanasia, which ironically diminis the very values of life the theory of the "now" self seeks to promote. MHADs can be made more effective tools for $\mathrm{d}$ requirements for their invalidation and extend their exp- ration terms. The construction of special long-term care space and peace of mind for persons diagnosed with dementia in the future. Genetic testing, liability of dementis

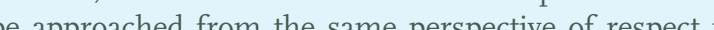
autonomy and integrating the patient's “then" sesp fint tor "now" self.

ENDNOTES

Rabins $2001(452)$
2. Rabins $1998(25)$

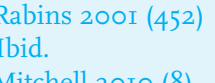

Mitchell $2010(8)$
Brodoff $2010(240)$

. Ibid.

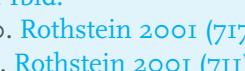

12. libid. 2090 (307)

15. Post 1995 (3I)

I7. Binstock et al. 1992 (74)
I8. Binstock et al. 1992 (177)

2. Rosenfield $200 \mathrm{I}(56$

2. Barber v. Superior Court, I47 Cal. App. 3d 1006 (198:)

re Conroy, 98 N.J. 32I App. $2 d$ neog tig8

Post $1995(311)$

. Binstock 1992 (77)

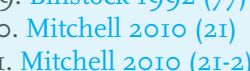

Mitchell $2010(3)$
Post $1995(317)$

. Ibost

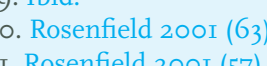

42. Rosenfield 2000154 
43. Rosenfield 200I (59)
44. Brodoff 2010 (244)

45. Ibici

47. Brodoff 2010 (260-287)
48. Rosenfield 2001 (65)

-

5. Brodoff 2010 (295)
52. Brodoff 2010 (251)

54. IJid
5.5 Ibid

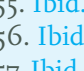

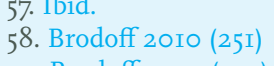

59. Brodoff 2010 (252)

6I. Rosenfield 200I (58)

62. Brodoff $2010(252)$

64. Finucane $1993($ (5I)
65. Finucane $1993(52)$

66. Ibic

67. Ibid.

69. Gillick 2000 (206-7)

70. Gillick $2000(207)$
7I. Ibid.

72. Hertogh 2007 (50)

73. Hid.

74. Hertogh $20007(49)$

76. Hertogh $2007(50)$
77 Hertogh $2007(52)$

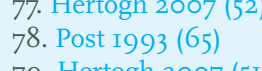

80. Post 1995 (3II)

82. Post $1993(6)$

84. Post to93 (67)

86. Mitchell $2010(49)$
87. Hertogh $2007(5 \mathrm{~L}-2)$

87. Hertogh 2007 (51-2)

9. Jennings $2010(403$

-1
go. Ibid.

92. Ibid.

33. Jennings 2010 (406)

94. Ibid.

96. Jennings $2010(408)$

97. Ibid.
99. Ibid.
Ioo. Jennings 2010 (408)

REFERENCES

arberv. Supenof Court. I47 Cal. App. $3 d$ roo6 (1983). Beresford, H. Richard. "EEthical Issues in Dementia." http://

Binstock, Robert H. et al., eds. Dementia and Aging: Ethics values, and Policy Choices. Baltimore: The Johns Hopkins Brodoff, Lisa. "Planning for Alzheimer's Disease with Mental
Health Advance Directives," Elder L.J.T.7. (2010): $240-209$. Dresser, Rebecca. "Dementia Research: Ethics and Policy for the
Twenty-First Century." Ga.

L. Rev. 66I, no. 35 (2001): 66r-69o.

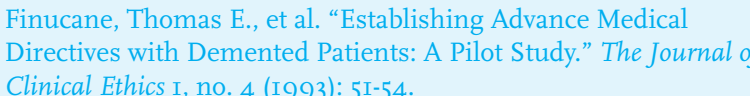
Gillick, Muriel R. "Rethinking the Role of Tube Feeding in $206-210$.

Hertogh, Ceese talal "Would We Rather Lose Our Life Than Lose Our self? "essons from the Dutch Debate on Euthanasia for
Patitents with Dementia." The American Journal of Bioethics, no.
$7(2007): 48-56$.

High, Dallas M. "Advancing Research with Alzheimer Disease Subjects: Investigators' Perceptions and Ethical Issue,
Alzheimer Dis. Assoc. Disord. 3, no. 7 ( 1 (1993): I65-I77.

In re Conroy. 98 N.J. 32I, A. 2 d I209 (1985). Jennings, Bruce. "Rethinking Dementia Care in Ethics and the
Law." Quinn. Prob. Law Jour. 398, no. 23 (2010): 398-410. Katz, Gregory and Schweitzer, Stuart O. "Implications of Genetic
Testing for Health Policy." Yale J. Health Poly L \& \& Ethics 9o, no. (2010): : 22-1333

Marmor, Theodore R. and Oberlander, Jonathan. “The Healts Bill Explained at Last" The New York Review of Books 19 A

Marson, Daniel C. et al “ "Assessing the Competency of Patient the Competency of Patien

Marson, Daniel C. et al. “Neuropsychologic Predictors of
Competency in Alzheimer's Disease Using a Rational Reasons Legal Standard." Arch Neurol 52, (1905): 055-098.
Mitchell, John B. "Physician-Assisted Suicide and Dementia: The Review 88, (2010): I-62

Post, Stephen G. “Alzheimer Disease and Physician-Assisted
Suicide." Alzheimer Dis. Assoc. Disord. 7, no. 2 (I993): 65-67.

Post, Stephen G. "Alzheimer Disease and the 'Then' Self"
Kennedy Institut of Ethics Journal 4 , no. 5 (1995): $307-321$

Post, Stephen G. The Moral Challenge of Alzheimer Disease.
Baltimore: The Johns Hopkins University Press, I995.

Rabins, Peter V. “"Dementia and Alzheimer's Disease: A

Rabins, Peter V. "Issues Raised by Research Using Persons
Suffering from Dementia Who have Impaired Decisional

Capacity."J. Health Care L. \& Pol'y 22, I (1998): 22-35.

Richards, Edward P. "Public Policy Implications of Liability
Regimes for Inuuries Caused by Persons with Alzheimer's

Disease" Ga. L. Rev. 62I, no. 53 (200I): 621-660.

Roberts, I. Scott et al. "Genetic Risk Assessment for Adult
Children of People with Alzheimer's Disease- The Risks

Evaluation and Education for Alzheimer's Disease (REVEAL

Study." Journal of Geriatric PSschiatry and Neurology 18, no. 4

Rosenfield, Elizabeth Ann. "Mental Health Advance Directives: Elder L.J. 53, no. 9 (2001): 54-8I. Rothstein, Mark A A “Predictive Genetic Testing for Allhheimer's
Disease in Long.-Term Care Insurance." Ga. L. Rev. 707 , no. 35

Zernike, Kate. "Love in the Time of Dementia." The New York
Times, 88 Nov, 2007 .

Zick, Cathleen D et al. "Genetic Testing for Alzheimer's Disease

and Its Impact on Insurance Purchasing Behavior." Health
Affairs 24, no. $2(2005): 483-490$. 
COPING IN JORDAN

The Plight of Iraqi-Female-Headed Households

"This dependence on foreign aid, for both the Jordanian government and for the Iraqi population in Jordan, is not a longterm solution for assisting displaced Iraqis in Jordan. . . . Encouraging methods of economic self-reliance will be crucial in the near future and over the long-term."

AS A HOST COUNTRY FOR DISPLACED IRAQIS SINCE THE 1991 GULF WAR, JORDAN HAS RECEIVED

WAVES OF FORCED-MIGRANTS FOR THE PAST TWENTY YEARS, WITH THE GREATEST INFLUX OF DIS-

PLACED IRAQIS ARRIVING AFTER THE 2003 IRAQ WAR. IRAQI-FEMALE-HEADED HOUSEHOLDS ARE

AMONG THE POOREST WITHIN THE IRAQI POPULATION OF JORDAN AND ARE CATEGORIZED AS

VULNERABLE PEOPLES BY THE INTERNATIONAL ORGANIZATION OF MIGRATION AND UNITED NA-

TIONS HIGH COMMISSIONER FOR REFUGEES. THIS STUDY CONSIDERS THE INFORMAL WAYS IN

WHICH IRAQI FEMALE HOUSEHOLD HEADS ARE COPING ECONOMICALLY WITHIN JORDAN. THE

STUDY SUPPORTS THE OBSERVATION THAT REMITTANCES, TRAVEL STIPENDS, AND VOLUNTEER PO-

SITIONS ARE THE MAIN WAYS IN WHICH FEMALE HOUSEHOLD HEADS IN JORDAN GENERATE IN-

FORMAL INCOME. THIS ARTICLE STRONGLY RECOMMENDS CONTINUED INTERNATIONAL SUPPORT,

CHANNELED THROUGH FUNDING FOR UNHCR AND NON-GOVERNMENTAL ORGANIZATIONS IN

IORDAN THAT SUPPORT SELF-RELIANCE STRATEGIES AMONG IRAQI WOMEN. 


\begin{tabular}{|c|c|}
\hline \multicolumn{2}{|c|}{ ACRONYMS AND ABBREVIATIONS } \\
\hline Сво & Community-based organization \\
\hline FHH & Female-headed household \\
\hline IDP & Internally displaced person \\
\hline IOM & International organization for migration \\
\hline IRD & International relief and development \\
\hline ID & Jordanian dinar \\
\hline MENA & Middle East and North Africa \\
\hline NFI & Non-food item \\
\hline NGO & Non-governmental organization \\
\hline UN & United Nations \\
\hline UNHCR & $\begin{array}{l}\text { the United Nations High Commissioner for } \\
\text { Refugees }\end{array}$ \\
\hline UNOCHA & $\begin{array}{l}\text { United Nations Office for the Coordination of } \\
\text { Humanitarian Affairs }\end{array}$ \\
\hline WFWP & Women's Federation for World Peace \\
\hline WRC & Women's Refugee Commission \\
\hline
\end{tabular}

INTRODUCTION

As a woman
whole world

$$
\text { Virginia Woolf }
$$

While the situation of displaced Iraqis in Jordan is exing role as a host country for refugees since the creation of the state of Israel in 1948. Notably, Jordan is not a signa-
tory of the 1951 Geneva Convention on Refugees, lacking laws for refugees or those seeking asylum in Jordan. ${ }^{2}$ Th Hashemite Kingdom of Jordan has a unique role in the region, having the highest ratio of refugees to population: one quarter of all Jordanian residents are considered refu'semi protectionist' policies toward Iraqi forced migrants i.e. letting them in, but depriving them of livelihood means to become settled.", A certain paradox exists in Jo-
dan. While it is considered one of the most politically stadan. While it is considered one of the most politically sta-
ble and safest countries in the Middle East it is one of the most resource-poor countries in the region and in the world.

Within the context of war and political unrest in Iraq, both men and women have suffered in unique ways. The focs fore, the study presents the situation and history of Iraq
hrough the experiences of Iraqi women three decades of conflict, women have endured losing hus bands, sons, brothers, and other male family members. These losses, coupled with increasing denial of equal ights by Iraq's previous socialst regine, have made them outside Iraq. Both Iraqi women in Iraq and those who have fled to Jordan face social barriers to working in the informal economy. A fenale-headed-household (FHH) sible for providing financially for her family Iragi $F H H$ in Iraq and Jordan are stigmatized for living alone (withou a male figure present). Women have played an importan role in shaping the politics and direction of their countr persons and those living abroad, must assume this role again in rebuilding their country.

According to recent statistics released in July 2010 by UN
HCR, there are currently 30,700 Iragis residing in Jordan. raqis in Jordan are not considered refugees, but rather temporary "guests." ${ }^{\circ}$ Most significantly, Iraais are not legally allowed to work in Jordan, depriving them of a source of income and livelihood. Aside from individuals who have the financial means to keep 50,000 Jordanian dinar ing in Jordan are not legally allowed to work. It is widely nown, however, that Iraqis engage in informal work in brdan to provide an income for their families. While tra is estimated that among the 30,700 active Iraqis registered with UNHCR in Jordan today, $20 \%$ of Iraqi households ar emale headed. These FHHHs typically comprise the poor the knowledge about or are not involved in mes inances of their household. It therefore becomes very difficult for Iraqi women who must assume the traditional fole of father, providing a source of income for the family. the same time. Many Iraqi women in Jordan have not previously taken on the role of household head before im migrating to Jordan. This situation often results in the exploitation of both men and women by their employers. or this exploitation in the Jordanian legal system. This study highlights the mechanisms by which Iragi FHHs are coping economically in Jordan in order to provide rec group of displaced persons in Jordan.

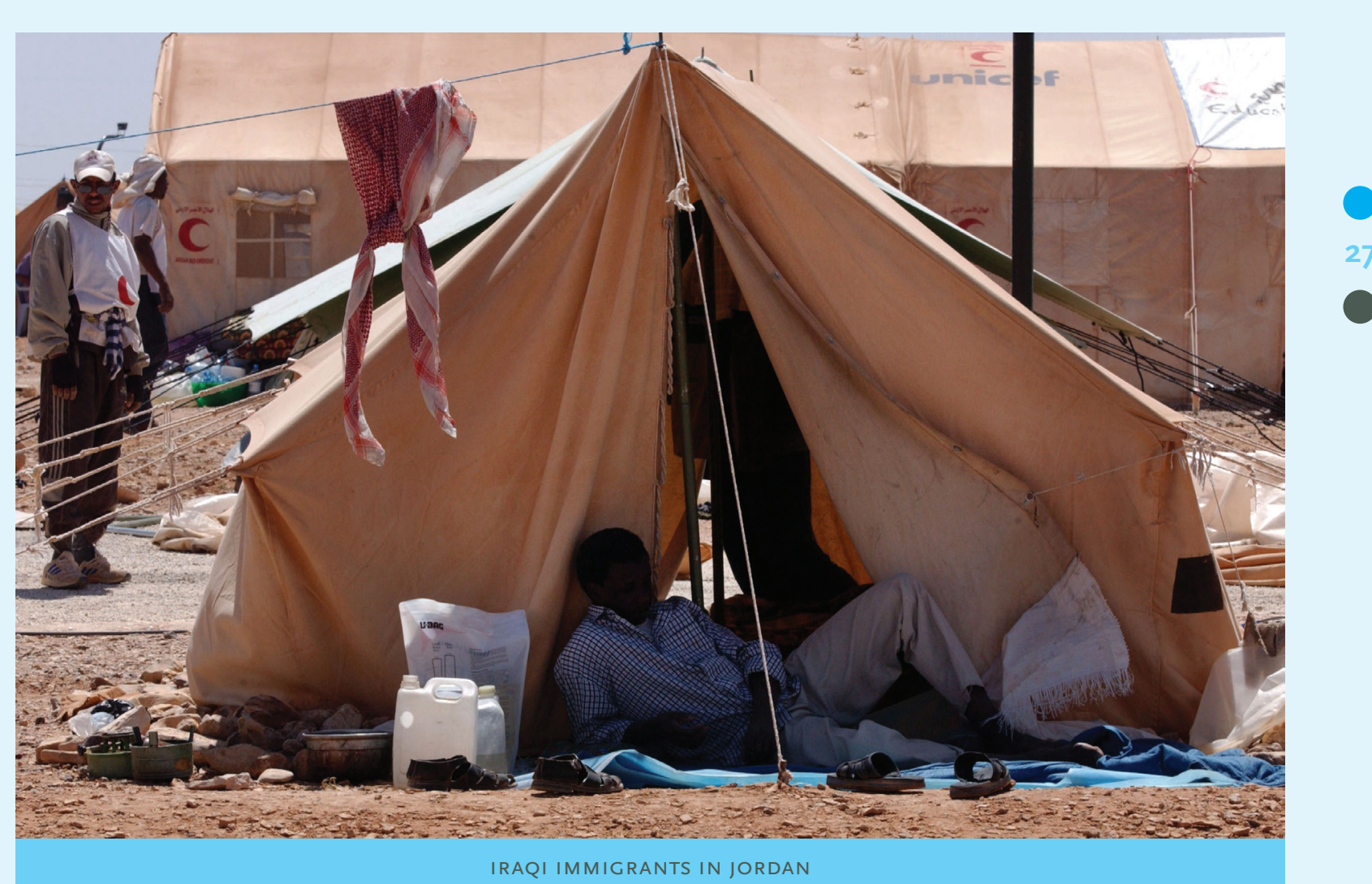

As a result of the oil boom in the I970s, Iraq's growing working in the formal economy in Iraq and theirinability porting foreign labor, Iraq encouraged the participation of the difficult situation of providing financial support for women in the work force as a policy to spur the economic oppressive regime, following his rise to power in I979, ur-
ban women experienced more social freedom and educa.

ban women experienced more social freedom and educa-
tional opportunities. Women were "perceived to play a

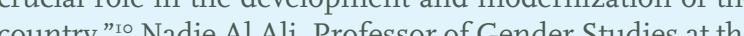
School of Oriental and African Studies in London, asserts, "Iraqi women became among the most educated and professional in the whole region."'" However, when politica and economic conditions changed during the Iran-Iraa
war and after the IggI Gulf War the state changed its rhet oric regarding women and their role in society. After the I99I Gulf War, in the era of the sanctions of the I990 economic conditions declined and the Iraqi regime urged in order to allow men to be the breadwinners of the fam
ly.'2 With Iraqi FHHs being socially discouraged from even formal interviews with representatives from local primary research was supplemented by texts which provided background information on the history of Irac ports on Iragi refugees in Jordan. Irapi $\mathrm{FHHS}$ were chosen based on their previous or current affiliation with Women's Federation for World Peace. Contacts at loca

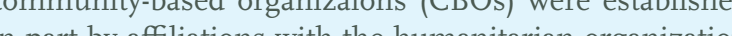
CARE a program already based in Jordan. Furthe only women who are heads of their households in Jordan 
$\begin{array}{ll}\text { were interviewed for this study, including women who } & \text { Hashmi Al Shemali, Wast Al Balad, and Sweileh. Non- } \\ \text { were divorced, widowed, or who had husbands living } & \text { Iraqis, namely case workers and program coordinators a }\end{array}$ were divorced, widowed, or who had husbands living Iraqis, namely case workers and program coordinators at es, various education levels, and varying amounts of time and were asked a series of questions relating to their expespent in Jordan. ${ }^{33}$ Women were between the ages of 20 rience working with Iraqis and how they perceive Iraqi feand 60 , and thus had varying experiences growing up in male household heads. Data was compiled from Iraqi Iraq.14 All interviews with Iraqi
with two male WFWP volunters present, who acted as translators. There was a base set of ten questions asked to all participants. While the Iraqi women interviewed reside in and around Amman, the program coordinators reside large concentrations of Iraqi refugees. Therefore, while the researcher did not have direct contact with Iraqi FHH in cities outside of Amman, data was collected from sec-
ondary sources regarding Iraai women in Irbid and Zarga.

jordan.

All Iraqis interviewed were receiving aid from UNHCR tance has been excluded from the ways in which Iragwomen are actively generating income. Recipients of $\mathrm{UN}$ HCR monthly cash assistance receive debit cards, to whic

"These positions, then, do not provide long-term solutions for generating an adequate source of income; rather, they are a way for volunteers to generate a small amount of supplemental income for a limited amount of time." Informal interviews with Iraqi women participants were depending on the number of individuals in the family. A
conducted in the form of discussions and, while a core set
single man or woman receives $75 \mathrm{ID}$ per month, two indiof questions was asked to each participant, the order in viduals receive IIo JD per month, a family of three receives which the questions were asked varied, as did the depth to 195 ID per month, while a family of four receives 2TO JD
which each question was answered. These discussions hsted no more than half an hour. Before their interviews, this stipend is usually enough for rent, utilities and some all participants were given a summary of the research food. However, it is not enough for other living expenses study and were informed of their rights as participants of such as phones, clothes, health care, and education costs

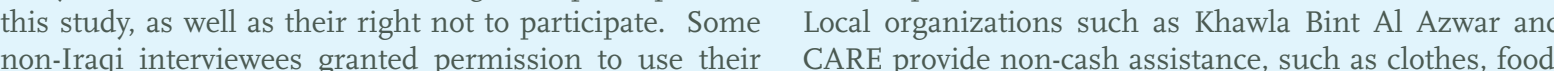
name in the study. Thus, some interviewe's names are and home goods to families who demonstrate need. Provi$\begin{array}{ll}\text { preserved. Translators acted as witnesses for those who } & \text { sion of non-cash assistance effectively decreases a family's } \\ \text { gave verbal consent. } & \text { expenditures. CARE International provides one-time }\end{array}$

FINDINGS

In total, fourteen individuals were interviewed, seven were were individuals who have had experience working with Iraqis in Jordan, and often times in the greater MENA region. All Iraqi female household heads interviewed had arrived in Jordan after 2006 , aside from one family th Iraqi women within Amman. Specifically in the areas of expenditures. CARE International provides one-time emergency cash assistance to new arrivals who demon-
strated need, in the range of $200-300 \mathrm{JD}$. Aside from hese sources of cash and non-cash assistance, it was concluded that there are five main ways in which Iraqi FHH are coping in Jordan: remittances, volunteer positions, Remittances All Iraqi FHHs interviewed had extended family in Iraq, seven interviewees stated they were receiving funds from had taken on a volunteer position at a local NGO was living Three out of these four families had two or more children attending school, and they reported that most of the fund received by family abroad were allocated towards the chil ing transfers from abrod, their living situations seemed fairly stable, and their lives generally more comfortable than that of other female household heads interviewed. Therefore, it became clear that remittances are seen as supplement to UNHCR cash assistance received each
month. Results from interviews did not indicte a clear making it difficult to generate conclusive findings. Interviews and observations suggested that while remittance nisms, they comprised a signific
those families that received them.

Volunteer Positions through Local NGOS

Although Iraqis in Jordan are not allowed to work in the formal economy many NCOs nate begen to al ing for volunteers. These assistants, usually women, take on these positions for two to three months and are pro between Ioo-200 ID Representatives interviewed from CBO in Zarqa, Jordan, explained that some women take two of these positions at once, and thus generate twice the amount for their work.18 In these positions, women work late programs within the local Iraci com the local community. Some of these organizations have volunteers work with local NGOS as teachers and help with correspondence between the $\mathrm{NGO}$ and partnering $\mathrm{CBO}$ for local NGOS, the number of volunteers hired may lowe as a result of restrictions in the annual budget. ${ }^{19}$ Also, be cause these NGOs seek to provide this opportunity to many different individuals, volunteers are usually no
hired for more than two or three months. These positions then, do not provide long-term solutions for generating an adequate source of income; rather, they are a way for vol-
unteers to generate a small amount of supplemental inunteers to generate a small amount of supplemental in-
come for a limited amount of time. It must be noted that for FHHs who have children, taking on these volunteer positions, which often involve working in an office or traveling within or outside Amman, is extremely difficult, as children at home must also be cared for. From laqui

Program assistants of local CBOs mentioned similar in

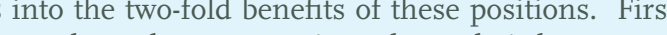
inge with other women and members of the comm nity.yo Second, generating a source of income, though a
modest amount gives beneficiaries a sense of selfigmp ance and allows them to be productive members of the held at least a bachelor's degree. Iraqi women who take o these positions are, more often than not, overqualified for he work they are performing, as many were former proessors, accountants, or worked in administrative positions.".
sense of taking on these positions, women can attain a volunteer positions benefit both the Iragi woman volu feer and the local Iraqi community: they allow Iraqi volunteers to directly work with fellow Iraqis in the local con-

Travel Stipends

ocational training and skills courses for women have be ways to provide useful programs to Iraqi wome and $\mathrm{CBOs}$ as All but two Iraqi female household heads interviewed re ported having attended such training courses, as well as psychosocial counseling sessions. These services are pro vewed repost roceiving travel stipends of $2-3$ ID eash While these courses provide valuable services and skills to the attendees, there is speculation as to whether individuals participate to benefit from the services provided from making it difficult to ascertain their true motives. A Women for Water Program (WFWP) representative stated that UNHCR and some CBOs almost consider these travel stipends as an indirect form of distributing cash assistance to to
ragis 22 A program coordinator in Irbid explained that for recent social activity sponsored by her orgnization, por icipants received a travel stipend of 3 ID; however, a bus was also hired to pick up and drop off participants in their "travel stipend" became simply a stipend for attending the activity.3. In other situations, women share taxis or use public transportation in order to save on travel costs. herefore, travel stipends, whether enabling Iraqi FHH 
women to profit from the amount remaining from the ac Self-Employment

Small businesses, solely headed by women entrepreneurs
were also reported in preliminary research to be sources of

30. were also reported in preliminary research to be sources of

home based, household heads can simultaneously run this business while taking care of dependents and daily house
hold work. Usually, female heads of household attend vohold work. Usually, female heads of household attend vo ing classes or business entrepreneurship training completion of such skills training courses, women receive a package that helps them to begin their own business ventures.

Some non-Iraqis interviewed also cited microcredit pro grams as being ways in which Iraqi FHHs generate in-
come. UNHCR, through UNICEF in Jordan, has sough to expand opportunities for Iraqi women and women in CBOs in Jordan such as WXFWP and Khawala Bint al Azws East Amman Charitable Association, and Al Amal have implemented similar microfinance programs. A WFW representative explained that while the theory of microf
nance for $F H H s$ is an excellent one small business entrepreneurship, among Iraqi women, have not been successful. 25 Irikora described her exper ence with Iraqi FHHs and small business entrepreneursee their sitution as temporay. Their mind is as as jor dan. ${ }^{226}$ Irikiora's insight that many women do not see Jordan as their home, but rather as a point of transit to a third country, was also observed by the researcher in her fifd. viewed intended to immigrate to the United States in the future. Despite studies that suggest small businesses be a sustainable source of income, no Iraqi female household head interviewed in this study had her own business entrepreneurship. While enthusiastic about the potentia of these programs for improving the FHHs' livelihoods, a program coordinator from a $\mathrm{CBO}$ in Irbid emphasized tha is notenough on to household with children. Nevertheless, like remittance and travel stipends, profits from small businesses are seen as a supplement to monthly cash assistance from UN-
Representatives from Khawla Bint Al Azwar, an organiza列

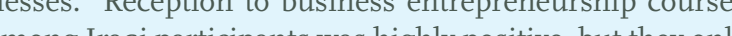
had funding for beginning level courses. They have no received sponsorship or funding to expand these courses

"On average, a social worker at an NGO in Amman reported that if paid for her work, an Iraqi

woman receives between one half and three quarters of what another woman, working legally in Jordan, would make in her place."

nd more significantly do not have the funds to provide tart-up costs for their micro-businesses. Taking out loans In Jordan requires collateral and a co-signer who, by law,
must be Jordanian. Iraqis, especially FHHs, often lack both of these requirements. ${ }^{27}$ They are seen as having an status in Jordan, as they may travel ou hey are not represented in the Jordanian legal system they are not seen as reliable debtors.
where Iraai feremale heads of household in the cases interested in starting their own businesses, a lack of funding is often an impediment to achieving this source of semi-self reliance.
inting Informal Work

Because the large majority of Iraqis do not have work pertor and be legally employed in tordan. Thus, along with having a self-owned small business, some Iraqi FHHs ar

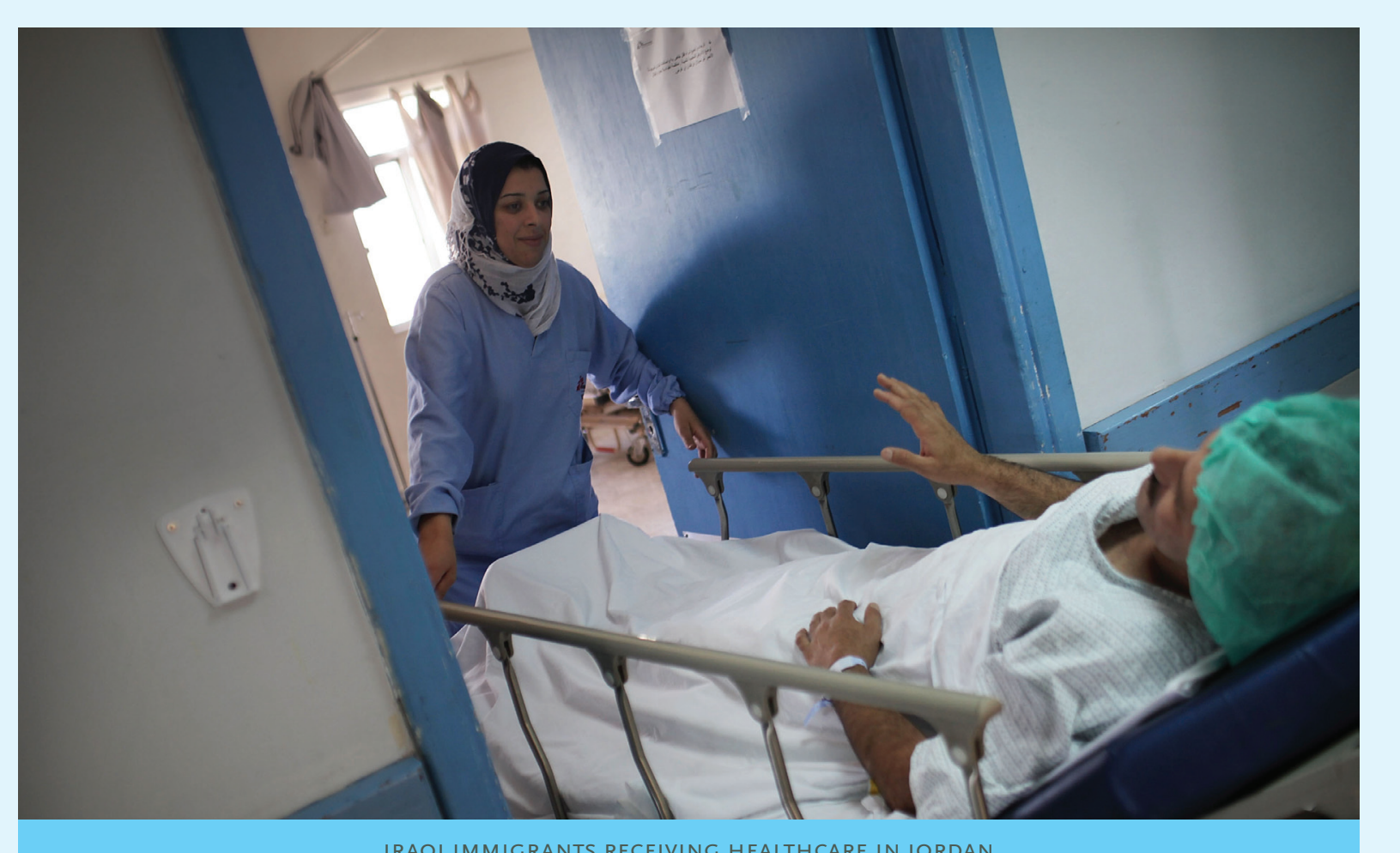

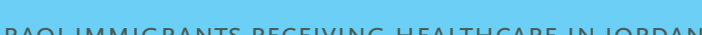
informal work than men do. ${ }^{29}$ Iraqi men typically expehesitant to harass women $3^{\circ} \mathrm{Also}$, especially for household work, it is easier for a woman to enter another family's home. Working as household cleaners or as seamstresses is the most common type of informal work reported

There are two main problems rising from Iraqi $\mathrm{FHHs}$ engaging in the informal economy: they are paid less than their Jordanian counterparts or are not paid at all. On aver. age, a social worker at an NGO in Amman reported that
paid for her work, an Iraqi woman receives betwen half and three quarters of what another woman, working legally in Jordan, would make in her place.3. This work is
illegal under Jordanian law and women cannot seek lega illegal under Jordanian law and women cannot seek lega irregular migrants working illegally.y.3. For Iraqi FHHs who
are faced with no other ontions to generate income for themselves and their families, they resort to more despeate means of survival. These may include selling gold endors, or sending their children to work.33 While the re作

CLUSTON

n light of current difficult situations for Iraqi FHHs in ordan, economic security is of the utmost importance. Which to ensure financial security for day-to-day necessiins, vulnerable Iraqis, namely FHHs, in Jordan have high dependence on UNHCR cash assistance as well as on foreign aid. Foreign aid is allocated to local NGOS and CBos who, in turn, facilitate programs for Iraqi and nonof household benefit from the skills acquired throad ns and from the extra cash generated by saving their travel stipends. These courses are seen as an oportunity to socialize with other Iraqis and bridge gaps
between the Iraqi community and the local community. 
Effectively, many Iraqi FHHs' livelihoods in Jordan are ing for volunteer positions and for travel, though UNHCR funding has begun to decline since 2009.,35 Furthermore the Jordanian government estimated in 2008 that Iraqi
guests in Jordan had cost the country 1.6 billion JD from guests in Jordan had cost the country 1.6 billion JD from
2005-2008; however, the Jordanian government has never

danian government has allowed Iraqis access to public schools and healthcare, there is speculation that Jordan
has "benefitted greatly" from the inflow of foreign aid, has "benefitted greatly"
aimed at assisting those directly iffected by the current conflict in Iraq. . $^{37}$

This dependence on foreign aid, for both the Jordania ave population, such as FHHs, encouraging methods of eco-

"Iraqi women don't have a stable mind here, as they see their situation as temporary. Their mind is not in Jordan." nomic self-reliance will be crucial in the near future and material assistance, allows families to meet basic needs. This aid, however, is not everlasting, and funding for UN years. Many organizations request additional funding in the form of aid or cash assistance, though these allocations are not a permanent solution for improving the lives of wards guided assistance in order to better encourage their self-reliance. ${ }^{3}$ This, in itself, presents a challenge, as Iraq cannot work legally in Jordan. Previous studies on the sustainable way to improve the liveliho d of the mosed Iraais in Jordan is for the government to grant them work permits. However, the chance of the Jordanian government allowing Iraqis to work in Jordan is quite slim. Thus, for
Such programs, channeled through NGO programs on the inancial self-reliance for Iraqis remaining in ereby reducing poverty among Iraqi refugees residing in fordan. These mechanisms could serve as a model for displaced Iraqiis in surrounding MENA countries, and, mor displaced peoples living in a foreign uture studies regarding the possibility and efficacy of es an is hing a permanent community fund for Iraqis in Jorcrease the livelihood of Iraqis in Jorda majority of Iraqis in Jordan will not be resettled to a third country or return to Iraq in the near future, there will be trategies core group of traqis in Jordan. Self-liance port for those Iragis remaining in Jordan, deserve attention in future research projects.

While this study has focused specifically on FHHs as a vulerable group within the Iraqi community in Jordan, new ularly those who are not in school or are not working-are also considered vulnerable.t" With a loss of employment amilial relations in a negative way. For example an IOM report found that domestic violence has increased amon raqis in Jordan due to the frustration of men who are no ble to financially provide for their families..42.$^{2}$ Future stud ces regarding low lraqi men are coping in Jordan, both means for NGOS to involve males, especially teenagers, in programs and psychosocial counseling. Equal inclusion essary for establishing an Iraqi society that can succed in aining peace and economic security.

ENDNOTES

IID $\approx$ I.40 USD
Guglielmo $2008(46)$

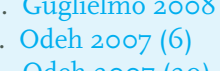

UNHCR, UNHCR - July 2010, Press Release (Amman:

7. Guglielmo 2008 ( 122

9. Odeh 2007

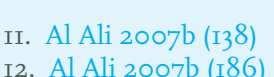

13. All Iraqi women interiduals in FrHs intervewed was 2 . s are distributed to Iraqi families, rather than the ordan each month. I7. Rheema, interview by S. Moradian, I4 Nov. 2010 8. Aya and Zeinab, interview by S. Moradian 23 Nov. 201 I9. Hiba
20. Ibid 2.I Ib:

23. Hiba interview by S Moradian, $25 \mathrm{Nov}$

27. Aya

Zeinab, interview by S. Moradian 23 Nov. 2010

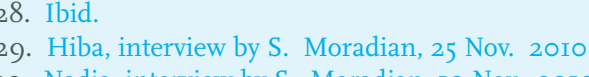

II. Leila, interview by S. Moradian, 25 Nov, 2010

2. While Jordanian law allows both legal and illegal workers to seek legal recourse for exploitation in the workplace, Iraqi
women feel that their working illegally yrevents them from
taking legal recourse when exploited for their working in the

33. Irikora, interview by S. Moradian, 9 Nov, 2010
3. Irikora, interview by S. Moradian, 9 Nov 2010

35. Niziale

37. Ibi.

38. Leila, interview by S. Moradian, 25 Nov. 2010

40. Odeh 2007 (I7)

41. Al Ali and Pratt 2009 (26)

REFERENCES

Al Ali, N. Iragi Women: Untold Stories from 1948 to the Present

Al Ali, N. and Pratt, N. Women and War in the Middle East. New

Guglielmo, S., Bartroloni, E.., and Nuri, R. Assessment on Psychososo
cial Needs of Iragais Displaced, in Jordan and Leebanon. Amman: Inernational Organization for Migration, 2008.

Khuzaie, W. UNHCR News Story: UNHCR Sees Deepening Need 2010 .
Qden, H. Political Responses to Mass Refugee Influx: The Case Press, 2007

at. "The Iraq Effect" IO Magazine, 2I April 2010.

UNHCR. UNHCR - July 2010. Amman: UNHCR, 20I0.

Women's Refugee Commission. Living in Limbo: Iraqi Your

Women and Men in Jordan. Amman: Women's Refugee Commis 
THE MYSTERY OF MITHRAS

Analyzing Religious Practices in Dura-Europos

"The strong presence of art and archaeology, despite a lack of textual evidence, shows how the distinct cult of Mithras acted not only as a supplementary religion for Roman troops, but also as a cornerstone of religious tolerance in this ancient city."

THE MIDDLE EASTERN CITY OF DURA-EUROPOS, WHICH WAS FEATURED IN AN EXHIBIT IN BOSTON

COLLEGE'S MCMULLEN MUSEUM, PROVIDES HISTORIANS WITH AN EXTRAORDINARY AMOUNT OF

INFORMATION REGARDING RELLGIOUS DIVERSITY IN THE ANCIENT WORLD. THIS ARTICLE FOCUSES

SPECIFICALLY ON THE RELLGIOUS CULT OF MITHRAS THAT WAS FOUNDED UPON THE WORSHIP OF

THE ANCIENT GODS MITHRAS AND SOL, AND THE SACRIFIIIAL TAUROCTONY. RELYING ON TH

EVIDENCE PROVIDED BY ARCHAEOLOGY, ARTWORK, AND THE CULT'S SITE OF WORSHIP, TH MITHRAEUM, THIS ARTICLE IDENTIFIES THE SINCULARITY OF MITHRAIC PRACTICES IN THEIR HISTORICAL CONTEXT WHILE ALSO EXPLORING THE RELATIONSHIP THAT THE CULT OF MITHRAS HAD 


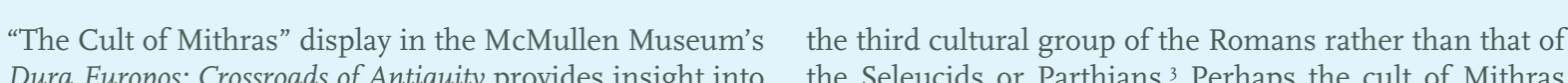
one of the most mysterious religions practiced at Dura- was a newer more attractive practice, but even more probEuropos before its fall to the Sasanians in 256 CE.'. Reli- able is that Dura-Europos was simply becoming an ingious relationships at Dura-Europos were exceptional in creasingly impressionable city that was open to various that Christians, Jews, pagans, and other cult members languages, cultures, and religions. Gail R. Hoffman re were atypically tolerant of and associated with each other.
For example the Roman soliders who were some of the

original members of the cult of Mithras were also involved with the renovations and expansion of both the Christian building and the synagogue. This demonstrates that whil different in tradition, they managed to establish tolerance an even influence each other's practhat deserves its own analysis. The lack of Mithraic texts necessitates conclusions about the group
based on the art and archaeolog based on the art and archaeology Mithraic history and religious attworks while cross-referencing the discover what made the cult of Mithras so unique and capable of

Tracing the foundation of the cult
of Mithras in the civilization of Dura-Europos is essential to the ligious significance and its fund mental deviation from the more popular religions of the city. The Mithraeum, the building of worship for the cult of Mithras, was
built along the northern wall of Dura-Europos in approximately 168 or 169 CE. Palmyrene archers serving in the Roman army were tices into Durene society, emph sizing the malleability of the religious culture of Dura-Europos. The Cult of Mithras actualy

Some scholars have assumed that one reason for the great variety of cults found at Dura-Europos is the variety of peoples STONE TABLET DEPICTING MITHRAS

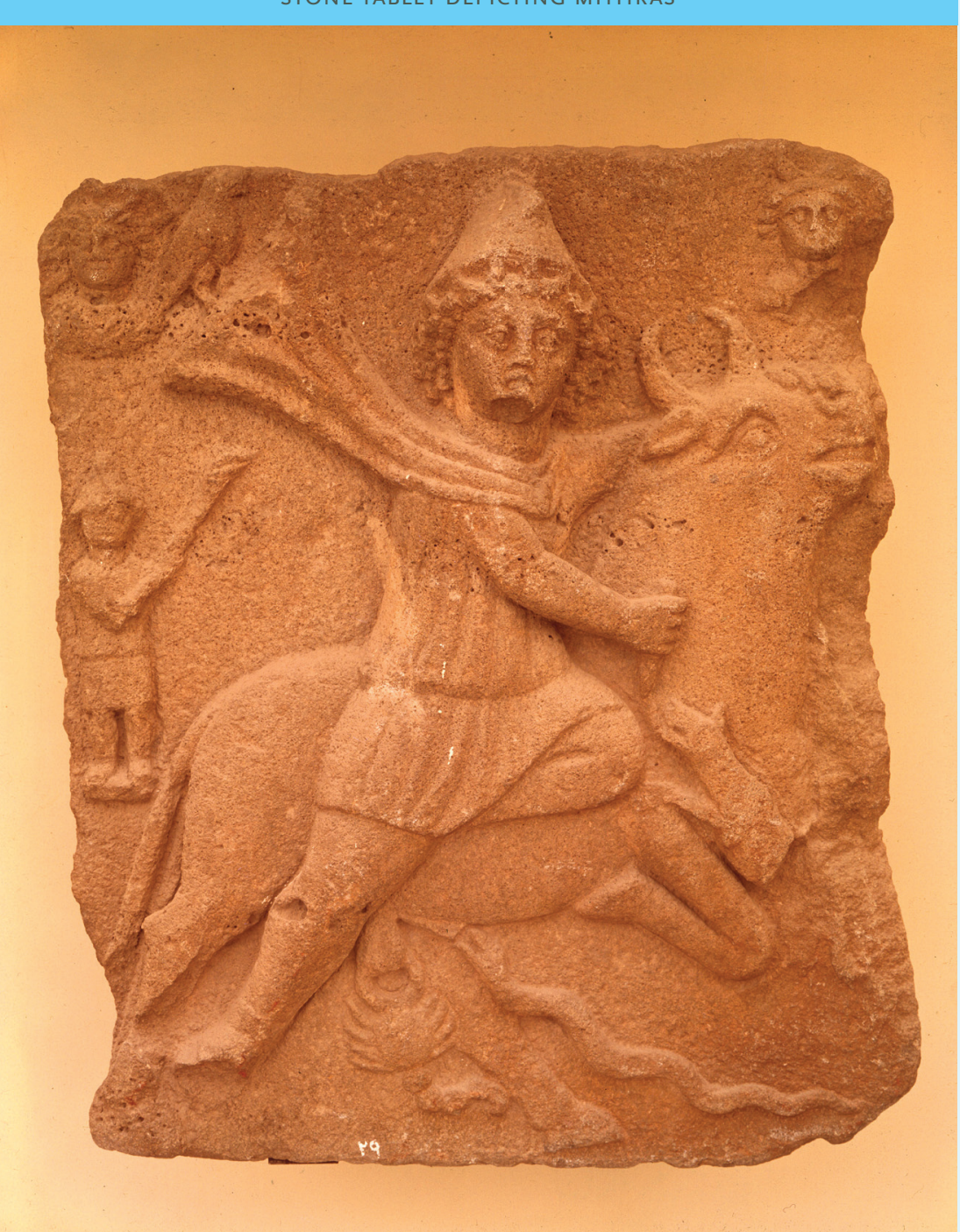

Because it was a military garrison and a strong trading and

As Palmyrene archers brought the cult of Mithras into the certainly seems that the cult of Mithras came with the Roman first visible during the Roman phase though they may have been present in the city earlier. ${ }^{4}$ political center, Dura-Europos was greatly exposed
countless cultural groups. By the time the Sasanians de feated the city in 256/257 CE, Macedonian, Seleucid, Parthian, Roman, Sasanian, Greek, Latin, and Persian influences had all been present at some point during the life of the cult of Mithras would have been able to the such a diverse community.

It is important to note that even though Palmyrene solMithras in Dura-Europos, it was not necessarily their only religion. The Feriale Duranum, a religious calendar dating
around $223 \mathrm{CE}$, was used by Roman soldiers in Dura-Euro around $223 \mathrm{CE}$, was used by Roman soldiers in Dura-Euro-
pos and reconstructs their entire religious year. No gods pos and reconstructs their entire religious year. No gods
from either Dura-Europos or Palmyra are mentioned in the calendar, and only the Roman gods actually worshipped in the city of Rome hold any stature; that calendar, in fact-which includes notes of army festivals, public fes up of mostly the same observances of the city of $\mathrm{R}$. self. Soldiers all over the Roman Empire used nearly identical copies of the calendar. In addition to participating in
this official Roman religion and worshipping Roman gods however, Palmyrene soldiers also worshipped other popuhowever, Palmyrene soldiers also worshipped other popp.
lar gods that were never adopted by Rome. could not practice Judaism or Christianity, as those would
prohibit sacrifice to the official Roman gods of the state. prohibiti sacrifice to the official Roman gods of the state,
they could indeed join various religious cults, such as that Jorify him because the time has come for him to sit udgment; worship the maker of heaven and earth and sea and the springs of water." Christians believe that a follower universe. Because the religion does not allow for its members to worship any other than God himself, Roman troops could not become Christians and follow the official Roman religion simultaneously.8 However, a religious cult such as
Mithras allowed for the men to contine with trad a pagan practices while also earning membership into new pagan practices
religious sect. of the third century CE, as well as those in the merchan trikingly different from religions such as Judaism and Christianity which welcomed, and in fact promoted, the ontersion of both genders.? However, one must not forcers Diples, or apostles in the Bible. According to Lucin Diven, the cult of Mithras became "a brotherhood of Dive chers, originally became exposed to the cult, there are sus While the historical context and religious participants are clearly important elements of any religion or cult. The acnt attention in this discussion. This myster"The Mithraeum at DuraEuropos is among the best preserved of the cult. Its architecture, decoration, and graffiti not only help to describe the cult in Dura but also to portray the cult during the first half of the third century throughout Syria."

ous religion was thought to include seven levels of initiation, ritual banquets, and a promise of salvation after Mithras, originally an Iranimn god whorshpped he god end, was born from a rock in a moment outside time and killed a cosmic, primeval bull, which he then dragged into a cave. Mithras and the sun god Sol then proceeded to feas

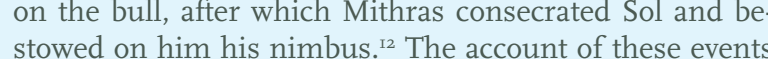


was taken from various pieces of art in the Mithraeu
which will be examined later on in the discussion.

ology because there were no documented texts such as The Aeneid or the Bible which scholars could use as religious
evidence. Little was recorded about the cult's beliefs and members would not have written much down, but instead would have expressed their religion through reliefs an other artwork in the Mithraeum. The graffiti on the walls
of the Mithraeum at Dura-Europos lists the names of initiates with their Mithraic grade, while paintings and sculptures hint at various aspects of their religious prac ices. ${ }^{13}$ Subsequently, the cult of Mithras shows the importance of artwork and archaeology to understan
ligions of Dura-Europos and all ancient cities.

The Mithraeum itself, as the site for worshipping Mithras, becomes an existential piece of evidence in unearthing the I68 CE by the Palmyrene archers who founded the cult in Dura. It was enlarged in 209-2II CE by the Roman com-
mander Antonius Valentius and was renovated again from

"It seems that though the cult of Mithras may have been traditional in holding ritual banquets ....the ideology behind such feasts remains very unique." 240 CE into the Late Mithraeum. It was subsequently dis
covered by excavators nearly two thousand years late. covered by excavators nearly two thousand years later
While most Mithraea are underground in order to symbolize the importance of caves to Mithras, the temple at Dura-
Europos was completely above ground, perhaps influenced Europos was completely above ground, perhaps influence commodations like those typically found in modern day synagogues or churches. ${ }^{15}$ This arrangement invoked ship. The Mithreum at Dura Europs is among the best preserved of the cult. Its architecture, decoration, and graf proughout Syria. All of the subjects in most Mithreea are Siniar to each other, yet the style and composition of the

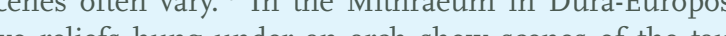
roctony which are then flanked on both sides by Mithraic hunting scenes

The two Mithraic reliefs are almost identical in the posiholding back the bull's head and thrusting a dagger into his neck. The top relief, which was placed by the Palmyrene commander Zenobius, included the dedicant, or the cult association. Their presence is significant in the they are not family members, which was typical of the Roman cult in which familial ties were unimportant, and hus creates a blunt contrast with Judaism and Christianour father and your mother so that you may live long in he land that Yahweh your God is giving you,"r,ist The cult of Mithras offers no such declaration of paternal or famillal prominence, and instead focuses on the relationship the Mithraeum at Dura-Europos, which was originally placed to the left of the cult niche during the building's

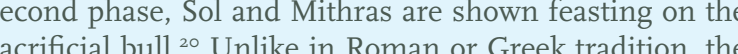
od Mithras himself seemed to be doing both the sacrific ing and feasting. This presents a problem in that it com-
pletely opposes traditional beliefs regarding sacrifice. When Hercules came to the aid of the Arcadians to kill the ut his gullet whitened and dried up with loss of blood He left the violence at that.2. He never ate the animal as a sacrificial feast and instead, "since then / This feast (by the Arcadians) is held, and younger men are glad / To keep the Mithras may have been traditional in hough the cult of quets for new initiates, as animal remains and purchase eceipts testfy. In any event, he ideology behind such feasts

Despite its distinctiveness, the cult of Mithras does maintain a subtle relationship with other religions such as
Christianity The pagan Celsus criticized that "superstiliristianity. The pagan Celsus criticized that "supersti
ions like Mithraism and Christianity are led by wicked
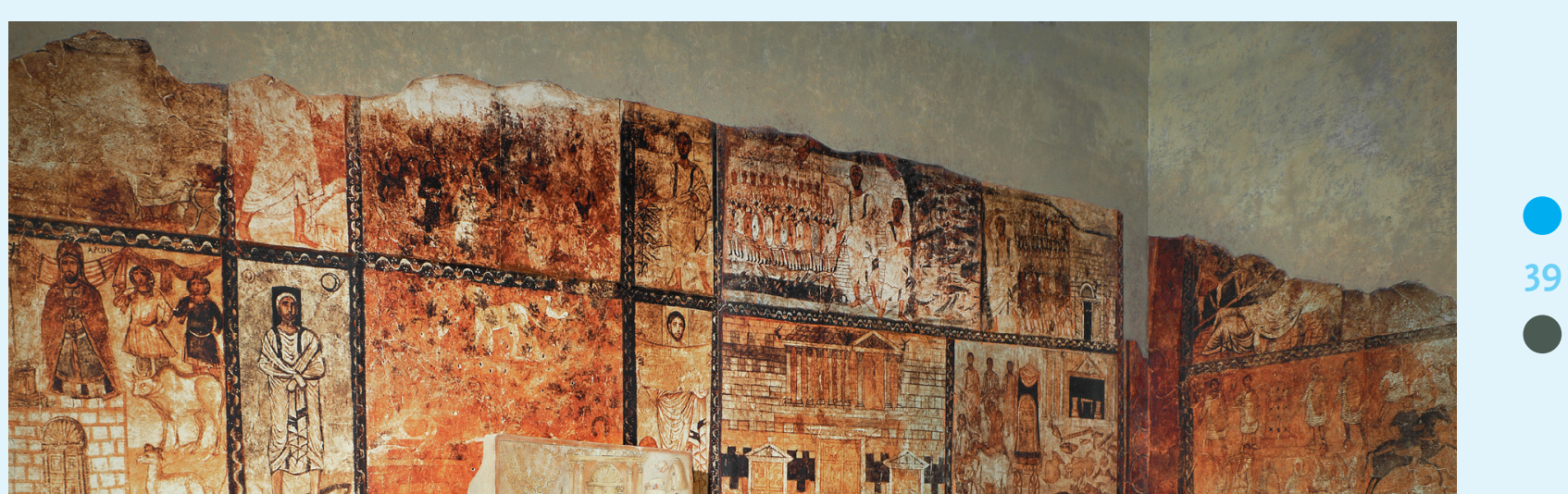

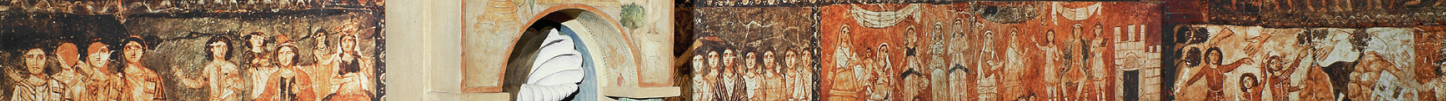
$-3+240$

(9)

TON OF THE SYNAGOGUE OF DURA-EURoPOS IN AN ISRAELI MUSEUM teachings without explanation. ${ }^{24}$ The grouping of Mithra- Such oppositions and critiques of Mithraism can actually
$\mathrm{ism}$ and Christianity seems faulty because the two are
work to demonstrate how well the different religiou wholly independent and individual religions. Unlike the cht of Mithras, both Judaism and Christianity claim a begroups coalesced in Dura-Europos. Although historica
and religious texts demonstrate rivalry and intolerance of different religions, the archaeological evidence for Mithraism, Christianity, Judaism, and paganism show adherence to other belief systems and a willingness to share common elements in their ritual space. The commonalties of the and decoration are especially unique and create a "Durene" style of art and architecture..$^{26}$ The typical rivalry and distrust usually seen among religions of the third century ence of art and archaeology, despite a lack of textual evidence, shows how the distinct cult of Mithras acted not only as a supplementary religion for Roman troops, bu 
I." "Dura Europos" 20Ir: “Military Presence" Exhibit Description 2. Ibid. 3. “Dura Europos" 2orI: "The Cult of Mithras" Exhibit Descrip-

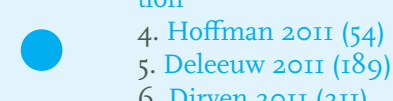

ublished in conjunction with the exhibitition “ ${ }^{2}$ Museum of Art Crossroads of Antiquity" shown at the McMullen Museum of
Art. 6. Diven 20II (2II)

8. Revelation $14: 7$

9. "Dura Europos 2orr: "The Cult of Mithras" Exhibit DescripVirgil. The Aeneid. Trans. Robert Fitzgerald. New York: Vintage
Classics, roge IO. Dirven 2011 (2III)
II. "Dura Europos" 20II: "The Cult of Mithras" Exhibit Description

13. "Dura Europos" 20II: "The Cult of Mithras" Exhibit Descrip. Itio “Dura Europos" 20Ir: “The Cult of Mithras" Exhibit Descrip-
If

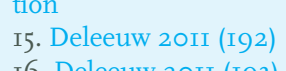

I6. Deleeuw 2011 (II93)
I7. "Dura Europos" 20II

18. Dirven $201 \mathrm{II}(2 \mathrm{2} 2)$

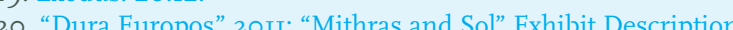

2. Virgil trans. Fitzgerald I990 (VIII: $345-346$ ) 22. Virgil trans. Fitzgerald 1990 (VIIII: 354-356)

Sol" Exhibit Description 25. Ibid.
26. Deleeuw 201 (r.95)

REFERENCES

Deleeuw, Patricica. "A Peaceful Pluralism: The Durene Mithrae Lisa R. and Hoffman, Gail L., eds. Dura Europos: Crossroads of Antiquity. Chestnut Hill: MccMullen Museum of Art. Published In conjunction with the exhibition "Dura Eurpos. Crosstoads
Antiquity" shown at the McMullen Museum of Art "Dura Europos." The Mccullen Museum of Art. Devin Hall
IO8, I40 Commonwealth Avenue Chestnut Hill, MA 02467. Dirven, Lucinda. "Strangers and Sojourners: the Religious Be havior of Palmyrenes and Other Foreigners in Dura-turopos: Europos: Crossroods of Antiguity Chestnut Hill Mc. Medullen M seum of Art. Published in conjunction with the exhibition "Dura Europos: Crosssioads of Antiquity shown at the MecMullen Mu-
seum of Ant Hoffman, Gail R. "Theory and Methodology: Study of Identities

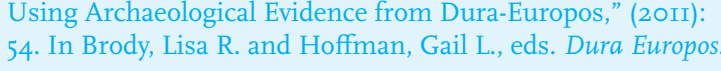


"Beyond the purpose of entertainment, historical films serve as portals to the past, and the power of film then becomes the ability to transport the viewer to that past."
SINCE THE 1960S, THE DEPICTION OF THE VIETNAM WAR IN FILM HAS CAPTIVATED AND POLARIZED AUdienCES WHILE COMPLICATING THE ICON OF THE "AMERICAN WAR HERO." historical FiLMS AND COLLECTIVE MEMORY SERVE PARALLEL FUNCTIONS IN THEIR ENDEAVORS TO RECREATE THE PAST AS A COLLECTION OF IMAGES, HOWEVER MEDIATED. INDEED, FILMS HAVE THE CAPACITY TO SHAPE HISTORY AS IT IS ACTUALLY REMEMBERED BY PRESENT-DAY AUDIENCES, THUS BLURRINC THE DIVISION BETWEEN 'OBJECTIVE' HISTORY AND 'SUBJECTIVE' MEMORY. THIS ARTILLE EXAMINES HOW, OVER A PERIOD OF DECADES, FILMS DEPICTING SOME ASPECT OF THE VIETNAM WAR HAVE CHANGED AND, CONCOMITANTLY, HOW THIS CHANGE RELATES TO RECOLLECTION OF THE ACTUAL EVENTS OF THE VIETNAM WAR. 
INTRODUCTION

With each new film adaptation incorporating historical accounts of the Vietnam War, America as the victor is an im-
age that begins to fade. The depicted role of American in-

volvement in the war becomes more ambiguous with each
passing decade Perhaps stemming from the turbulent

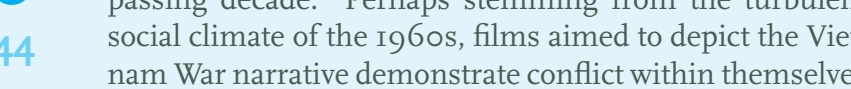

to reconcile the outcome of such a traumatic event in ture of the Vietnam War made the distinction between "good" and "bad" an impossible moral dilemma, exasper
ated by American ouths rebelling gagainst the "stablish
ment" and publically displaying antiwar sentiment There has been a recent desire to recapture this time of revolltion as one of revitalization as well as fear, anger, and resentment. Such are the conflicting sentiments depicted in during soon after and long after the end of the wat.

Throughout the past half century, film has become an ideal and powerful vehicle for reflecting the personal sent ments of this image-laden war. Rich Warland expressed entry, “The Other Living-Room War: Prime Time Comb Series: I962-1975," by describing the proximity between the Americans at home and images of those abroad in amine elements such as the musical score of the fim demonstrates the ability of Vietnam War themed films to reflect the dissonance of the current society. Temporality proves to be a marker of change for the following Vietnan
War related films: MASH (I970), Apocalypse Now (I979). Platoon (I986), Casualties of War (I989)), and Forrest Gump (1994). Each film ultimately reflects different stages of
contemplation and understanding of the Vietnam Warcontemplation and understanding of the Vietnam War. While only a few, these selected films attempt to demorimage from an indisputable figure of power to a war-torn
soldier traumatized by battle, and finally to a reconciled soldier traumatized by battle, and finally to a reconciled character with an altogether novel identity. This final place
of reconciliation, as portrayed by the main characters of these films, serves to mirror American society's self-aware ness and recovery from the Vietnam War.

CONFLICT IN THE SOCIAL CLIMAT While war films had previously created an image of the
brave American as a hero of revolution fighting against a diear-cut enemy to ensure domestic independence and jus. mphasize the image of he foreign enemy. Self-awareness of one's place in society seemed to be the pursuit of many in 1960 s American culthe realiza ence as opposed to a protector against violence. During this time of great uncertainty, the "enemy" became unclear -is the enemy the uncivilized foreigner in a distant land surprisingly in many of the Vietyour home-land? No

"Inherent in the Vietnam

War themed movie persists a reflection of contemporary society's intense curiosity to hunt in earnest for the unsolved mysteries of Vietnam."

the "villain" becomes increasingly difficult to appropriate. Which group terrorized and which group suffered the ter-
rorizing becomes a difficult question to discern. Just like the general public, these historical films struggle with the participation of America in the war. We continue to ened, produced, and distributed.

nherent in the Vietnam War themed movie persists a relection of contenporary society's intense curiosity to hun Sturken, author of Tangled Memories: The Vietnam Wart the IDS Epidemic, and the Politics of Remembering, addresses the urge to relive the past when she writes, "Those who war movement are fascinated by this war or the antiThis need for our current culture to look back into the pas is prominently exemplified in the increased production of Vietnam War themed films. Sturken reflects this fact when he notes, "The media have become nostalgic for thei the 'real' stories of the war, which the military and political point out that this search through the past rings true for our collective society as a whole, rather than for any spe-
cific group or individual. In concurenece with the theme of cific group or individual. In concurrence with the theme of
public memory and history, the prevalence of these his orical films is the result of a collective yearning for the past.

FILM AS A VEHICLE FOR MEMORY

Serving beyond the purpose of entertainment, historical hen becomes the ability to transport the viewer to th past. Yet the camera does not necessarily reveal history films with historical premises present images of a medated history to an effect similar to conjuring images in memory. Luckily for a contemporary society intent on made this a unique reality. In the case of Vietnam Wh themed movies, film as a collection of images becomes the perfect vehicle to deliver the mystery of the past to this starved and desirous modern audience. For Marita Stulinked with the process of remembering the past. In Stry-s. ken's view, the power of the camera showcases the process of filming as the attempt to recapture what once existed

Cmera images, whether photographs, films, or television fooage, whether documentary, docudrama, or fiction, are central to the interpretation of the past.... Just as memory is often
thought as an image, it is also produced by and through imaag.

Sturken expresses how images are not just physical, but metaphysical as well. For Sturken, the metaphorical images reflect a form of art that materializes the process of film as the art of image capturing and simultaneous mem ory construction creates an appropriate plattorm for histo-
y-based films. These films utilize history and remain

While film becomes a mechanism for bringing the past to the present, the presentation of these historical films be
comes part of the way the public remembers the past. To depict history in film becomes a simultaneous way of loot- re-fashioning its presentation to shape the contemporary
public's memory of the past. Sturken notes this anabolic and catabolic interaction between a flum history and nemory when she explains, "The relationship of the camOn one hand, photographed, filmed, and videotaped in hey have the capacity, through the power of their pres nce, to obliterate them."4 Film has the power to delire history from the past, but it also has the influence hus to change or mediate history in the public's eye. Th significant when remembering history becomes an issue Wr remembering it accurately. William Guynn, author of ng history and of the consequence of influencing the pub-
lic's memory of the past when he discusses the concept of collective memory

The desire of collective memory to preserve the past in the pres. ory is steeped in emotion and is often guided by the self-inter
ont est of the group. A society's look back toward the past is infused with nostalgia for the absolute harmony of social relations and cates there. The affective and ideological dimensions of $\mathrm{fsc}$. memory are clearly incompatible with the professional historian's ideal of objectivity that can come only from rigorous ap.
plication of historical critique.5

Guynn argues that history and film are at odds because of he difference in the objectivity of history and the subjectivity of film. This difference is the basis for mediated his that viewers receive. Does this film version coincide wh he public's already perceived notions of the past? Is the film viewing process an affirmation or a contradiction to he public memory of past? Film has the capacity to sway

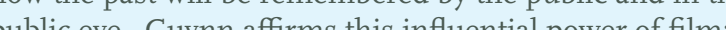

Historians acknowledge that filmic representation has such power that it overwhelms other forms of recollection by impos. nng indelible images of the past on the public imagination ey consider erroneous but compelling representations. His orical 'fictions,' they argue, tend to replace the real documents of events in the public imagination. 
Guynn goes so far as to state that historical films, as medi-
ated forms of the past, serve as substitutes for historicl documents. While the objectivity of history may come into question, Guynn points out an interesting phenomenon
Despite inaccuracies, the public would rather remember or end up remembering the mediated version of the past
through film. The discrepancy between what actually hap 46 through film. The discrepancy between what actually hapbecomes particularly significant when examining Vietnan
War themed films especially since the historical context these films are the crux of the plot.

THE VIETNAM WAR AS HISTORY IN FILM

Vietnam War themed films play a significant role in shap tural memory" of America. Sturken describes this partic ar memory when she states, "Cultural memory is a field of cultural negotiation through which different stories vie for "ition of "ollective memer" or esen "psullic me but "cultural memory" implies another dimension directly interacting with how a culture perceives itself and how th

"Vietnam War themed

films play a significant role in shaping public memory as they have come

to reorient the 'cultural memory' of America."

image may or may not endure. This deliberation over historical films encounter in their attempt to accurately convey the past. Ultimately, multiple narratives about his lory exist, and which ones semain in the legacy of a culture given in this article, Sturken highlights the basic binate that many historical films of the Vietnam War seem to encompass:

As rative films depicting a highly charged event in US his.

tory, Vietnam War docudramas offen have two conflicting in ther

For Americans and American culture, the Vietnam War epicted in films represents both of these conflicting in an be " Inetestingly, the augmentation of this conflic can be witnessed over several decades, suggesting a link
between the levels of conflict in the film and the real confict present among Americans' reactions to the Vietnan War. Vietnam War films can be categorized based on the level of conflict expressed in the films' narratives. Indeed, ment of the Vietnam War film from the Ig6os to the ment of the Vietnam
I 99 os when she writes:

David James has divided the mainstream films made about the war and up until the late 190ss, of which were very few $I$. films made in the late 1970s... which could be called the firs wave of Vietnam films; films made in the early 1980 (the er of revisionist history launched by Reagan administration) that
depict MIAs as icons of the vengeful veterans refighting the war $[. .$.$] ; and the fourth phase$ films made in the late r 980 s and riggos and concerned primarily with questions of realism.?

The trend among Vietnam War films has been observed vent in American history and the mark it has left on American culture. Sturken finds significance in elaborat. ing on the fourth phase of the evolution of Vietnam films of several Vietnam veterans and major directors; it has of ten been characterized as representing America's finally coming to terms with the war. ${ }^{\prime \prime O}$ In theory, the trajectory
of these films over several decades should culminate in al resolution of conflicting sentiments evident in these Vietnam War films. In order to accurately trace the evolulion of he Vienam War film throughout recent history, an

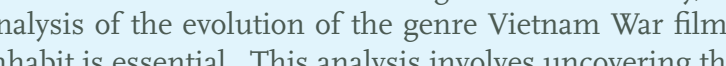
Ading figure of the American victor that at one point in
American film history prevailed above all other archetypes. GENRE

The poignant figure of the American hero in war films is at once questioned with the sudden and evolving conflic "combat flim" ware. The tratives in the context of the film is most jarring when contrasting the machinations of War films. Robert Eberwein's compilation contains an say by Dana Polan entitled, "Auteurism and War-teurism:
Terrence Malick's War Movie," in which Polan analyzes Terrence Malick's War Movie," in which Polan analyzes
the evolution of this "combat film" genre. Initially, the combat film was as direct as the black and white film it was film as the history of a genre in which experiments in form and in content are both at work, pushing individual worls to say new things about the experience of war and to find
new forms in which to say those things. Traditionally the combat film was a highly codified genre with a set struc. ture and set meaning., ${ }^{n_{11}}$ Polan then delves into the content of the early combat films produced during World War

For the wartime World War II combat film, meaning was natu-
ral. There was mission, both the literal mission faced by the oldiers and the national mission of the war effort, and its pur that commitment isnt imposed on the subject from witho but wells up from within, the narrative of conversion makes growth into commitment natural, logical, ordinary."

The World War II film narrative is straightforward and reflective of the epoch from which it was produced. Polan
explains that during World War II, Americans needed strong support system and sense of purpose:

Here is a genre where ease of style, naturalness of narrativity

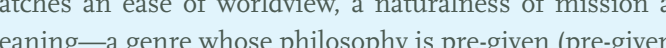
meaning-a genre whose philosophy is pre-given (pre-given to
he filmic form, to the characters in the narrative, and to the arget audience).

consensus. Fast forward to the era of the Vietnam War, a . lems of national pride. In fact, the meaning of an enem ports this notion of a confused and divided natian supion to Vietnam as opposed to a unanimous and positive combat film, unity - unity of form and content, of mission nd meaning, of character and moral purpose-frequently lect upon the uneasy social climate of America, they $m$. hero icon in combat films. Interestingly, as the decades pass, and more time allows for more reconciliation with harged atmosphere of the rogos, the Vietnam Whically transforms once again. In the most recent film adapta-

e manifestations of the genre in these later historical $\mathrm{mo}$ nents adhere to initial meanings of the genre (the mission a ing that the original organic unity of the genre is no longer easily or readily to be had.

Thus, the struggle to maintain the codes of the combat film genre proved difficult as sentiments about the Vietnemory of Americans. Unable to reach a resolution, the es of the American hero remain as do the sentiments tha polarize a nation.

HE I97OS: MASH (I970) AND APOCALYPSE NOW (I979)

It is no wonder that the combat films of the I940s and I950s thrived from the patriotism and steadfast belief in American exceptionalism. In any case, the heroes and vil life for Americans. Fighting two wars with distinct markers to their Communist, Fascist, and Nazi adversaries al-
lowed Americans to distance themselves even further away from their foe. Not surprisingly, the "target audience" tional and political climate. Creating film for the World War II crowd was simple when the enemy and the cause were unanimously understood and agreed upon by publ

Focusing on the following Vietnam War related films, Robett Altman's MASH (1970) and Francis Ford Coppola's Apocalypse Now (I979) present two distinct historical me rast as one embodies a satiric and comical tone, while the other exemplifies a highly stylized and serious approach to the Vietnam War. In Robert Altman's MASH (1970), the fers to the absurdity of America's particicipation in the Viet nam War ${ }^{16}$ In contrast to MASH is Francis Ford Coppolats Apocalypse Now (II97), which delivers an intimate and
haunting portrayal of the negative outcomes of the Viet- 


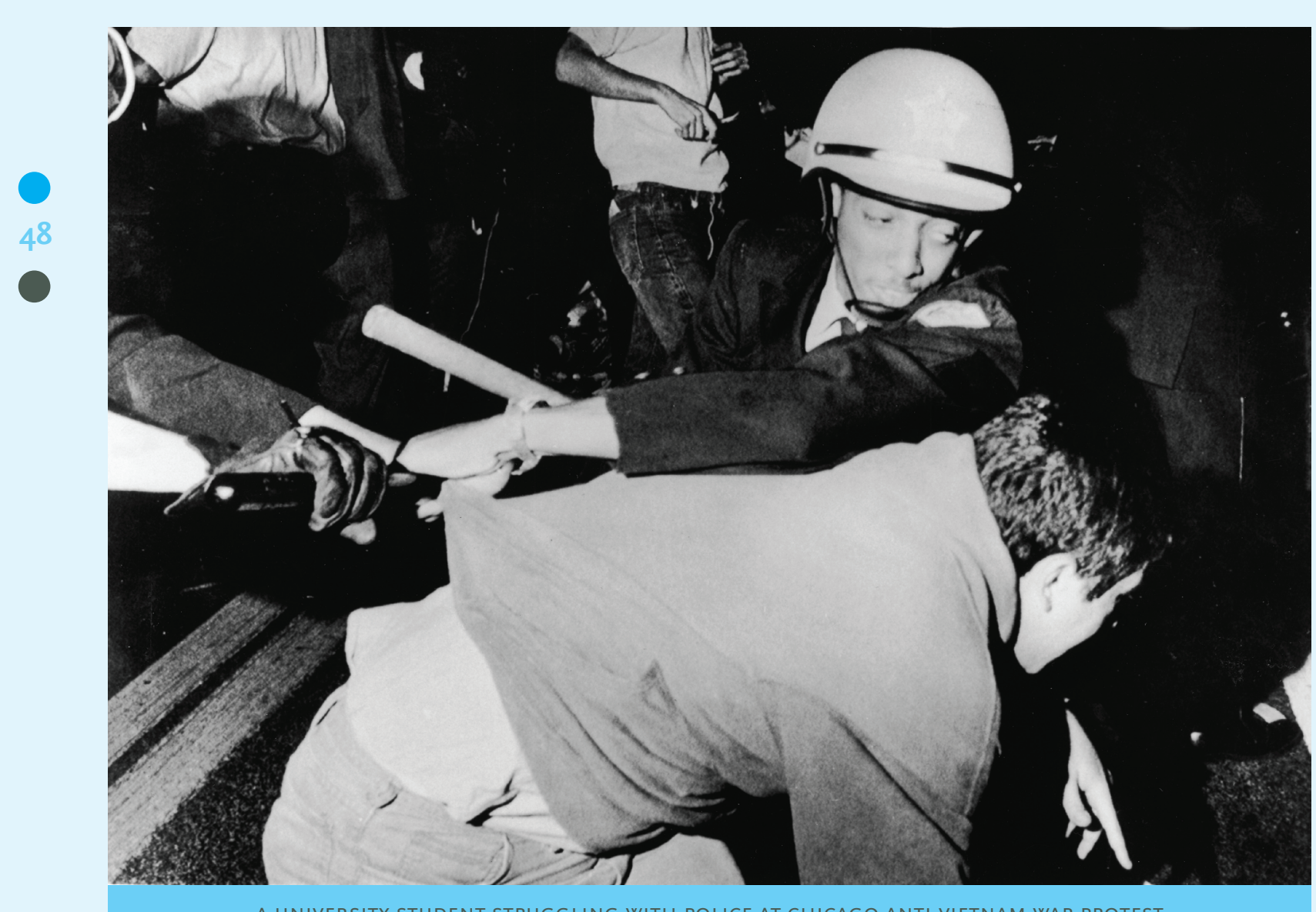

政 social and political environment of America during the era situation abroad. One way in particular the film demonthe "Introduction" of his compilation of essays. The War som Film, "Historical films become a way to comment on the of the actual scene, the background music of choice is present." Both MASH and Apocalypse Now, while techni-" hany times cheerful and upbeat, almost carefree. Again. cally inaccurate in the factual depiction of the war, aim to such a dissonance could be reflective of the tension be present the turbulent climate surrounding the war at tween supporters and protestors of the Vietnam War. Yet,
home and abroad. $\mathrm{d}^{\mathrm{s}}$ While not necessarily classified as a combat film, MASH $\begin{aligned} & \text { with the loaded topic of war, or antiwar. In direct opposi- } \\ & \text { tion to Altman's comedic and lighthearted portrayal of the }\end{aligned}$

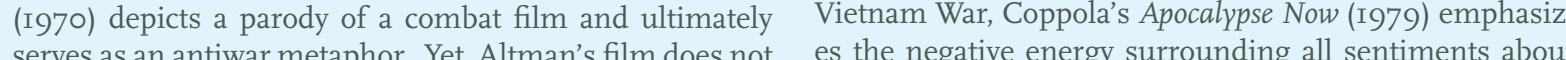
outwardly convey this antiwar sentiment, but utilizes the the war. The film submerges the viewer just like the main double meaning behind its amusing imitation of army life character in the story, into the tangled jungles of Vietnam. during the Korean War. The stories of four army surgeons We learn that Marlon Brando's character has gone AWOL during their time in Korea quickly dissipates as the viewer and the suggested reason for his insanity is the duration of
becomes consumed with the humor and wit that Altman
time spent in the jungle. Karen Rasmussen and Sharon
Downey stress the importance of creating mystery in Apoc- approach to depicting the war. In fact, the films produced alypse Now through scenery and creative technique. ing from image to image Coppola creates a war of mad- Sturken suggests that this shift in sentiment when porness with neither rules nor purpose ${ }^{\prime \prime 9}$ Immediately, Viet- traying the war on film may have been related to the estanam becomes a dangerous and transformative place Interestingly the film portrays the Vietnam War with most seriousness, but at the same time purposefully displays inaccuracies about the war. Sturken elaborates on
the goal of the Vietnam War film during this decade and states by stating, "The films of the late Ig7os subordinated codes of realism in order to depict the war metaphorically and find its larger meaning,.
lighting, and character development reflects this desire to . The most recent Vietnam films were in many ways a reaction
against the inaccuracy of the earlier films. Produced after the construction of the Vietnam Veterans Memorial, the most re narrative gented by the part of he rewriting of he wirs process of healing and memory. These films are alsom more selff conscious about their role as historical works.

In being more "self-conscious" about the historical depic

"Jarring subject matter may appear as nothing more than 'shock value' story buffers, but in the Vietnam War film, these moments in the film's narrative are indicative of a society's desire to accept and welcome historical accuracy."

these Vietnam War films, their rebellious nature to defy genre and form is indicative of the sentiment placed into the production of the film. In other words, "Without a co-
herent ideology to shore it up, the war film becomes drectly incoherent.".pir These two films are mirrors of th American soldier in the Vietnam War. This realizatio pushes the evolution of the combat film into unclear terviin. In other words, Americans are no longer considere both the wins and losses of battle. Without a clear visio for the American soldier at war, the film's approach to the war, and the public's memory of the war evole this incom-

THE I980S: PLATOON (I986) AND CASUALTI OF WAR (I989) From confusion to extreme opposition, the Vietham War

Derated raw and devious acts such as gruesome vioWlliams' article, "From Romance to Collateral Damage: Media Treatment of Civilians in Wartime and What it Wer then he states "These films, for the first time on for "Tion, the killing of civilians, and other atrocles being committed by American soldiers. ${ }^{23}$ Critical

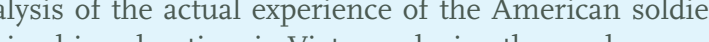

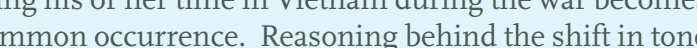
might help illustrate the importance of accuracy in these films, no matter how uncomfortable the subject matter. arring subject matter may appear as nothing more than
"shock value" story buffers but in the Vietnam War film hese moments in the film's narrative are indicative of society's desire to accept and welcome historical accuracy. For example, both Platoon (1986) and Casualties of War (t) 
depict such a disturbing and visually assaulting act of vio-
lence such as the rape of a young woman resonates with the notion of "senseless violence" that became a commo sentiment among protestors of the war. In an attempt to explain the ration
Polan writes:

50 A space of floating, of meaningless violence that can come A srom anywhere, but also of the effect of just watiting, of living
with nonaction One might want to 0 magine that his is the ex perience of war, but it is also an experience of cinema, a com-
ment on modern cinema's narration, its rediscovery of what ment on modern cinema's narration,
Gilles Deleuze famously termed the 'time-image,' 1 confirmation of modern cinema's ambitious and
find a clear way to recount war today.2.

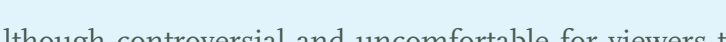
accept violence agains yong wome did hor wend the war, and to exclude this social dimension would onl mediate the past in film once again. In the same manner
that the soldiers in the film do not know how to comprehend the atrocities that surround their every sense, the same confusion and frustration is reflected in the film plottine. The struggle to even include sexual violence
alone demonstrates America's own apprehension to the alone demonstrates America's own apprehension to their
presence in Vietnam. Once again, the hero of the film ought to be the American soldier but to praise a soldier who commits such unspeakable acts of violence again innocent women as a "hero" becomes problematic. I light of these more gruesome Vietnam themed movies,
the glorified figure of the "war hero" becomes more complicated and multi-dimensional then once assumed. It is safe to say that the Vietnam War film has reached a level of accuracy, but at great cost to the iconic image of the AmerTHE I99OS: FORREST GUMP (I994)

After two decades of grappling with the dissonance clearly depicted in the previous films, the 199 os brought to the public a possible resolution with America's role in the
Vietnam War, beginning with Robert Zemeckis' Forres Vietnam War, beginning with Robert Zemeckis' Forrest
Gump (I994). While only a small segment of the film, this chapter depicts the famous friendship between the protagonist and Benjamin Buford "Bubba" Blue that blos soms during their time as soldiers in the Vietnam War.

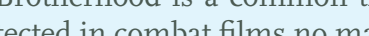
screen; yet, the bond these two "brothers" share becomes significant when set in the jungles of Vietnam. Two naive elligence of the war's actual soldiers but their simplistic point of view enhances the purity of their love for one another and heightens the trauma surrounding them on the battlefield. As stark contrasts to any of the previously menof the American hero at war these two chanstors can rep resent the public's understanding of the war. As outsiders looking in on a foreign world, the Americans at home at in this prolonged war. Just like Forrest, the public's perceived notion of America's role in the Vietnam War was never officially stated, as they instead preferred a passive approach to understanding their place in the war. Yet, the mbiguity that befell the Vietnam War is due to the honorable character of Forrest Gump, who transcends every marginality to embody every American. Forrest survives

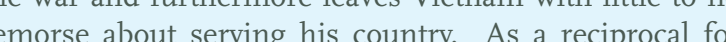
merican sentiment toward the Vietnam War his apathet ic feelings toward the war match the dissipated level of we do not foedates our current American culture. While CONCLUSION

No one has seemingly felt the need to portray the Vietnam War in a film recently. The contemporary public seems to have reached a more comfortable place, or at least a better understanding of its role in the war. Not only have we re

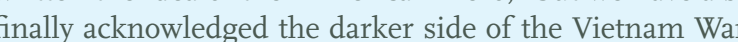
With Ig8os film depictions of the Vietnam War, such as Platoon (1986) and Casualties of War (1989), directors took critical stance against America's role in the East, conveyYet during the evolution of the Vietnam War film, the memory of the war becomes rewritten again and again

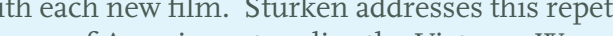
Indeed, memory often takes the form not of recollection but of cultural reenactment that serves important needs for catharsis and healing. In the films about the Vietnam War, in the actions
of Vietnam veterans at the memorial , reenactment is revcial in providing a means to confront loss and transform it into healing. It is precisely the instability of memory that allows for letting the tension of the pas

Reliving a culturally significant event in American history
through "reenactment" can alleviate any negative sentthrough "reenactment" can alleviate any negative senti-
ment that is associated with the memory of that event in the past. Visiting the past becomes even more efficient when utilizing the medium of film to deliver the images of American history. Yet, the healing process continues de-
spite a recent decrease in production of Vietnam War respite a recent decrease in production of
lated films. Perhaps the current social climate does no need these films as it once did during the era of the Vietnam War. Indeed, as reflective as memories are of history so too is the movie screen of chlure and of that chltury

ENDNOTES

I. Sturken 1997 (76)
2. Ibid.

3. Sturken 1997 (II)
4. Sturken $1997(20)$

5. Guynn 2000 (17)
6. Guynn 2006 (165)

7. Sturken 1997 (I)

9. Ibid.
Io. Ibid.

II. Polan $2005(54)$
2. Polan $2005(55)$

I3. Ibid.
I4. Ibid.

I5. Polan $2005(56)$
I6. Sturken $1997(279)$

17. Eberwein $2005($ (I2)
18. Sturken 1997 (18)

9. Rasmussen 2010 (18

20. Sturken $1997(88)$

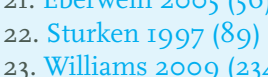

24. Polan 2005 (6I)

REFERENCES

Apocalypse Now. Dir. Francis Ford Coppola. Perf. Marlon Brando
Rocertr Duvall, Martin Sheen, Laurence Fishbourne, Denni

Hopper, Harrison Ford, Frederic Forrest, Sam Bottoms,
Albert Hall. Paramount Pictures, I979. DVD.
Casualties of War. Dir. Brian De Palma. Perf. Michael I. Fox,
Sean Penn, Don Harvey, John C. Reilly, John Leguizamo, Ving

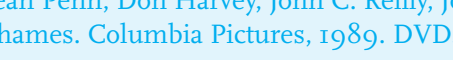

erwein, Robiest

Worrest Gump. Dir. Robert Zemeckis. Perf. Tom Hanks, Robin
Wright, Gary Sinise, Mykelti Williamson, Sally Field. Paramoun

Guynn, William. Writing History in Film. New York: Routledge
Taylor \& Francis Group, 2006.

MASH. Dir. Robert Altman. Perf. Donald Sutherland, Elliot
Could, Tom Skerritt, Sally Kellerman Robent Dlant, Renee berjonois, Michael Murphy. Twentieth Century Fox, I970. DVD Platoon. Dir. Oliver Stone. Perf. Charlie Sheen, Tom Berenger,
Willem Dafoee. Metro Goldwyn Meyer Orion Pictures, Ig86. Polan, Dana, “Auteurism and Warteurism: Terrence Malick's
War Movie," in The War Film. Robert Eberwein, ed. Chapel Hill:
Rutgers Sniversity Press War Movie," "in The War Film. Rs
Rutgers University Press, 2005 .

Rasmussen, Karen and Sharon D. Downey, "Dialectical Disori-
entation in Vietnam War Films: Subversion of the Mythology of (1) Sturken, Marita. Tangled Memories: The Vietnam War, the AIDS
Epidemic, and the Politics of Remembering. New York: University of California Press, I997. Williams, Bruce A. "From Romance to Collateral Damage: Media
Treatment of Civilians in Wartime and What it Means for How
America Wages War," in The Communuication Review I2, (20og): $227-238$ Worland, Rick. "The Other Living-Room War. Prime Time I998): $3-2,3$ 
THE VIRGIN OF JEANNE D'EVREUX

"Indeed, the Virgin of Jeanne d'Evreux An Affectionate Mother in an Unaffectionate Era was commissioned and crafted during an exceptionally transitional period in French history; to a certain extent, the statue stylistically exemplifies this transition from the treasured prosperity of the thirteenth century to the impending controversy of the fourteenth century."

NAMED AFTER THE THIRD AND FINAL WIFE OF KINC CHAPLES IV OF FRANCE, THE VIRGIN OF JEANNE D'EVREUX IS AN ORNATE, SILVER-GILT STATUE OF FAMILIAR ICONOGRAPHY—THE VIRGIN AND CHILD. THIS EXQUIIITE RELLQUARY STATUE, COMING OUT OF THE LATE GOTHIC PERIOD, EMBOdies the deVOtional fERVOR OF THE MEDIEVAL WORLD, THE PRECARIOUS POSition OF FRANCE DURING THE FOURTEENTH CENTURY, AND THE VERY VISION OF ITS PATRON, JEANNE D'EVREUX. CRAFTED AMIDST A CRISIS OF SUCCESSION IN THE FRENCH MONARCHY, THE VIRGIN OF JEANNE D'EVREUX HINTS AT A KINGDOM IN TRANSITION, WHILE, AT THE SAME TIME, EVIDENCINC A PIVOTAL TRANSITION IN ARTISTIC STYLE. INDEED, BEHIND THE FAMILIAR ICONOGRAPHY OF THE VIRGIN AND CHILD LIES A FASCINATING BIT OF HISTORY, OF WHICH THIS RELLQUARY STATUE ITSELF MAY SERVE AS A RELIC. 
In I339, English forces under the leadership
of King Edward III were arriving on the cortinent of Europe and were laying brutal siese to the Flemish city of Cambrai.' Meanwhil less than one hundred miles to the south,
Parisian silversmith was completing an elab

orately adorned reliquary statue of the Virg
and Child, a statue known in moden to

as the Virgin of Jeanne d'Evreux. Indeed, the Virgin of Jeanne d'Evreux was commission and crafted during an exceptionally transextent, the statue stylistically exemplifies this transition from the treasured prosperty of the thirteenth century to the impending dition to the style and its bearing upon the iconography, there are other aspects of the Virgin of Jeanne d'Evreux worth discussing functionlity as a religuary Thus, this paper begins by examining the patronage of the statue, particularly amid the turmoil surrounding the onset of the Hundred Years Wor Jeanne d'Evreux, with regard to both the sta ue itself, as well as the statue within the context of the Late Gothic Period. Finally, the one which remarkably contains the relics Christendom, Mary.

The Virgin of Jeanne d'Evreux was named a was the third wife of King Charles IV of

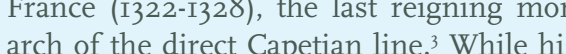
ory regards the brief reign of Charles IV a insignificant, the death of Charles IV was of

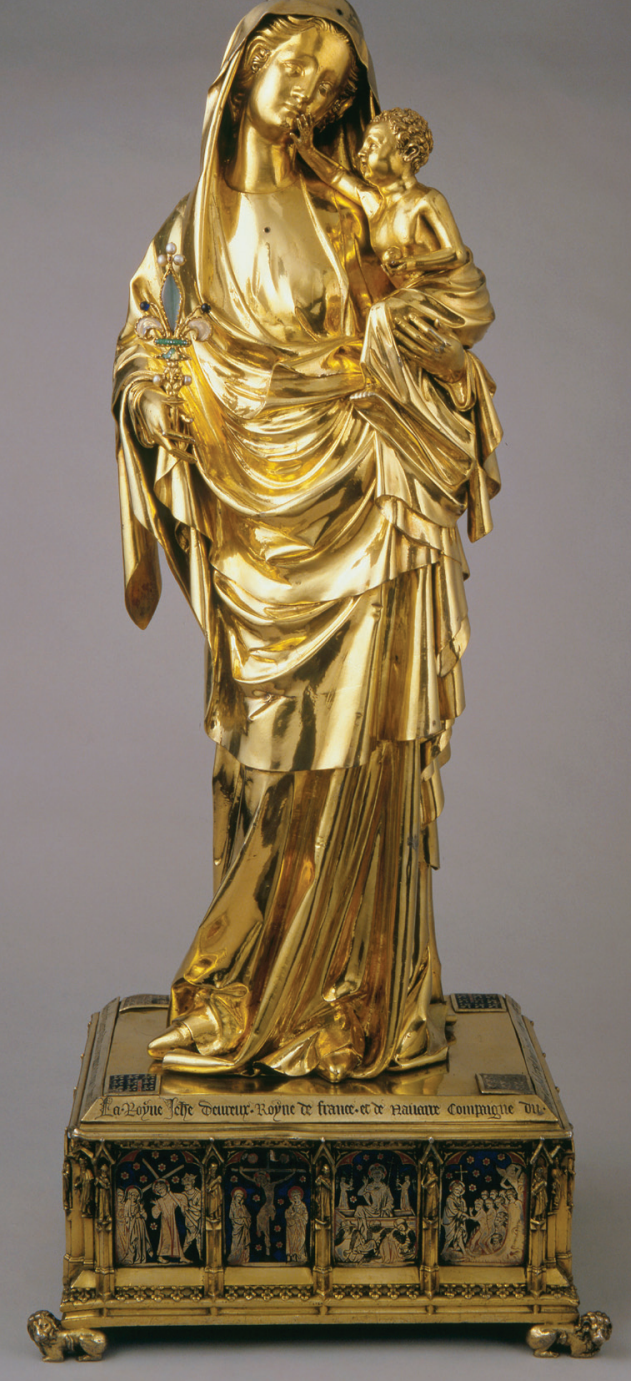

THE VIRGIN OF JEANNE D'EVREUX
Blanche of Burgundy, gave birth to a son and a daughter
who both died as infants.5 SThe second wife, Mart hrone. Charles IV the third son of King Philip IV (1268I314), inherited the throne upon the deaths of his two older daughter surviving into adulthood. ${ }^{6}$ The third and final brothers, Louis X (1314-1316) and Philip V (1316-1322), each wife, Jeanne d'Evreux gave birth to three daughters.? Thus, 作
Nevertheless, there were male descendents of Philip IV in The conflict escalated rapidly. Unbeknownst at the time
I328. King Charles of Navarre and King Edward III of Eng-.
the Hundred Years War was already underway. It was dur-

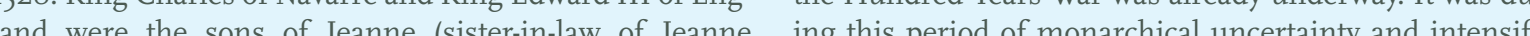
$d^{\prime}$ Evreux) and Isabella, respectively, and thus the grandsons of Philip IV, for Philip IV had several daughters, in a grandson of Philip IV to succeed Charles IV. However it was a longstanding tradition within the French monarch

In all likelihood, Jeanne d'Evreux commissioned the statue onset of the Hundred Years War. ${ }^{1}$ The statue was not com

"But more than anything else, the lack of a garment on the upper portion of Christ's body exemplifies this tender relationship between the Virgin and the Child, a natural connection between a mother and her son."

mit the throne.9 Therefore, the throne passed to the cousin
of Charles IV. Philip of Valois, known as Philip VI Io The ascendance of Philip VI to the kingship of France was a a guably the start of the Hundred Years War.

Even after the coronation of Philip VI, Edward III of Eng. more so than Charles of Navarre." It is important to note that the English already maintained a strong presence on the European conthent. The vast Duchy of Guyenne in the trol for a long time. ${ }^{2}$ Nevertheless, the territorial control that England exerted over Guyenne paled in comparison to the economic control that England exerted over Flanders. ally wealthy country larely because of the textile ind try.3 However, the textile industry was almost entirely dependent upon wool imported from England. ${ }^{14}$ Hence, the economy of Fanders was controlled by the English. And there were signifint foudal ties between both sates: French nobility were often simultaneously Flemish nobity.15 Certainly, economic and political influences were pulling Flanders in opposite directions. With the controEdward III decided to exploit the tenuous kingship of Phil ip VI and invade Flanders in 1337.6 But even before the forces of Edward III were able to arrive on the Europea was aready laying siege to English forte pleted until I339, according to a dated inscription on the ndustries that existed within the medieval world. . $^{\circ}$ In rance, the guilds were differentiated based upon the ma erial that was used, rather than the object that was pro-
duced ${ }^{2 t}$ For example rosary-makers who used longed to a separte guild from rosary-maters who used amber. ${ }^{22}$ A statue such as the Virgin of Jeanne d'Evreux composed of multiple materials, was almost certainly the ing to several different guilds. Therefore, the stat the grive possibly represents more than fifteen years worth of crafts. manship, given that different craftsmen could be working

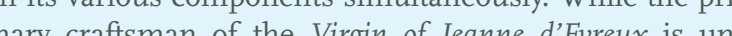
nown, it is likely that this craftsman worked near the Grand Pont in Paris. In many instances, guilds gravitated toward geographic districts or quarters. ${ }^{23}$ Money changers the siver, the statue was probably crafted, at least partially his location. Once the Virgin of Jeanne d'Evreux was finally completed, its namesake donated the statue to the royal merit ${ }^{25}$ Jeanne d'Evreux never intended the statue for por devotion, but for public

As a public devotional image, the iconography of the Virgin of Jeanne $d$ Evreux is quite accessible-the Virgin and 
the statue, which is silver-gilte.6. The Virgin holds Christ in
her left hand and the fleur-de-lis, a traditional symbol of the French monarchy, in her right hand. Functionally, combination of silver and enamel., . $^{27}$ Surrounding the base there are fourteen enamel panels elaborately depicting
scenes from the life of Christ including the Nativity the Annunciation to the Shepherds, the Adoration of the Magi

"During a time of monarchical uncertainty, and uncertainty more generally, the fleur-de-

lis likely served as a hopeful sign of unending prosperity - a hope that all but disappeared in the following century.

the Flight into Egypt, the Presentation in the Temple, the
Massacre of the Innocents, the Descent from the Cross and the Resurrection. ${ }^{28}$ And appropriate for a statue of the Virgin and Child, the Annunciation and the Visitation are
also depicted in the enamel panels.s. Additionally, the base
contains twenty-two, miniature relief statues which separate the enamel panels. Altogether, the entire statue is ported by four lions, one at each corner of the base.

The style of the Virgin of Jeanne d'Evreux brilliantly enrichguishing characteristic of Late Gothic sculpture. By the conclusion of the thirteenth century, the austere, enstanding Virgin. $3^{\circ} \mathrm{And}$ by I324, the affectionate Virgin was widespread throughout French sculpture, both stone an
metal. The beginnings of this trend are visible as early metal. The beginnings of this trend are visible as early a
the middle thirteenth century with the fluid and graceff movements of the Virgin at Reims. ${ }^{31}$ The trend continued and culminated in the early fourteenth century with statsrikingly simlar. In addilion to being crafted within the Christ

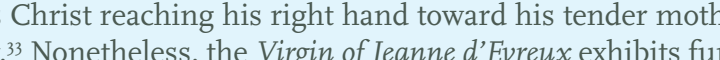
her stylistic developments that even the Virgin of Paris does not. The Virgin of Jeanne d'Evreux no longer wears he face of the Virgin rather than simply her garmenes 35 All hese elements reinforce the movement toward a more af fectionate, humanlike rendering of the Virgin and Child. unper portion af Christ's body exemplifes arment on the ionship between the Virgin and the Child a natural connection between a mother and her son. The progression hroughout the centuries is telling: in the twelfth century wore the robe of an infant: in the foute Christ was only covered by the fold in the garment of his mothers In the Virgin of Jeanne $d$ Evreux, the upper por thor esentation foreshadows the gradual conclusion of the

While the Late Gothic style clearly influenced the Virgin of his particulur tatre likely influenced it as well still influences of this latter type are mostly specultive. Even o, they are worth mentioning. When the statue was commissioned in I324, Jeanne d'Evreux was a rather young 1326, I327 and I328. It is possible that the statne emberies the affectionate, maternal instincts that Jeanne d'Evreux was about to experience. Perhaps the anticipation of these maternal instincts influenced the commission. And Virgin of Jeanne d'Evreux can easily be attributed to trends in the Late Gothic style, the fact that the Virgin of Jeann $d^{\prime}$ Evreux departed so significantly from the Virgin of Paris created just four years earlier, gives credence to the theory be significant that the Virgin holds a large fleur-de-lis in her right arm. As previously mentioned, the fleur-de-lis was a filip IV died without a

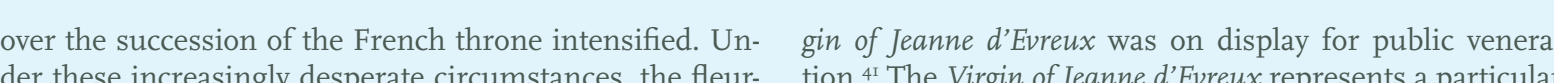
monarchy. And though the Virgin of Jeanne d'Evreux is as- the Late Middle Ages, the ostensorium.42 In an ostensorsuredly not the first instance of the fleur-de-lis appearing um, the relic is visible through a glass or crystal window. $\begin{array}{ll}\text { in religious artwork, it is definitely a noteworthy instance. } & \text { Before the Fourth Lateran Council in I2I5, relics were nor } \\ \text { During a time of monarchical uncertainty, and uncertainty } & \text { mally encapsulated by the reliquary and thus hidden from } \\ \text { more generally, the fleur-del-lis likely served as a hopefull } & \text { sight. } 33 \text { After the Council, there was an emphasis in the }\end{array}$ sign of unending prosperity - a hope that all
but disappeared in the

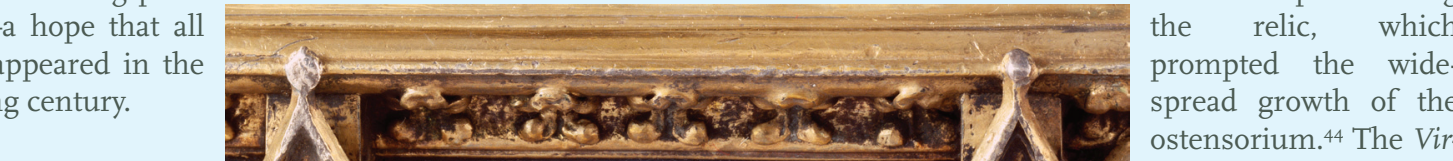
In addition to the sym-
bolism associated with
the fluer-de-lis, the

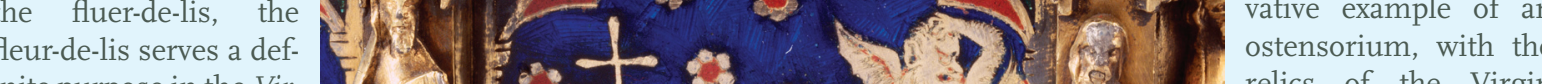
inite purpose in the Vir 191 . $\%$ relics of the Virgin

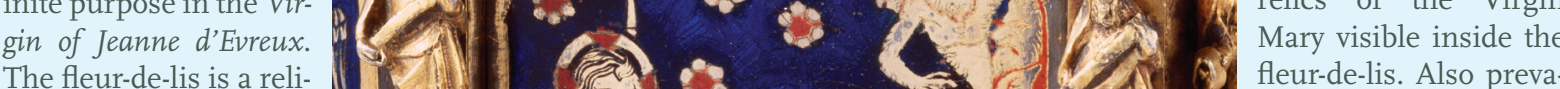
quary, the Virgin of quary, the Virgin quary $\quad$ statue. ${ }^{37}$ The fleur-de-lis purportedy head of the Virgin dieval period, the relic of saints and the Virgin Mary were venerated
because it was believed that God was most accessible through thes
mortal remains. ${ }^{39}$ In some sense, the venenta
tion of relics broug stability to a very multuous period ch acterized by war, ease, and fam

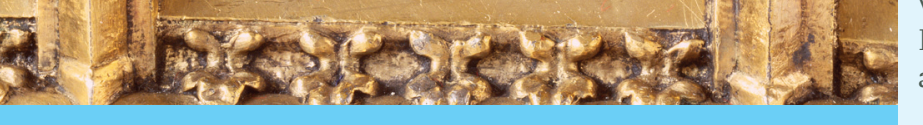

fleur-de-lis. Also prevaMiddle Ages was a heightened devotion to the Virgin Mary and an
increased veneration of increased veneration of Fourth Lateran Council emphasized seeing the
elic the Council also relic, the Council also
emphasized seeing Christ. The Virgin Christ. The Virgin
Mary was obviously the world, particularly in the form of relics. Peasants and the style of the Late Gothic Period, but created during a royalty alike attributed prosperity and even miracles to the period of crisis in the French monarchy. It contains ex
veneration of relics. King Charles IV of France was no ex tremely precious materials-silver and enamel ception, amassing a tremendous collection of relics: the by individuals skilled in the work of those particular mate collection of Charles IV was almost certainly the source of rials. Such a beautiful statue as the Virgin of Jeanne d'Evreux the hairs contained in the Virgin of Jeanne d'Evreux.40 In was considered an appropriate reliquary for the relics of celics in the royal abbey of Sint-Denis, where the Vir- tendom. Nevertheless, the Virgin is not depiced a a ti- 
umphal queen, but as a tender and affectionate mother REFERENCES

ENDNOTES

Duby, Georges. Foundations of a New Humanism: 1280-1440
Trans. Peter Price. Cleveland: World, I966.

France in the Middle Ages: $98-1460$. Trans. Juliet Vale. Oxfor

Evans, Joan. Life in Medieval France. Rev. ed. New York: Phaido Evans,
I957.

Kleiner, Fred S. and Mamiva, Christin J. eds. Gardner's A
Through the Ages. $2^{\mathrm{th}}$ ed. Vol. I. Belmont: Thomson, 2006 .

MacDonald, J. R. Moreton. A History of France. Vol. I. London

Male, Emile. Religious Art in France: The Late Middle Ages Prin eton: Princeton University Press, 198\%

Snyder, James. Medieval Art: Painting, Sculpture, Architecture

an Os, Henk. The Way to Heaven: Relic Veneration in the Midd

Vierge a Y'Enfant." Louvre. I2 April 2008 <http://cartelen.louvre.

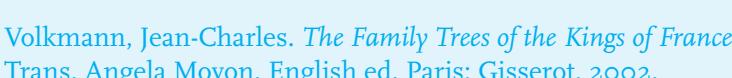

I8. "Vierge a l'Enfant"
I. Duby I966 (2I)

20. Evans $1957(48)$

22. Ibid.

25. Duby I 966 (2I)
26. Ibid.

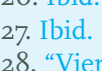

"Vierge a l'Enfant" 2008

30. Male r 987 (1537)

33. Ibid.

36. Male I987 (1537)

37. . .leiner 2006 (385)

39. van OS $2001(20$

4. Ibid.

44. Ibid

45. Ibid 
A VIABLE OPTION

Organ Procurement in the Face of a National Shortage

"Transplant statistics indicate a growing disparity between supply and demand in the transplant community. During this national shortage, any ethically indicated source of organs should be considered a viable source of organs."

CURRENTLY, THE NEEDS OF THE ORGAN DONATION COMMUNITY ARE NOT BEING MET. THE SOLE

USE OF BRAIN-DEAD DONORS IS LIMITING THE AMOUNT OF POSSIBLE VIABLE ORGANS THAT COULD BE DONATED EACH YEAR. FOR THIS REASON, A HANDFUL OF HOSPITALS HAVE IMPLEMENTED PROTOCOLS TO INTRODUCE NON-HEART BEATING CADAVER DONORS INTO THE POOL, AND MANY MORE ARE INVESTIGATING THIS AS AN OPTION. NHBCDS ARE INDIVIDUALS WHO HAVE EXPERIENCED THE CESSATION OF CARDIO-RESPIRATORY FUNCTION BUT ARE NOT BRAIN-DEAD AND SO COULD BE RESUSCITATED IF LIFE SUPPORT WERE REMOVED-IN THIS WAY THEY DO NOT YET FULFILL EITHER OF THE TWO CRITERIA FOR DEATH. IT WOULD NOT BE UNTIL THE SURROGATE CONSENTS TO DONATION THAT LIFE SUPPORT WOULD BE REMOVED AND IRREVERSIBLE DEATH COULD BE DECLARED TWO TO FIVE MINUTES AFTER CESSATION OF HEART FUNCTION. THE AMA'S COUNCIL ON ETHICAL AND JUDICIAL AFFAIRS ESTIMATES THAT THE INCLUSION OF THIS GROUP COULD EXPAND THE DONOR POOL BY 2O-25\%. NHBCDS HAS BEEN CRITICIZED FOR TESTING THE BOUNDARIES OF IRREVERSIBLE DEATH, AND THIS ARTICLE ADDRESSES SUCH CONCERNS IN ORDER TO SHOW THAT THE PROTOCOL IS BOTH ETHICAL AND INCREASINGLY NECESSARY 
INTRODUCTION TO THE ISSU The number of organs needed each year greatly exceeds
the number available for transplant. Over IIO,000 Americans were wilug for transplant. Over 110,000 Ameri-

28,664 organ transplants that occurred in 2010 came

from just I4,506 donors. ${ }^{.}$Some of this disparity stem

62 from the strict eligibility criteria set forth by the Organ

Protocol establishes criteria for age, living donors, as we
as medical criteria regarding for instance, hypers

intracerebral hemorrhage, and impaired renal function Despite programs such as the Expanded Criteria Donor (ECDS) which loosen OPFN criteria, the few additional or healthy transplant patients.

Many hospitals, medical personnel, and transplant centers recognize the need for an increased supply of organs to be achieved by opening up an entirely new category of donors: non-heart beating cadaver donors (NHBCDs).4 In
order to dispel misperception, it is important to distinorder to dispel misperception, it is important to distin-
guish between heart beating and non-heart beating cadavers. A heart beating cadaver is currently the most cormon type of organ donor: a brain-dead individual existing with the aid of life-support. A non-heart beating cadaver is an individual who has experienced the cessation of cardio resuscitated if life support were removed. 5 The Council on Ethical and Judicial Affairs (CEJA) estimates that full utilization of NHBCDs may increase the organ pool significantly by 20-25\%, and evidence from the Uniorgans function close to or as well as those from hear beating cadaver donors. ${ }^{6,7}$ However, NHBCD protoco tests the boundaries of death, or, more specifically, irre versible death. For this reason, many biomedical ethicis with regards to donation in what
versial branch of medical practice.

This article will provide a brief history of organ procure other avenues of organ donation. In addition it will outline, define, and provide current protocol for the most im portant method of donations from NHBCDs: controlled discuss the specific ethical issues of DCD in NHCD s nally, it will offer suggestions for future public policy sup- porting the use of NHBCDs and provide a conclusion of

ain Death: (As provided by CEJA) "Brain death occurs citeria (i.e., the irreversible cessation of the functions of the entire brain, including the brain stem). Though the person has died, cardiopulmonary function may be main-

Cardiac Death: (As provided by CEJA) "Cardiac death oc curs when a person is declared dead according to cardio

Dead Donor Rule: An unwritten standard used to guide the rule states includes killing patients in order to retrieve reval, which And second, that organs must not be taken from patients unt hey die, with exceptions made for living donors and partial nsplants between relatives as a reasonable exception. ${ }^{\circ}$ HISTORICAL BACKGROUND

The first cadaveric organ donation was performed by Dr he first live donation between identical twine herformed This firs $\mathrm{HBCD}$ set a precedent for the newfound transplant community as it operated under the traditional and only definiThe success r the cessation of heart and lung function. Since organs were only taken from those whose heary thad stopped beating, all procured organs were of noor quality due to warm ischemic time-the time during which the organs themselves begin to die due to the lack of oxygenway to retrieve oxygenated organs from dead donors either
more quickly or efficiently than they had previously ac more quickly ox
complished.

The mid-to-late Ig6os brought about the definition of "breath death" and the push for it to be a criterion to define heart and lung function of neurologically devastated patients through mechanical ventilation despite ongoing cel realized the amazing implications for organ donation that

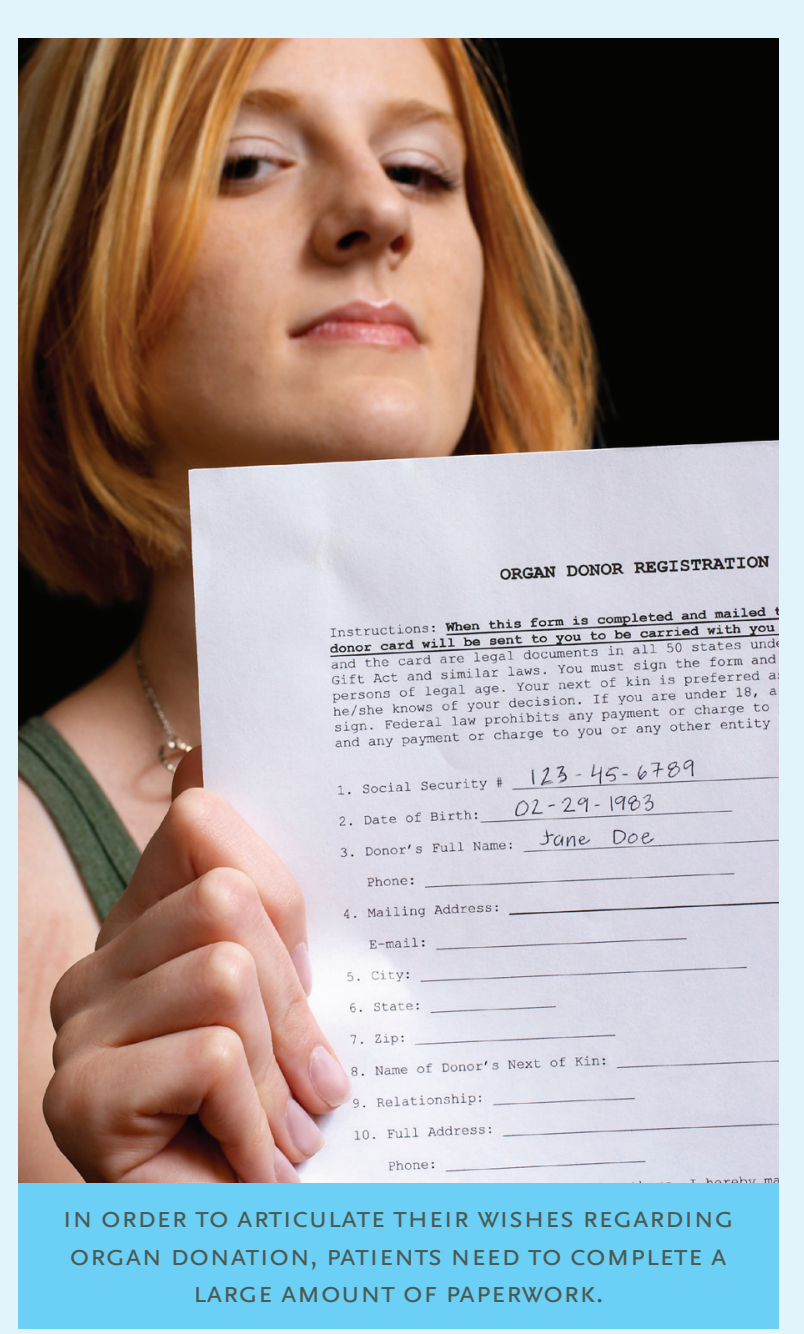

neurologically devastated patients presented. If surgeo could procure organs from heart-beating cadavers, warm ischemic damage would be essentially eliminated, vastly the transplant community and increasing the recovery and survival rates of transplant patients. However medicali personnel feared criminal and civil implications of homcide absent a legal redefinition of death

Much to the relief of the transplant community, the Ad Hoc Committee of the Harvard Medical School propose nation of death in a I968 JAMA article
Our primary purpose is to define irreversible coma as a new
criterion for death There are two reasons why there is need for a definition: (I) Improvements in resuscitative and supportive measures have led to increased efforts to save those who are

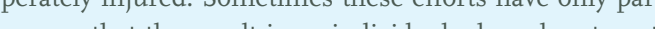
so beat but whose brain is irreversibly damaged. The bure on their families, on the hospitals, and on those in need of fho pital beds already occupied by these comatose patients. (2) $\mathrm{O}$ in obtaining organs for transplantation.

The mission of the Committee was clear: to decrease the strain on the family of a neurologically devastated patien well as to enable an entirely new category of organ donor with which the success of the transplant community would no doubt improve.". After the Committee's publication states began to adopt the new criterion for death. Despite Giled to enact the new brin death legishtiss. In order to precipitate a unanimous adoption, Congress assembled a interdisciplinary body under the sponsorship of the PresiMedicine and Biomedical and Behavioral Research. This body after exploring the issue, wltimately recon the adoption of the Uniform Determination of Death Ac (UDDA) in $198 \mathrm{I}^{18}{ }^{8}$ The act states that:

An individual who has sustained either (I) irreversible cessa tion of circulatory and respiratory functions, or (2) irreversible tion of circulatory and respiratory functions, or $(2)$ irreversitible
cessation of all functions of the entire brain, including the
brain stem is dead A Adetermination of death must be made in brain stem, is dead. A determination of death
accordance with accepted medical standards.'

The Commission's recommendation was met with widespread approval, and its implications were monumentaAfter almost every state adopted the UDDA, or some form Dr. havine M H Hrrington Professor of Le at Tera. W eyan University School of Law, explains " "Legl recogntion of breath death led to the almost universal abandonment of organ procurement from persons suffering he vast majority transplants involved obtaining viable gans from brain-dead, heart beating cadavers. This massively increased the quality of available organs by diminishing the harmful effects of warm ischemic damage. 
With time, the medical community saw the improvement identify an acceptable donee. The patient is brought down
of organ preservation with immunosuppressant drugs,
to the operating room (OR) before being disconnected of organ preservation with immunosuppressant drugs, to the operating room (OR) before being disconnected
like cyclosporine as well as improved cooling techniques f However, even though the number of viable organs per surgeons will wait until cardiac death is declared (any year grew, so, too, did the number of those in need of where from two to five minutes after the cessation of carthem. As the survival rate and quality of life of post.trans- diorespiratory function ${ }^{2}$ ) and then quickly remove the or plant patients increased, doctors began to prescribe trans-
plantation to those with organ failure regularly. Simply the donor's body in order to avoid warm
ischemia. As mentioned above, prior to 1968 , DCD was

put, the supply could no longer meet the demand. In I997 the standard protocol for organ donation, but cooling and there were 9,539 donors for 55,500 patients needing trans-
preservation techniques were significantly less advanced
plants. By 2006 these numbers increased (disproportion-
than they currently are. In I 1997 the Department of Health

"If surgeons could procure organs from heart-beating cadavers, warm ischemic damage would be essentially eliminated, vastly increasing the quality and viability of organs available to the transplant community and increasing the recovery and survival rates of transplant patients."

ately) to 14,756 donors for 98,263 patients needing trans-
plants. The problem since has not gotten any better, as the plants. The problem since has not gotten any better, as the
discouraging figure noted in the introduction indicates. ${ }^{2 t}$

Despite efforts to use older donors and those with underlyng diseases, as in the Expanded Criteria Donors (ECDS
program, the medical community began to turn its atten tion back toward medicine's original source of organ non-heart beating cadavers. Since this reexamination did munity was confident in its ability to surmount the former problems associated with warm ischemic damage in order to preserve viable organs. ${ }^{22}$ From this refocused attention method for $N$ Hed dod donation after cardiac death (DCD) It is here. the history of organ donation, that the medical community finds itself struggling ethically today

CONTROLLED DONATION AFTER CARDIAC

DEATH

In DCD practice, a patient or his/her surrogate consents to

and Human Services (DHHS) submitted a request to the he practice of DCD. After subsequent IOM reports, in oncerns, including lack of protocol, physician resistance,
organ quality, determination of death, and financial re sources, among others. ${ }^{24}$ This, however, revived the plauint listing and ecessarily controversial protocol was the Uniersity of Pittsburgh Medical Center in May of Ig92 with HE PITTSBURGH PROTOCOL The University of Pittsburgh Medical Center (UPMC)

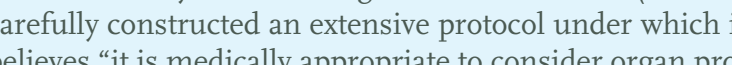
curement from nonheartbeating donors ${ }^{226}$ The oprinciples of the protocol are as follows. First, decisions regarding treatment and management of the patient shall be conducted separately from any dialogue about organ donation
This topic should only be breached after the patient//sworgan donation while he/she is sustained on life-support. This topie shests remlybe breached after the patient/sur- surrogate addresses the matter unprompted. Second, care
of the patient should remain the attending physician's ultimate end. In other words life support should only be moved in order to provide the patient with palliative care not to secure the institution's interest in organs. Thirc
only those for whom it is certain that cardiac death will oc cur within a few hours of the cessation of life support w
be considered as candidates for organ donation. Fourt medication may only be used to alleviate pain and guarantee patient comfort, not to hasten death. Similarly, any intervention meant to curtail the life of the patient is pro-
scribed. Finally should a health care professional find this method of organ procurement against his/her pes ethical, or religious beliefs, he/she is by no means require to participate. ${ }^{2}$

The published procedure of the Pittsburgh Protocol is most important articles are as follows. First, all proces ses associated with organ retrieval may only commence if the competent and no surrogate is present by he/she be considered for organ donation. Second, an Intensive Care Unit (ICU) physician and ICU nurse mus oversee the withdrawal of life support in the OR, prefera inty without the OR staff present to avoid any confict must have nothing to do with either the procurement of organs or the treatment of those patients receiving said or gans. Third, the OR staff must have no hand in the weanduct surgical preparations for the sake of timeliness afte the patient becomes unconscious. Fourth, organs can, by no means, be procured prior to the ICU Physician's decla che cardic dethe clare cardiac death, with use of an electrocardiagraam
(EKG) lead placement, no earlier than two minutes after ventricular fibrillation, electrical asystole, or electrome chanical dissociation. At this point the OR staff may step in and procure the donor's organs, which must ave at the cost of the patient's palliative care while dying.

DCD AND NHBCD ETHICAL CONSIDERATIONS The Pittsburgh Protocol is essentially the poster child of DCD protocols. Much has been written and many have questioned the protocol at concerns with NHBCDs as a whole.

\section{Deration and Definition of D}

The determination of when a patient is 'dead' is perhap the most controversial aspect of DCD protocol. The Dead organ removal. However it does not provide the specific
iteria necessary to declare someone dead 20 UDDA, circulatory and respiratory functions must have ngly, this causes a problem with DCD protocol. For intance, it is entirely possible to resuscitate someone who case in the Pittsburgh Protocol. In order to declare a med. ically irreversible death, doctors would have to wait lon nough after cardiac death to declare brain-death as well, donhich point warm ischemic damage would render the

There are two solutions to this problem, and they deal with imilar issues. Patients in DCD programs have agreed to DNR orders as part of the DCD process. It would make no suscitote sitself a DNR. Consider a patient without donor status der inthrawal of life support. Should the patient have despite the reversibility of the condition after two dith s. 30 It is the mere fact that the medical comm uity has s.thing to gain from a DCD patient's death that causes some to question the legitimacy of death after two minutes tent's requst to be freed from life support and pery the indicates that resuscitation would be contrary to the atient's expressed wishes. The council shares the view hat the patient's loss of cardiopulmonary function may

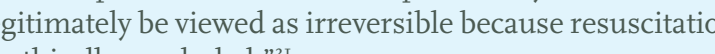
Similarly, it has been deemed unnecessary to nitpick about he period of time between cessation of heart and lung two minutes. Irreversible brain damage will not toceyon til ro-Is minutes after cessation of cardiac function. When dealing with the viability of organs, every additiona minute spent has a substantial effect. One will find in 
that the period of time between cardiac arrest and 'death' a period of two minutes.s. ${ }^{34}$ Despite criticism, it has been
ranges normally from two to five minutes, any time beranges normally from two to five minutes, any time be and which would seriously compromise the viability of organs. However, the less time surgeons wait to procure a drawal of life support, is irreversible. Waiting longer than donor's organs, the more scrutiny they undergo. In re- that two to five minute window would be disrespectful to sponse, The American College of Critical Care Medicine the wishes of the donor, the program, and toward the po-

66 period of two minutes and a period of five minutes ate

physiologically and ethically identical. 33 Furthermore, they
deemed any period of time between two and five minutes Death on Operating Table

to be acceptable for the declaration of death and the com- One may assume that any patient would prefer to die in an
mencement of organ procurement This is because no mencement of organ procurement. This is because no aesthetically $\mathrm{p}$ as ever auto-resuscitated (Lazarus Syndrome) after

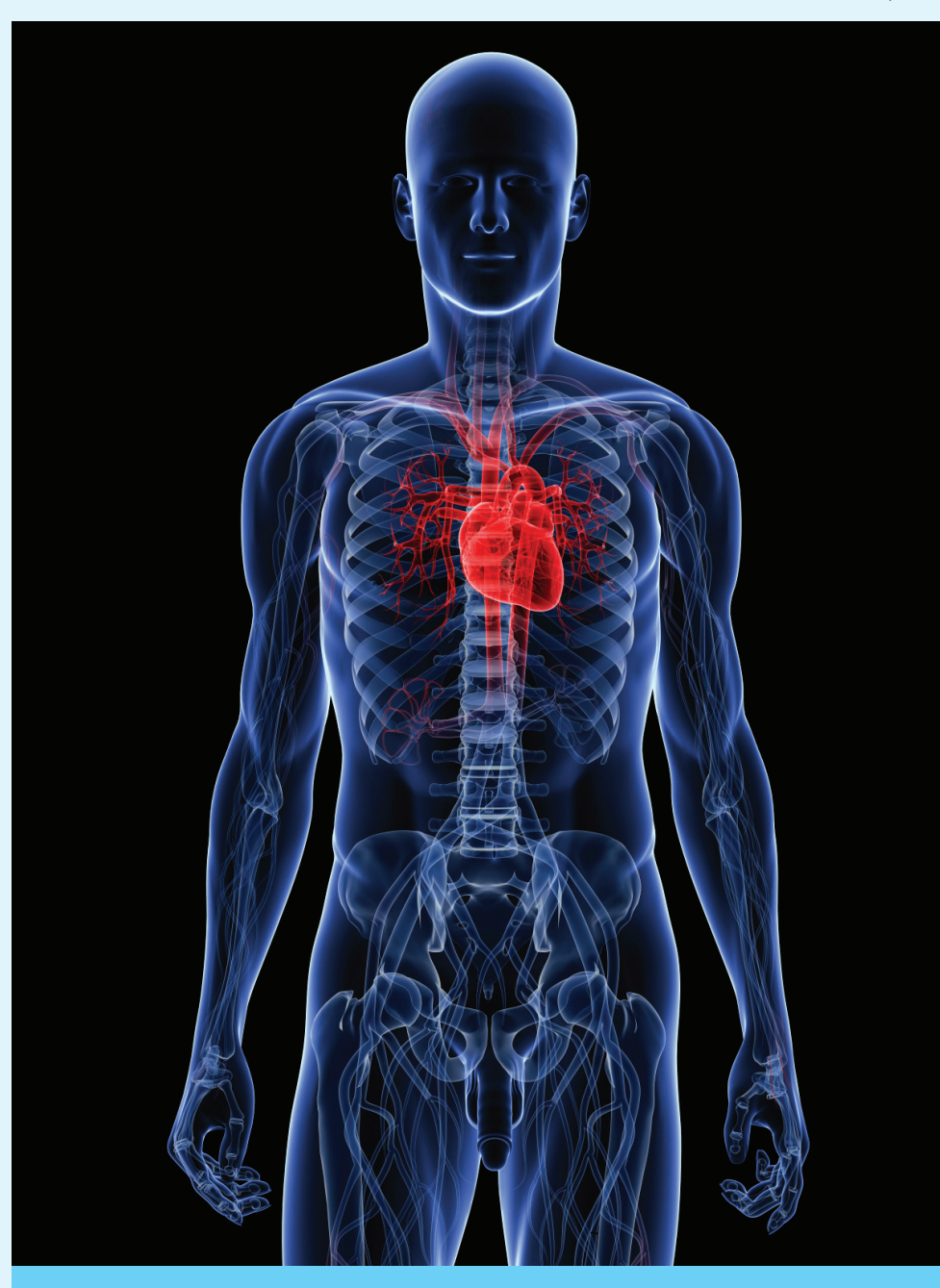

hose few who will remain conscious in the OR upon the removal of life support.
This assumption, however, disregards the personal preferences of each patient. For surrounded by family while dying makes them uncomfortable- that they would raththave their family's last memory be one of ounded by highly trained professionals in $\mathrm{OR}$ with specific technology for treating scomfort may alleviate the fear of dying

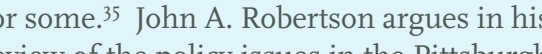
Protocol, "It is not clear at all that these concerns differ materially in substance from concerns that already attend retrieving or-
gans from heart-beating donors. 36 He ex-
plains that DCD patients and brain-dead onors will both 'die' in ORs, absent of famy, surrounded by medical staff and highequipment. Perhaps the consideration

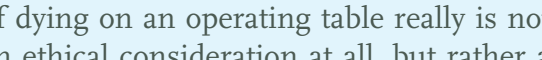
ecision with regard to personal or surro政 puired to disclose all details of the proce dure to the patient/surrogate upon agree-
ment to follow through. This includes the manner and location of dying. ${ }^{37}$ And as per burgh Protocol Policy and IOM recomdonation at any point, even after consent prejudice or resistance
One might argue that surrogate consent is a critical concern regarding the withdrawal of life support in favor of surrogate's decisions about the withdrawal of life support . the patient alone. However, the power of surrogates has already been established in the American medical community and without surrogates the wishes of many incompe involved in removing surrogate power with regards to o gan donation may be greater than sustaining the role of a surrogate. Although the power of the surrogate may unfortunately cause physicians to stay important conversa
tions until after a patient is incompetent (due to the dis. comfort of discussing DNR orders or organ donation with the patient), this problem is not unique to the withdrawa of life support and organ donation. 39 The removal of sp result in disregard for the wishes of many incompetents.

CONFLICTS OF INTEREST

Healthcare Motives

There are two significant conflicts of interest that healthDCD patient. The first is an institution or organ bank's motives in desiring to expand the donor pool by implementing NHBCD protocol with specific emphasis on the
public's perception of such motives. Second is the attend public's perception of such motives. Second is the attend-
ing ICU physician's conflict between 'doing no harm' and promoting the viability of potential organs once DCD status has been established.

A series of different public policy changes have been su number disparity between available organs and patient needing a transplant. Among them have been presumed consent, living donors, and procurement from condemne prisoners, ane dals, and chancephalic infants. Those proNHBCDs in favor of shrinking the gap, since a lot of thes suggestions carry more controversy than NHBCDs do. Those opposed, however, $m$ my
NHBCD protocol differently
"Perhaps the consideration of dying on an operating table really is not an ethical consideration at all, but rather a decision with regard to personal or surrogate preference." First, a greater availability of organs is necessary in order growth of this branch of medicine will cease without a ditional organs..$^{\circ}$ While the protestor might find this outcome acceptable, a large extent of industry and job creation most complicated of all motivating factors in medicine

Up to this point, little has been said in this article regard ing money because it seens improper to utilize financis However the protestor will not ignore the fact that the transplant industry is a burgeoning money-maker with widespread interest. For instance, of the average $\$ 259,000$

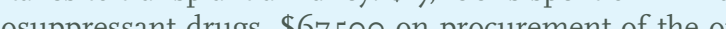
gan and \$92,700 and \$17,500 on hospital admission and physician fees respectively." Clearly immunosuppressant ghina fracturess and hospital administrators have a lot munosuppressant drugs are constantly being mew im tred in order to promote the success of transplantatio post-operatively. Similarly, hospitals with transplant units

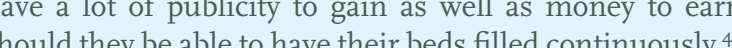

This thought however, is representative of a view contrary to that of this article and its author. To deny the installment of NHBCD protocol due to the distrust of motives is the Kennedy Institute of Ethics Journal states

It seems impolite, if not downright paranoid, to wonder abou
the motives of those who argue for 2 shift in professional prac 
tice or public policy in the procurement of organs when lives

Since it would be difficult to prove ill intent, it seems nec essary to provide institutions, transplant centers,
pital administrators with the benefit of the dowbt.

Care of the Dying

- The second conflict of interest addresses the medical team's split interest between the care of the donor and the fect the life and/or care of the DCD patient. When there reason to think that donation is a possibility, doctors an surgeons may find it harder to manage a patient as some potential donor capable of saving lives. For example, a ICU physician dealing with a patient who has already agreed to DCD status may provide the patient with hepari co prevent clots or vasodlators to promote organ viability
contrary to the medically indicated care of the patient who deserves, first and foremost, palliative care. ${ }^{44}$ Even exclud ing complete malpractice, negligence, and corruption,
these are very real concerns, each of which depends solely hese are very real concers, nician attending a potential NHBCD patient. Additionally the suggestion or even mention of organ donation may color a patient/surrogate's views one way or the other, and
would be considered unethical, despite the potential to obtain otherwise

There is, however, hope for this dilemma as well. Each dures. This article has already outlined the procedures of the Pittsburgh Protocol extensively. It is evident that the UPMC has sought to eliminate this specific conflict of incharge of potential NHBCD candidates must never have anything to do with either the transplant team or the pahents receiving transplants. Additionally, in the ICU al palliative care decisions can be easily met with a series of the institution reviews decisions for care in end-stage NH BCDs. As in the Pittsburgh Protocol, a "review process assumes a secondary role, meant to police the effective sonnel's duties " 45 Should there be an ethe medical perany decision (like the administering of heparin or vasodilators, unless medically indicated) then a board of ethic may handle the potential intervention and termination of
NHBCD status on behalf of the patient $4^{6}$ Moreover, on will most likely never see the case where a physician is able port and the subsequent proceedings lie with the patient surrogate. In fact, as mentioned previously, the doctor may only offer organ donation as an option once the deci-

"To deny the installment of NHBCD protocol due to the distrust of motives is itself morally depraved." Institutions are constantly implementing safeguards or consideration, coupled with the public's munity should alleviate these concerns and pical com

RECOMMENDATIONS FOR PUBLIC POLICY There are two major concerns regarding the best way to move forward. First, it must be understood that the topic of death and dying is an extremely sensitive one in the
public arena. The CEIA notes, "Policy changes that, however unfairly, encourage public perception of organ procurement as ghoulish or disrespectful of decedents or heir families should be avoided. "J" It is often not enough heir motives and reasoning behind decisions the the restain definition' of death and procurement of organs from the dead will likely be perceived as corrupt and immoral if such decisions are made behind closed doors. Second ies entirely on civic particiption st Should rapidly che ing public policy without public input chase off potentia donors, the civically uninvolved implementation of $\mathrm{NH}$ CD protocol may serve to decrease the donor pool.

Considering the continuation and enforcement of the guidelines of the OPTN and IOM, recommendations of the CEJA, and methodic policies such as the Pittsburgh Protocol, this paper offers two additional recommenda-
First, there should be open discussion and debate of polic dying is not one specific to the medical profession. In fact. the medical profession is one dedicated to life and livin Death is an extremely personal topic, dealt with primarly
among family and close friends. If policy change is forced among family and close friends. If policy change is forced
abruptly upon the shoulders of the public, many will feel
as if their loved ones or they themselves are subject to exploitation, abuse, or premature death inside hospita make decisions regarding NHBCDS without accepting will allow for such input, awareness, and approval. Additionally, community members will give preceding consid eration to the thought of organ donation prior to trips to protocol "will assure the public that organ donation is an
altruistic act and that its practice is highly regulated and scrutinized." ${ }^{33}$ Familiarizing the community with standard NHBCD protocol may also serve to make the subje

Second, the successful implementation of NHBCD protocol around the country may rely on the slow implementation of policy. A 'policy creep' has been widely recomidea of donation after cardiac death. 5.556 Although difficult to the community that $\mathrm{NHBCD}$ s are a significant source of organs would allow for protocol to strip certain restricting
criteria over time. To what extent and how slowly this poi icy creep should take place depends entively on the receptivity of the community. A community fully in favor of NHBCD protocol should see it implemented in full, while slowly one policy ch se at a time. The details of ach a creep would, most certainly, be leff to the institution attempting to implement NHBCD protocol in order to avoid
the misaplication of some irrelevant standard guidelines. CONCLUSION

Transplant statistics indicate growing disparity between supply and semats in haring gans should be considered a viable source of organs. Wit out unnecessary nitpicking, it is entirely possible to arrive at NHBCD protocol that the majority will accept. While ans it is not the goal of $\mathrm{NHBCD}$ activists to pervert the practice of donation. The debate over NHBCD protocol is nology, protocol, money, ability, and demand to expand the donor pool. It is, however, no surprise that medical polic ion. In the absence of an overwethith great oppos. garding the acceptability of death and its declaration, the low implementation around thBCD protocol lies in the the conntrinuation of this trend tainly encouraged.

ENDNOTES

www.UNOS.org 3. Light $2008(735)$ 6. Harrington 2009 (344) 7. Arnold 1993a (104)

. Ibid. 1.. Arnold $1993 \mathrm{~b}(264$

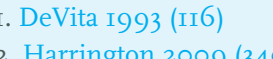
13. CEJA Report 4 I 1994 (I-94) 4. Harrington 2009 (340) 16. Ad Hoc Committee 1968 (335)

1. Harric

(3) rington 2009 (343-34

23. Harrington 20091346

rgh Medical Center Policy and Procedure anual" 1993 (A-1) Pedical Center Policy and Procedure Manual" To93 (A-T-A-2) "University of Pittsburgh Medical Center Policy and Proce Gre Manual" "9993 (A-2-A-G) 9. Fiddler

(E) Eeport 4 I 994 1-94 


\section{Ibid.}

35. CEJA Report 4 I994 I-94

37. CEFA Report 4 1 $1994 \mathrm{I}-94$.
38. "University of Pittsburgh Medical Center Policy and Proce
dure Manul"

dure Manual" 1993 (L.L.: A-4)

40. Caplan I993 (255)

43. Caplan 1993 (254)

45. Shaw $1993(185)$

46. CEJA Report 4 I 994 I-94

47. Caplan I993 (256)
48. Harrington $2009(36)$

49. Fiddler I993 (123)

50. CEJA Report 4 I 994 I-94

51. Harrington 2009 (379)
52. Robertson $1903(246)$

53. Fiddler 1993 (123)

54. Caplan 1993 (260)

55. Arnold 1993b (272)

REFERENCES

"Ad Hoc Committee of the Harvard Medical School to Examine he Definition of Brain Death. A Definition of Irreversible Coma Journal of the American Medical Association Vol. 205 (1968): 33 .

Arnold, Robert M. and Stuart J. Youngner. “Back to the Future Abath o gars cessed r7 November 2010 - httrp: / muse ihu edu/C

Amold, Robert M. and Stuart! Youngner. “The Dead Donor Rule ffthics Sournal 3.2 (1993): 263-278. Project MUSE. Accessed ry November 2010 <http.

Caplan, Arthur L. “The Telltale Heart: Public Policy and the Util. zation of Non-Heart-Beating Donors." Kennedy Institute of thic (5)

Devia, Mithe minally III Patients Who May Become Organ Donors after Dee
Following the Removal of Life Support." Kennedy Institute of Eth(a)

eVita, Michael A. and James V. Snyder and Ake Grenvik. "His Institute of Ethics Jounnat batients with Cardiac Death." Kenned eessed r7 November 2010 <http://muse.jhu.edu/s. Death: The Pittsburgh Protocol. CEJA in AMA. (1994): Report 4

Ethical Issues in the Procurement of Organs Following Cardiaa (994): Report 3. I-94.

iddler, Suzanne A. "Implementing Donation After Cardiac

Financing a Transplant." Transplant Living. Accessed is Augus oII. nance/costs.aspx>

Harrington, Maxine M. "The Thing Flat Line: Redefining Who is egally Dead in Organ Donation After Cardiac Defor
niversity Law Review Vol. 86 (2000): $355-380$

light, Jimmy A. “Organ Donation and Death from Unexpected Girculatory Arrest: Engaging the Recommendations of the Inst Gre or Me Arest ses and Piffalls" Iournal of Law Medicine \& Ethics Vol 36 2008): $735-739$

rgan Procurement Following Cardiac Death, Amendment CEJA in AMA. (2005): Report Io, A-O

Robertson, John A "Policy Issues in a Non Heat Beating Dono Protocol." Kennedy Institute of Ethics Journal 3.2 (I993): 241-250. (1) November 2010 <itp.//muse.jhu Shaw, Byers W., Ir. "Conflict of Interest in the Procurement of

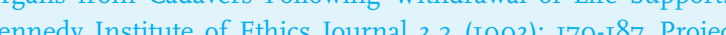
Kennedy Institute of Ethics Journal 3.2 (1993): I79-187. Project
MUSE. Accessed r7 November 2010 <http:/muse.jhu.edu /> University of Pittsburgh Medical Center Policy and Procedure roject MUSE. Accessed r7 November zoro chttp://muse. hu
"United Network for Organ Sharing." Accessed 3I March 20 
FRANK LLOYD WRIGHT

The Power of Illumination in Architecture

"Wright's general concern for the proper use of light stemmed from a desire to give people a sense of freedom and openness while creating a closed, functional shelter for them."
THE SIGNIFICANCE OF LIGHT TRANSCENDS CULTURAL AND GEOGRAPHICAL BARRIERS, CONNOT-

ING SPIRITUALITY, KNOWLEDGE, AND GOODNESS IN A VARIETY OF CONTEXTS THROUGHOUT THE AGES. ARCHITECTS HAVE LONG USED LIGHT TO HIGHLIGHT SPACES AND STRUCTURAL FEATURES OF BUILDINGS AND LANDSCAPES. THE CULTURAL, INTELLECTUAL, AND INDUSTRIAL DEVELOPMENTS OF THE 19TH CENTURY GAVE BIRTH TO A NEW THEORY OF LIGHT IN ARCHITECTURE, REALIZING PREVIOUSLY UNTHINKABLE MANIPULATIONS OF NATURAL AND ARTIFICIAL LIGHT. RENOWNNED ARCHITECT FRANK LLOYD WRIGHT'S MASTERY OF ILLUMINATING TECHNIQUES IS MANIFEST IN HIS MOST FAMOUS DESIGNS, AND HIS INNOVATION CONTRIBUTED GREATLY TO THE EMPHASIS ON NATURAL LIGHT SO APPARENT IN CONTEMPORARY HOME ARCHITECTURE. 
itself, has inspired the imaginations of couptless artists, light is charged with much allegorical and spiritual mear. France, used light as a metaphor for God's majesty, tran4 Ir34, he had the portal of Saint Denis Church engraved with, "Our darkened spirit arises to Truth by the means of
material things, and seeing the light, comes back from the original Fall." Here, light and architecture create a space of sublimation and dematerialization

Since Suger's time, light has lost none of its potency in the creation of spaces, although the specific connotations of bridge to the heavens and more as a mediator between building's artificial exterior and its natural exterior. Frank Lloyd Wright conceptualized this view as "organic architecture. Nature and building, he thought, exist in a symb-

ceptions of light. More specifically, the architectural conImpressionism, the Arts and Crafts movement of the

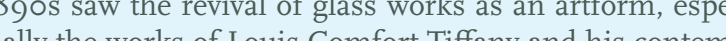
porang ing this period, was certainly influenced by these evolving itt movements, which ultimately led him to contemplate ght and glass.

It is also helpful to consider that since Wright grew up in a rather conservative and pious family, light as a spiritual young man, the architect lived in Wisconsin, in the pres days of his yound open spaces. Thinking back to the hrough the trees and falling on leaf-covered ground. rom dancing illumination on the ground, he drew his

Wright grew up in a rather conservative and pious family, light as a spiritual metaphor for God must have been emphasized. As a youth, the architect lived in Wisconsin, in the presence of natural and open space."

Wright's upbringing in the nineteenth century was charac- Wright worked with Louis Sullivan, who was heavily influterized by industrialization. In the recent past, glass had enced by Ruskin, Richardson, and the Chicago School. Albeen expensive and technically difficult to produce. Be-. though the degree to which Chicago School architects $\mathrm{d}$ to use as a structural element of buildings, or in large pan- known to have worked within the Prairie School, which els. Beginning in the 1840s, however, a series of innova- originates from the Chicago School. Wright was also quite tions gradually made its use easier, cheaper and increas- well read and became acquainted with the thoughts of Emr8sos toughed of a revolution in interior liehting enalling novel manipulations of space and shadow. In addition to suifed to intuit the principles of nature and live in harmo these technical innovations, artistic movements had a sig- ny with it. Thoreau pleaded for a "return to nature" and nificant role in rethinking light. The Impressionist move- symbiosis with it. He was fascinated with lakes and ponds cially introduced in the United States in an I886 att reflected the landeape wie exhibition. Impressionism attempts to capture the world with every breath of wind or change in light."3 Wright, who as does the human eye in a glance. As all impressions are was following their vision of nature, transposed into archi-

characterized to some degree by the play of light and shad- tecture their theories: a house should fit in the landscape
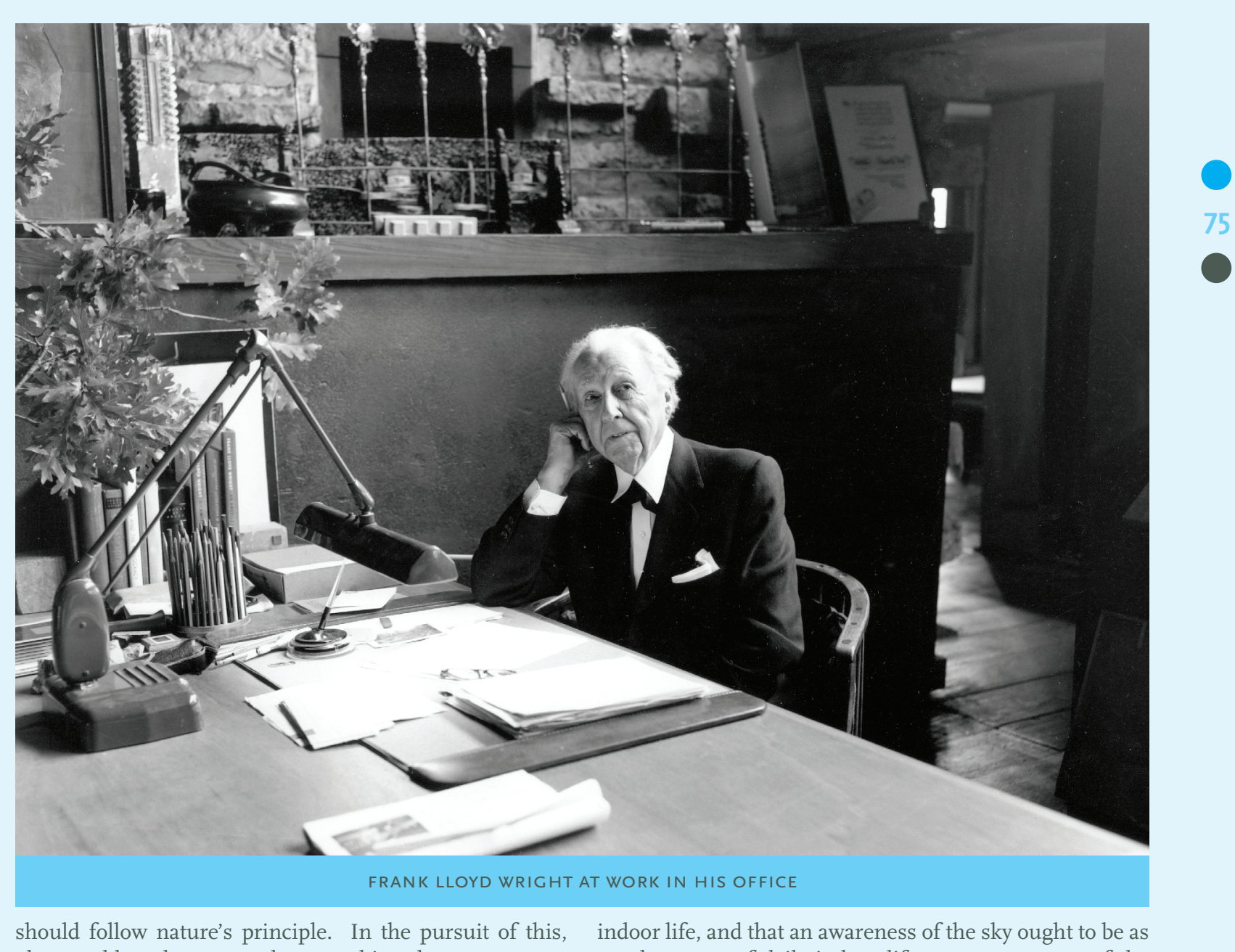

should follow nature's principle. In the pursuit of this, in nature.

With this background in mind, it is easier for us to consider the presence of ight in wight shouses. To wight understood it, but rather a materialization of spirit. "The open landscape was nature's eloquent way of making freedom visible; to Wright, buildings too should speak of free-
dom $v_{4} A$ dwelling should be open on naturte full of light and receptive to nature's and time's changes. It should be "a broad shelter in the open" as he said, an invtation to freedom. 3 He conceived of his buildings with great consideration for the primary forces of nature, and the basic requit for the door life, and that an awareness of the sky ought to be earth.7 Light, to him, was ac fitural order, existing un-violated in cities and thus lization

Wright regarded glass as the materialization of light the wightless medium of sight. Out of all the materials he a d glass was his favorite because it allowed for the esin the openings of my houses, glass as a place comparable to
precious stones among all the other materials.... This super-
material that is ass is in the way we currently use it is pure 
wonder. Air in airs, to keep air in or keep it out. Itself light in
light, glass diffuses light, reflects or diffracts it9

Another major desire, was that the openings would not
look like holes in wall but rather would form an apen

Glass is the architect's dream because it is such malleable

could see with perfect clarity, a "lens by which the land
scape could be structured with a erace suffien the

pictural art redundant."'olo It could be as refractive as ice,

as iridescent as a butterffly's wings" " "translucent, of transpar

ent, opalescent or opaque; polished, frosted or rusticat-

els in a house, for example, marking the boundary between

"Shadow itself is of the light," accroding to Wright. He was just as obsessed with shadow as light, as one always of half-light Wright was interested in indirect lighting and smooth contrasts. A dwelling is meant to be a refuge, retreat; this is one of the reasons the Prairie houses have not just esthetic for they guarantee inside. Shadows are as well as the creation of a quiet and comfortable entrance in a dimly lit space.

"Wright was well aware of the effects that each of his arrangements would create with light; with this knowledge, he manipulated the way light itself would interact with the observer."

In stark contrast to architects such as Ludwig Mies von der Windows were to remain a protective screen: a kind of frontier, giving the dweller a feel of intimacy and privacy while also lending a taste of freedom and possibility to wit-
ness changes in time and nature. Glass stands out amon ness changes in time and nature. Glass

by means of glass something of the freedom of our arboreal
ancestors living in the trees becomes a precedent for freedom in the zoth century life. It is by way of glass that the sunf order of the human spirit ... free living in air and sunlight.

Wright's general concern for the proper use of light stemmed from a desire to give people a sense of freedom for them. Houeses were to contained the interply of shadow and light to give the sense of a soothing shelter. He wanted to have dim intimate spaces interspersed with areas flooded with light. He also desired his houses to a landscape and he started experimenting with the use of rifts and patterned glass ceilings as soon as $1893 . "$ Wright firmly believed that the purpose of the building architecture which is really architecture proceeds from the
ground and somehow the terrain; the native industrial conditions, the nature of materials and the purpose of the building building

The weather conditions would have an effect on the shape of the house and thus the choices of lighting, and the natument artificial sources. In the case of the Praire hoples. or instance,

alternate extremes of heat and cold, sun and storm, have to be considered. The frost goes four feet into the ground in winter both to shade the building from the sun and protect the walls for freezing and thawing moisture.

The overhanging eaves were meant to exclude the sur the sur

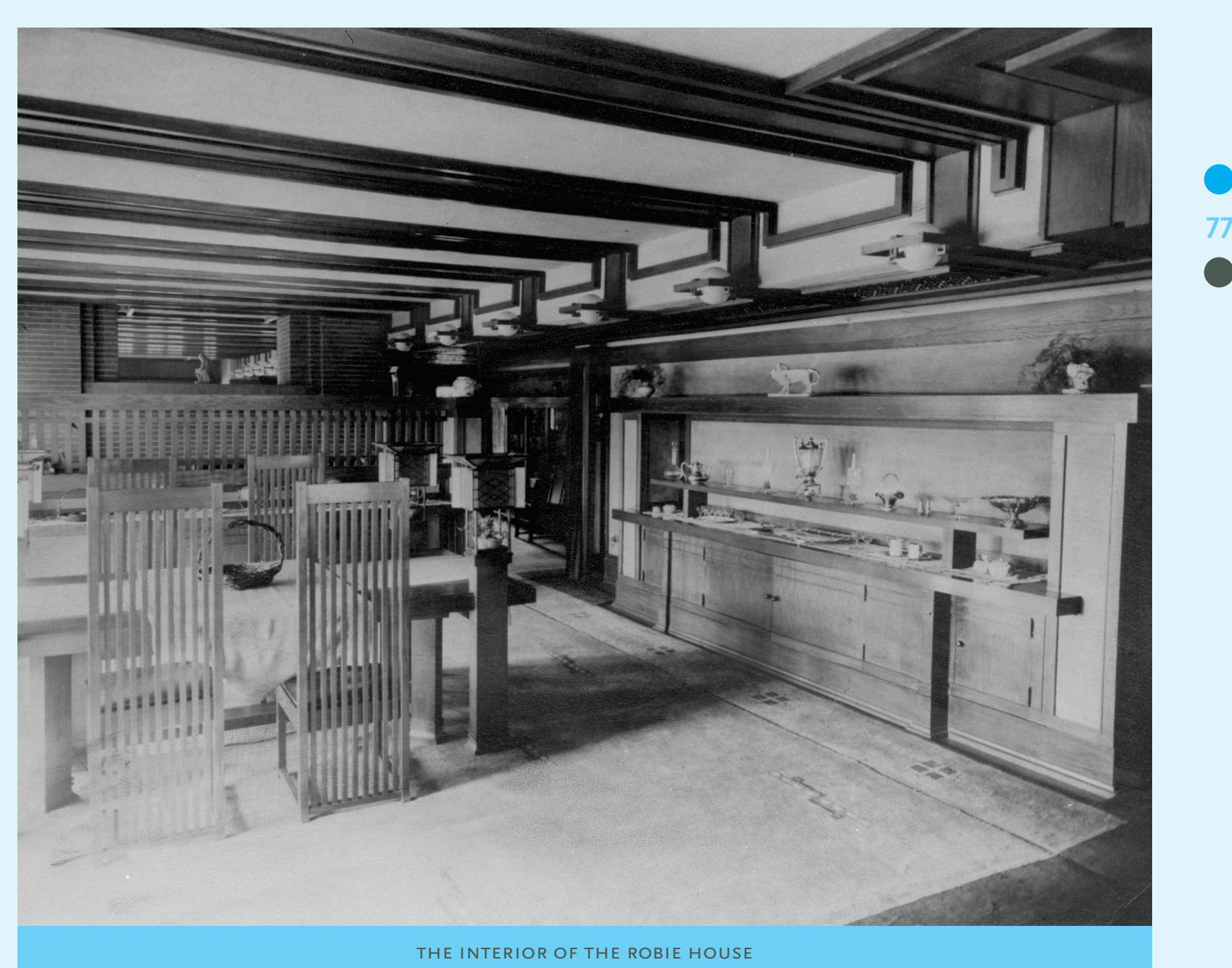

ing hot summer days, while keeping rain and snow away house walls turned into large light screens would disinte-

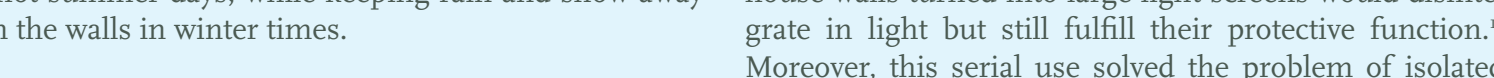
Wright mastered the use of natural light. He adapted his $\begin{aligned} & \text { Moors and windows that clearly marked separation of the } \\ & \text { architecture to the function of his building but all of his } \\ & \text { house from the street and the environment It is partiot }\end{aligned}$ architecture to the function of his building, but all of his house from the street and the environment. It is particu-
designs place a premium on light. The classic way to be- larly true of Wingspread's fifteen-foot high living room gin a building's relation to light is to orient the building to windows that completely overshadow the smaller entrythe South and slightly to the East so that it gets the best way. ${ }^{8}$ These rows of windows also often allegorically re light of the day. Wright used this design every time it was ferred to weed or flower fields, as they were also ornament-

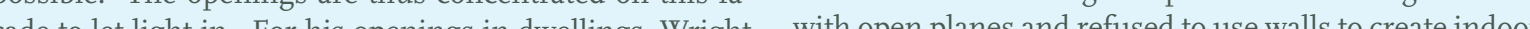
liked to use high casement windows and French doors. To spaces, he employed light to articulate and determine the maximize their effect, and to give vigor to the outdoors and use of the space. In Fallingwater, for instance, narrow rifts overcome the continuing and enclosing walls, he grouped from floor to celling at Wright ho walls of senvant wings 
riffts to recreate skylighting that would nicely cast flakes of forced the feel of their lowness with paint and thin wood
light and contrast the floors from anove sugesting aleafy breading cover soffly pierced by sunlight. $\mathrm{z}^{\circ}$ Conversely he would use rows of clerestories to give energy, rhythm, and strength to a room, as he did in Wingspread, for the "wig. wam" (the living room). In some buildings dedicated to

8 Work or social function, such as the Larkin Building or

source of light. In the Larkin Building, a glass roof over
the atrium lets light in for all the stories. In Unity church. series' of square windows on the top of the four sides let
dim light enter while the auditorium is given " aura of a cloudless day" thanks to the rifted roof In $\mathrm{h}$ later Johnson Wax Administration building, there are ab solutely no windows; all the light comes from the glass
roof and the horizontal band of glass tube that replace the traditional cornice.

Wright often used glass to efface the shadowy, enclosed Wright created new aning plwo panels of glass at corners. clients recalled that such glass corners gave the impres. sion that the roof was floating above walls."2. It also gave new sense of volume and freedom. In the Johnson Wax
building, the walls and roof are in continuity, the contrast building, the walls and roof are in continuity, the contrast
between the plaster and the glass filled cornice first, and the cornice and roof secondly, give an aerial feel to the building. In the houses he designed, Wright used glass towers and light wells to create volumes, emphasize spe-
cific spaces, and create contrasts. This is the case in Fallcific spaces, and create contrats. This sisthe case in Fall erraces and extended parapets while verticals are concerned with light with the three-stories tower of glass and the light screens of the kitchen and West bedrooms. Wingspread, the "row nest," entirely in glass, lets some
light in near the massive chimney, creating an interesting contrast, while the Guggenheim museum, entirely lit by its roof, could embody the idea of light itself. Wright loved put light and openings in unexpeted places to

eilings could be brought down over onto the walls by the way
of the horizontal broad bands of plaster on the walls themselves above the windows and colored same as the room ceilings ceiling-surface and color down to the very

e used colors knowing fully well how they would interac fuse light indirectly. This is why he mase a space or dif rey and beige to cath light as well as ory and oak tones to create warmth. ${ }^{23} \mathrm{He}$ had han the overhanging eaves and sometimes the cantilevers' bottoms painted in clear colors, so that they would protect the bedrooms from

Wright also used electricity and fire lighting. Fire was important to him because it was earthly, complementary to the seasons, as fire is linked to winted to whe passage of the is associated with summer. The intimacy of a fire's arm, dim light is reinforced by the heat it gives off. The

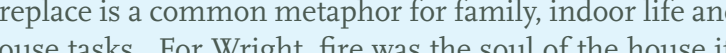
elf "the spint within ", ${ }^{25}$ Chimneys wellings Wright built, the focal point of the household both the center of gravity and the gathering place for the

As for electricity, Wright was ahead of his contemporaries. e loved to test new technologies and adapt their use. He hid the cables and, obsessed with light coming from above, used lantern-shapes and warm lighting in the places he
could not or did not want to skylight. His lighting itself constituted real artworks and while also functioning as little suns, casting a warm toned light from above. He of en built lightng into the house, and made wide use of re
sistance devices that could dim the light from his fixtures.

Wright was well aware of the effects that each of his arrangements would create with light. With this knowledge, he manipulated the way light itself would interact with the the rugs' design, their shadow superposing the rugs patterns at some hours of the day, as in the Robie house. To create intimate atmospheres while letting light in, he
brought the ceilings down to a "human size" and rein-

The sensibility for the use of light which Wright showed early in his career remained central to his progression. In
deed, his concern for light was bound always to his concern for the management of spaces, volumes, ornamenta dynamics of light and the titions leave an illuminating legacy for architects, but mos itions leave an liluminating legacy for architects, but most
of all for we who live in the insight of his designs today.

\section{ENDNOTES}

I. Gerard (14)
2. Hoffman $1986(5)$
3. Hoffman $1086(20)$

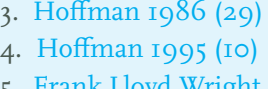

guted in Hoffman 1995 (94)

6. Hoffman I995 (18)

8. Lipman (194

9. Frank Lloyd Wright, quoted in Staib 26

10. Hrank Loyd Wright, quoted in Hoffman $1986(29)$

12. Frank thoyd Writheya Wright Architecture and nature p29

12. Frank Lloyd Wright, quoted in Hoffman $1995(9)$
13. In the anteroom of his Chicago office.

4. McCarter, “The Integrated Ideal," in McCarter (2005) 28 .
15. Frank Lloyd Wright, quoted in Spencer I979

16. Horfman $1995(12)$

I8. Hertzberg $2004(26)$

20. Hoffman 1995 (33)

2. Hoffman $1995(39)$

(2.)

24. Banham 1969

25. Wright was very interested in Native American culture, an

REFERENCES

anham Reyner. The Architecture of the Well Temp

Bolon, Carol; Nelson, Robert; Seidel, Linda, eds. The Nature of

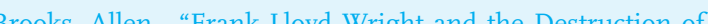

Box" in Jurnal of the Societry of Architectural Historians 38 . No (1979): 7-14.

Brooks, Allen, ed. Prairie School Architecture: Studies from “The
Westerm Architect" Buffalo: Universith of Toronto Press Clausen, Meredith، "Frank Llovd Wright. Verticas Sper Chicago School's Quest for Light," in Journal of the Societert of Arch tectural Historians 44, No. I (1985): 66-74.

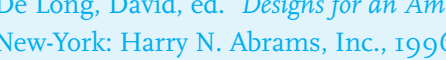

wis

Hertzberg, Mark. Wright in Racine. San Francisco: Pomegrana

Hoffman, Donald. Frank Llopd Wright Architecture and Natur New-York: Dover Pblications, 1986.

ling Frank Llopd Wright's Architec.

ture. New-York: Dover, 1995.

Kaufman, Ir. Edgar "Frank Hoyd Wrieht: Plasticity Cong 37, №. I (1978): 34-39.

Kruty, Paul "W Wribet Spencen Winterthur Portfolio 30, No. 2 (1995): 103-12

Levine, Neil. The Architecture of Frank Llopd Wright. Princeton Princeton University Press, 1096

ind Carla Frank Llovd Wright's Prairie Houses. San Francisce Archetype Press and Pomegrante Pres 1994

ind, Carla. Frank Lloyd Wright's First Housses. San Francisco: A chetype Press and Pomegranate Press, 1996 .

Lipman, Jonathan. "Consecrated space" and McCarter, Rober. the Antegrated Ideal," in On and BY Frank Lloyd Wright: A Primer eton Architectural Press, 2005.

pencer, Brian, ed. The Pr

ttaib, Gerard. "Des origines au mouvement classique," in Con-
struire en Verre col. Lausanne: Lausannes Presses Polvtechniques 
TRANSCENDENTAL GEOLOGY

Towards a Phenomenology of Nature and History

"The chiasm, the interweaving of nature and history into the fabric of our experience, is fundamental, and thinking of them in a way that is faithful to experience requires thinking through both of them together."
IN HIS LECTURE COURSE ON NATURE, THE FRENCH PHENOMENOLOGIST MAURICE MERLEAU-PON-

TY MAKES THE INTRIGUING CLAIM THAT AN ONTOLOGY OF NATURE IS THE PREFERRED PATH TOWARD ONTOLOGY IN GENERAL. THIS ARTICLE EXPLORES WHY HE MAKES THIS CLAIM AND ASKS WHAT PHILOSOPHICAL SIGNIFICANCE THIS APPROACH TO ONTOLOCY MICHT HAVE. MAKING USE OF MERLEAU-PONTY'S NOTIONS OF CHIASM AND FLESH AS THE FUNDAMENTAL ONTOLOCICAL TRUTHS, THE AUTHOR ARGUES THAT NATURE AND HISTORY ARE RELATED TO ONE ANOTHER ACCORDING TO THE LOGIC OF THE CHIASM AND THAT THINKING ABOUT THEM IN TERMS OF THIS RELATIONSHIP OPENS UP AVENUES FOR ADDRESSING LONG-STANDING PROBLEMS IN BOTH PHILOSOPHY OF NATURE AND PHILOSOPHY OF HISTORY. SPECIFICALLY, THIS ARTICLE EXPLORES MERLEAU-PONTY'S RESPONSE TO THE PROBLEM OF A SCIENTIFIC-HISTORICAL METHODOLOGY DISTINCT FROM THE METHODOLOGY OF THE NATURAL SCIENCES. HIS RESPONSE, IN ITS RELLANCE ON THE LOGIC OF CHIASM, MOVES THE PROBLEM BEYOND THE STATE IT REACHED IN THE WORK OF WILHEM DILTHEY AND EDMUND HUSSERL. 
Nature as a leaf or layer of total Being-the ontology of Nature
as the way toward ontology-the way that we prefer because the evolution of the concept of Nature is a more convincing propa deutic, [since it] more clearly shows the necessity of the onto-

logical mil
always the

82 Maurice Merleau-Ponty

Why is the ontology of nature the way toward ontology in
general? And why, in turn, is a history of the 'evolution' of nature as a philosophical concept the way toward the ontocance of historical-philosophical reflection on nature by way of Maurice Merleau-Ponty's ontology of the visible and
the invisible. The answer to this question lies in two ideas. the invisible. The answer to this question lies in two ideas
First, if we assume the validity of Merleau-Ponty's ontoloFirst, if we assume the validity of Merleau-Ponty's ontolo-
gy as presented in The Visible and the Invisible, we find that

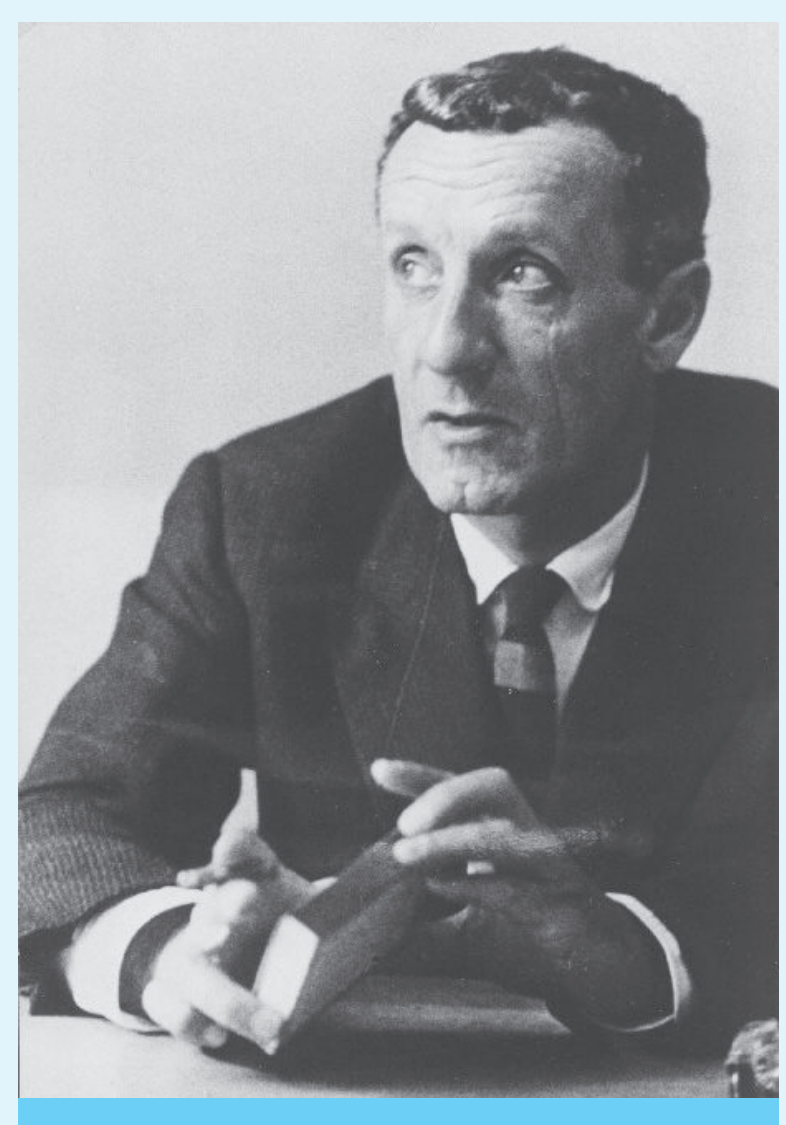

a tion, we obtain a fruiful approch to apprehending the meaning of both.

The question that focuses Merleau-Ponty's later philosophical work is that of chiasm as the fundamental ontoing reconversion of transcendence and immanence." Following the lead of other philosophers, most notabl Ediques western and Martin Heidegger, Merleau-Ponty crilerms of opposing conceptual pairs.

Rather than accepting that conceptual pairs such as transcendence/immanence or material/spiritual accurately of certain assumptions, the clear lines that demarcate
these conceptual pairs do not hold. More basic than these concepts is the relation of continual reversibility that exists believe that in is belonging to one side or another of a conceptual system. Either something is visible or it is not. Either something is reflective or unreflective. However, a sustained investiga od that comes between clear hours of light and darkeess. When one tries to point out precisely where something
ceases to be visible and becomes invisible or where transcendence ends and immanence begins or what constiing that does not once-clear concepts bleed into each ing the
other.

The secret of being does not ultimately rest in the things which enter into this relation; in fact, making being a static
property of things leads to incoherence. One of the great lessons that phenomenology has drawn from the history of philosophy is that the assumption of the primacy of things is flawed precisely because it is impossible to pin
down what things are while simultaneously sssuming th eing is concentrated within things. Instead, being rests in
the movement of the chiasm. Being is more productively associated with the dynamic relationships between a given subject and its possible objects. Examing this back-and-
forth reveals a stuf that is neither material forth reveals a stuff that is neit,
what Merleau-Ponty calls flesh.'
[Flesh is an ultimate notion .... a relation of the visible with
itself that travereses me and constitutes me as a ser this circle Which I do not form which forms me this coiling over of the visible upon the visible. ${ }^{3}$

reflective meaning that lies within the sensible, constitutpoint for understanding nature. "Nature is what has meaning without this meaning being posited by thought:" Rather than have us think of reality as ultimately materiad two, Merleau-Ponty dismisses the tradition dialectic of the basic substance. Flesh is a meaning relation, but not an
intellectual one. It is not matter, but neither is it thought because it is a relation that involves tangibility and visibilraditional concepts of matter and spirit flesh is not constituted by these two things. Merleau-Ponty asserts tha flesh is an always-already present relation, out of which mate notion, the structure of flesh is also the structure derlying and manifested in the world and ourselves. What we perceive as objects are intelligible as such only by
means of their engagement in this relationship of the means of their engagement in this relationship of the
flesh. "What exists are not present things' or forces but systems of differential relationships in an ongoing process of integration, disintegration and reformulation. "4

Given flesh, given this relational system, how is the con'privileged expression'? Why do we teet nathe and the ontology, historically, through studying the evolution of the concept? These are the questions which can be answered by asserting the existence of a chiasm between nPonty means by Nature. One of the implications of the ide of flesh is that meaning in not existentially dependent o setience; rather, it can exist beneath thought. There is un-

"As an overarching concept or horizon of experience, nature is 'a carrier of all the possible,' a configuration that is the originary source of any sentient reflection concerning it."
It is also what underlies all of our experiences--percepin of the Spatiality of Nature, Merleau-Ponty distinguish e objects are engendered." ${ }^{\prime 6} \mathrm{As}$ an overar ing concept or horizon of experience, nature is "a carrier of surce of any sentient reflection concerning it:

The sensibility of nature must then exceed attempts to $r$ lect upon it because it is both the point from which reflec scendence and immanence which Husserl, and later Mereau-Ponty, understood as an essential characteristic of perception. Sentient reflection on nature is "ontologically "Wrth" and the " nature, springing from the "soil," the mains for the personal self a prehistory an irrecuperable past."' Reflection takes up nature and in doing so deals something ontologically related to itself. But the re

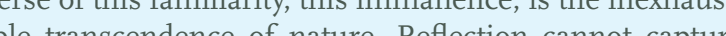
ry possible relation with nature in its gaze, and it is this experiential fact that preserves reflection from being iden-

Reflection emerges from the unreffective when a subject, explore its history. This phenomenon dox. We seem to experience nature directly and unreflec lively all the time as we perform habitual tasks in our daily
lives. But if the unreflective expresses itself only throug reflection, then this mediation is a condition for understanding nature and direct access is impossible. As soon as nature is thematized, as soon as it stands out from the
background of the world one lives through the ackground of the world one lives through, then reflection

What are we doing in the majority of our relations with nature? At any given moment, the meaningful sensibility hing else. It is the "soil of our experience," as Husserl put it, "not an object among other objects but the living stock

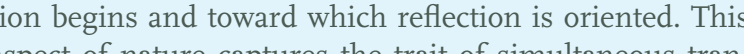


of nature is flowing into the meaningful sentient of hu-
man life which is its expression. The doubling back of reflection, the effort to join itself to its originary source, must always be incomplete. Reflection cannot seamlessly rejoin the unreflective that is its beginning.

stitutive and expressive of both-this movement is pre

When nature passes into reflection, it passes into history when reflection enters into nature, so too does history en ter into nature. This relation of reversibility, of chiasm, ob-

Although a seamless rejoining is impossible, there is re-

onsib does nature flow into human reffection, but reflection

der to reframe some traditional philosophical problems. nsible lived- As a beginning, 1 will trace a question which was impornon-lexical meaning always ended by people who speak of nurn' in this way, discloses a cruc both reflection and nature. moves through and in time, in

this self-rending movement of exression is not a potentiality of the (a) sonse, can only be a moment of are's own sell-unfoliding express

This temporal expression of nature ably passes into history, concer

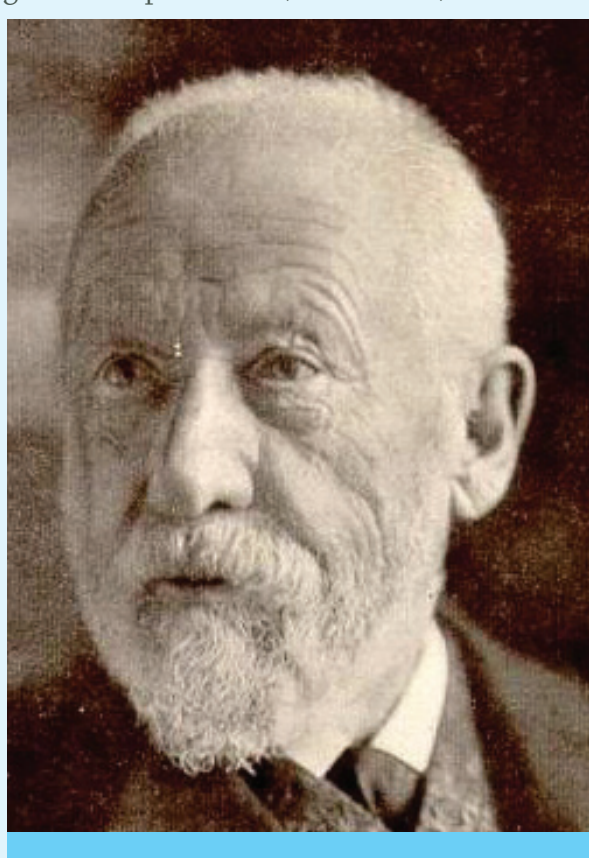
Invisible. The problem is this: can be endowed with sistorical study Ithey do not obtain by a meliadity oy parallel to the natural sciences?

The neo-Kantian Wilhelm Dilthe saw history (and the human sciward capturing important toments in the flow of the 'nexus of life' [Lebenszusammenhang, by ity between nature and psychic life. Due to the fleeting nature of experience, the human sciences are tasked with working to relate bek to a ceative, enthis nexus active source, someth presses and objectifies itself.," Their goal is to come to an underof life from within. Ditthey wants Human thought and activity in history, even as it moves the human sciences to be scientific, but recognizes that
forward and differentiates itself from nature, also seeks to because their orientation is different from that of the nature-enter that from which it came, to understand the secret ral sciences, so then must their method differ. Rather than in nature, in prehistory, and the continued movement of ences, the human sciences as Dilthey understands them history receives its force from the effort to fold the sentient must begin and remain rooted in lived experience [Erleb. back over to meet and apprehend the sensible. One could nis. Their efforts to study the nexus of life will not be suc understand natural scientific thought and technological nutan between the psychical and the physical This is advancement, for example, as thoroughly historical and nuity between the psychieat and pasis for seeing such dis-
reflective events which find their meaning and movement
because there is no experiential basis in their desire to plumb the depths of the unreflective that continuity in the nexus of life. A study that begins from is their soil. Therefore, what happens between nature and this abstraction already distances itself from the nexus of quiry. This condition introduces a tension which Dilthey priately genereral with respect to histroy when carried out by ences which are determined by their own particular his-
torical horizons? Dilthey's own philosophical and histor torical horizons? Dilthey's own philosophical and histori-
cal assertions are merely expressions of life which have their place amongst the interconnected systems that for the socio-historical nexus, but which do not constitute an Archimedean point from which to make univers
ments about the essence of the human sciences.

Husserl, in reading Dilthey, paid close attention to this problem and attempted to move beyond it in formulating his own philosophy of history in The Crisis and in his essa the dilemma of the scientificity of the human sciences, es pecially history, is that reflection upon these sciences dicloses an a priori structure always already operating in our experience of and reflection on history. "The historical ho-
rizon

each of the sedimented layers. The purpose of historicalmeaning which wo

This idea is fascinating, but "The Origin of Geometry" leaves the structure of history undefined and unexplored. ceptible to a critique. The trouble is not that there is no priori structure to discover: Husserl has given us an acount of structure that moves us beyond the formulation ow reflection is equipped to discover this structure. The essence of reflection is mediation. How then can reflection penetrate back through sedimented layers of meaning to and more layers to histor in and access the structure of what lies beneath words, the tension that omerges here is the same tension that character
unreflective.

"Reflection must add more and more layers to history in its attempts to double back and access the structure of what lies beneath it."

through methodological inquiry,"12 What this structure tation, a metaphor that Merleau-Ponty continues to make use of in The Visible and the Invisible. He tells us that "his tory is from the start nothing other than the vital move ment of the coexistence and the interweavings of origin phor of sedimentation combines the geological image of an exposed cut of bedrock with the structure of a deductive discipline like geometry in which each new discovery horizontal layers of sedimentary deposits (works of $\mathrm{ph}$ losophers, cultural artifacts, etc.) which have hardened into rock, so to speak, or which have become the ground or bedrock, upon which our present cultural world rests, vertical chains or nets of meaning such as those logica links which unify the axioms and theories of Euclid's Elements. Husserl would have us understand the structure of the meang

Merleau-Ponty has this dfficulty in mind in his discussion Gle and the Invisible. His idea for moving forward relies on the chiasm between nature and history. He formulates the problem by talking about the history of philosophy and wast philosophers took of their own proben the viets ways in which we understand their problems in Can there be continuity in philosophy if we understand the questions of past philosophers differently from how they their integrality are a question, the internogtive theught which makes them speak is not overcome by what comes ater." 14 We can trace the structural development of something like philosophy through time if there is a questionows thinking at a later time to be faithful to the proiects nd problems of previous times.

There is but one solution: show that there is transcendence, to 
plane, but that, in this plane, staggered out in depth, they nev-
ertheless refer to one another, it is nevertheless a question of which has its rights along the "bbjective" history of philoso
wathen 86 phy.

This idea of the continuity of questioning through time is similar in structure to the passing of the sensible meanin into sentient meaning - the logic of chiasm permeats them both. Nature has doubled over itself to produce his toubling over in order to move forward. I said before that the movement from nature to history is reversible, that the march of history finds its motivation in its desire to re-en-
ter the mute sensible which generated it. So, adherence to the logic of the chiasm requires not only a continuity of questioning through time, but that this continuity also be a folding back over which seeks to complete the circle of its
reflection. In this dynamic the act discovers the impossireflection. In this dynamic the act discovers the imposs This is, in fact, the next step Merleau-Ponty takes in his

He works to show that a structural philosophy of history he crossing of history and nature is what resolves the problems that both Dilthey and Husserl deal with in their works. Near the veryend of he notes for The Visible and the Invisible he talls about a philosophical account of history derstood in terms of geography than in terms of history:

Whereas geography - or rather: the Earth as Ur.Arche brings to light the cannal Unistoric (Husserl-Umsunza. In fact tit is a graphic" of history and transcendental geology, this very time that is space, this very space that is time, which I will have re discovered by $m y$ analysis of the visible and the flesh, the a historical landscape and a guasi-geographical inscription of history. Fundamental problem: the sedimentation and the reac history. F'
tivation.'

Here Merleau-Ponty references Husserl's concepts of sediOrigin of Geometry" " How this sedimentation and reactimology), must be grappled with within the context of ontology which apprehends being in terms of crossing, or and the natural world, is found in the moment of heir crossing, then there can be a structural philosophy the while recognizing the truth of incomplete reversibility a condition for any reflection.

The way to come to this point is, as Merleau-Ponty points . und eversibility and shows that history, too, is incorporated tho this pattern by being that which nature touches and 列 fundame and thinking of them in a wa tat tis fith ful to expereince requires thinking through both of them (a)

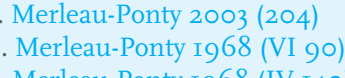

Ponty 1968 (IV I4)

. Merleau-Ponty $2003(6)$

Toadvine 2009 (132)

1. Merleau-Ponty $2003(3)$

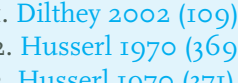

4. Merleau-Ponty 1968 (199)

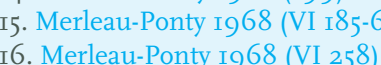

REFERENCES

Dilthey, Wilhelm. The Formation of the Historical World. In Wit

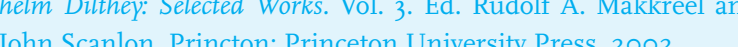
Husserl, Edmund. The Crisis of European Sciences and Transcender. Universtip Presess. Trans. David Carr. Evanston: Northwester Merleau-Ponty, Maurice. The Visible and the Invisible. Trans
Claude Leffort Evanston. Northwestern University Press, 1068 .

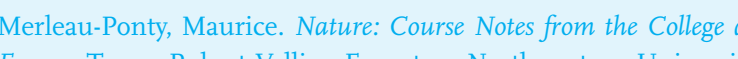
Press, 2003

Toadvine, Ted. Merleau-Ponty's Philosophy of Nature. Evanstor

Toadvine, Ted. Merteau-Ponths's Philosopp
Northwestern University Press, 2009. 


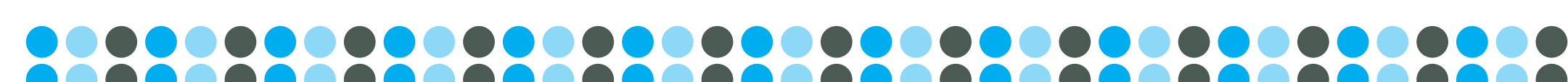

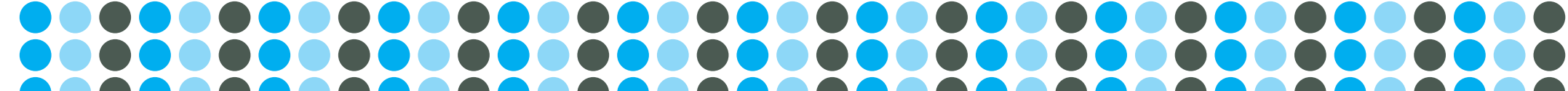

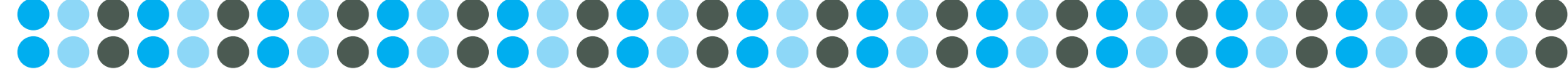
○

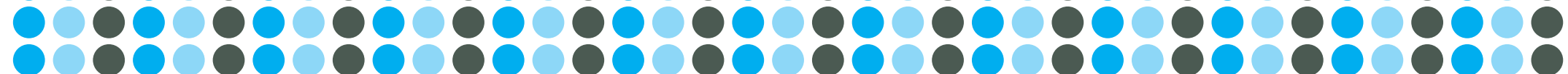

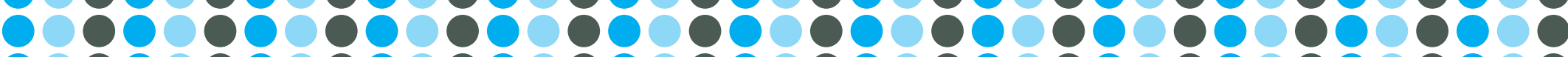

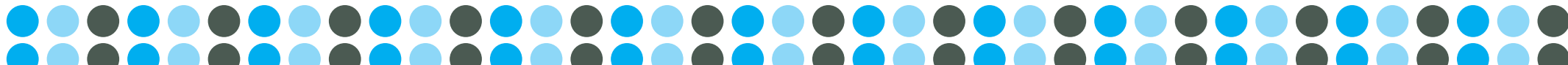

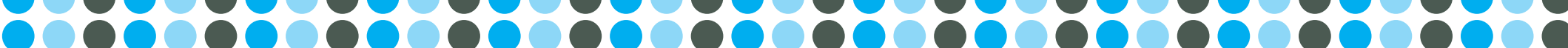

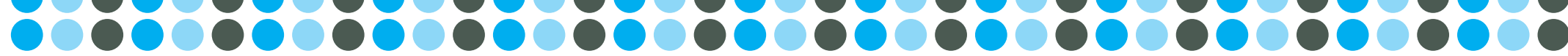
Q ○

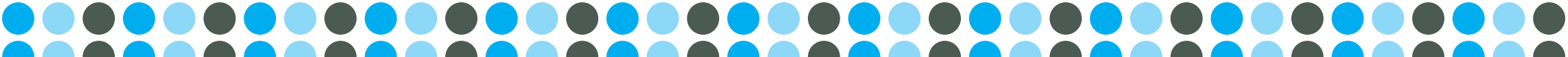
88808808808

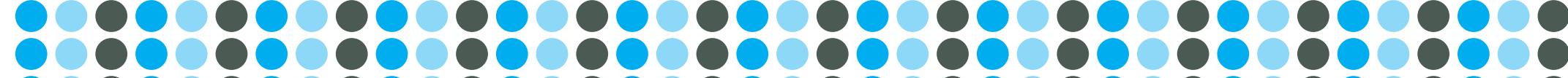

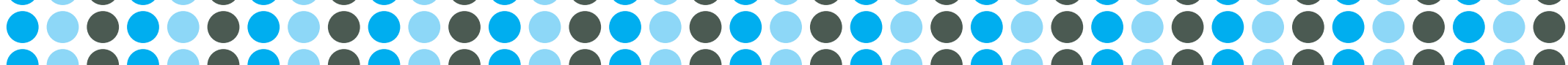
\&

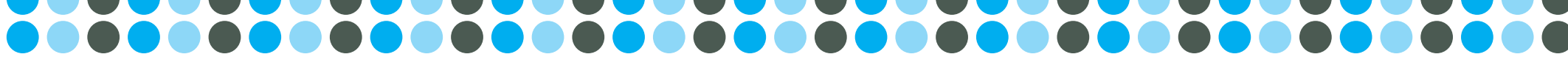

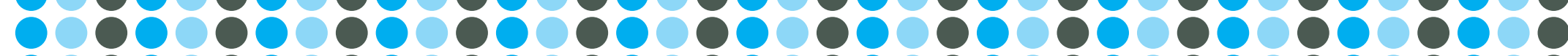
○

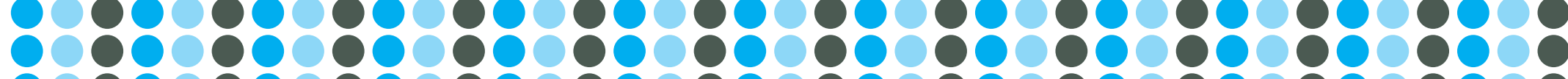
○

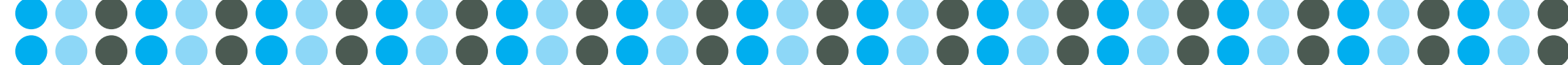
○ ○ \&888

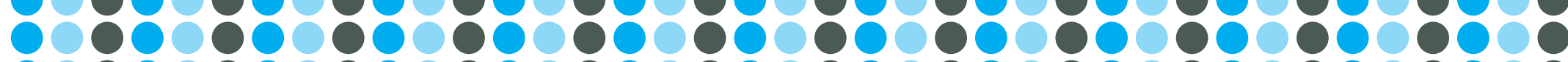
○

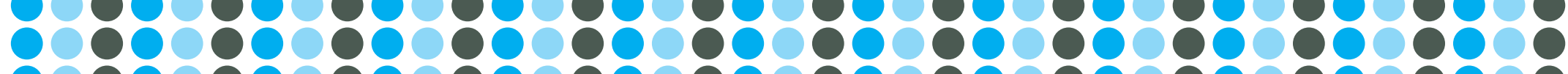

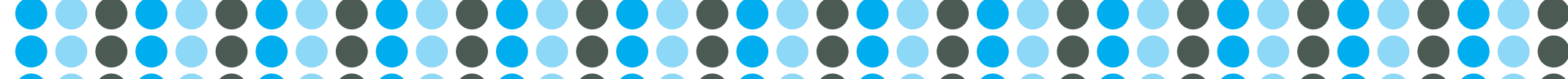

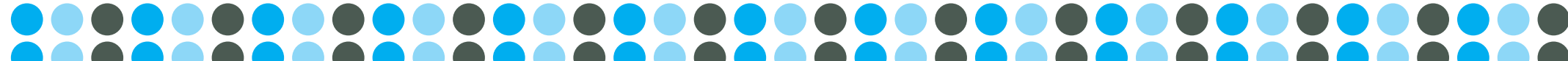

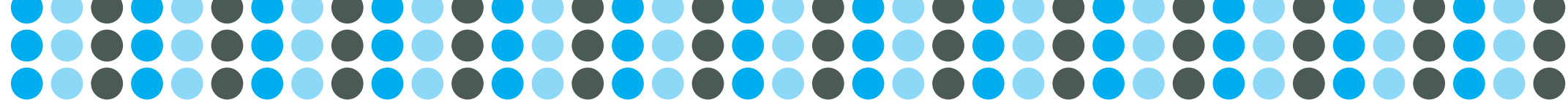

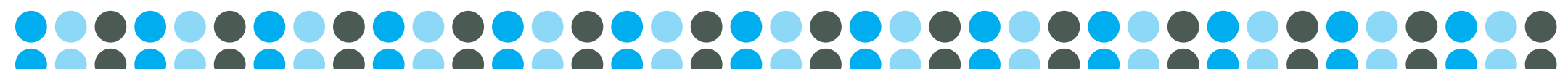

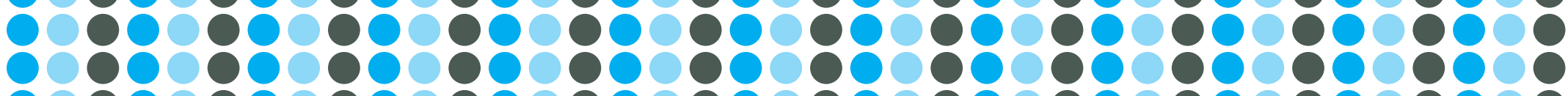

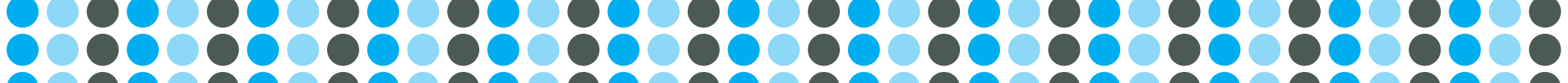

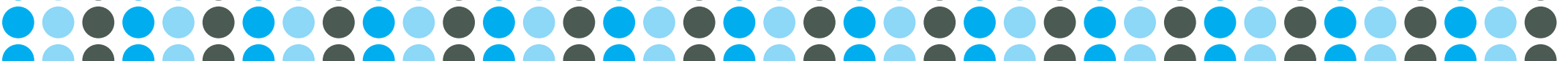
8 ○888 808888 ○88 ○

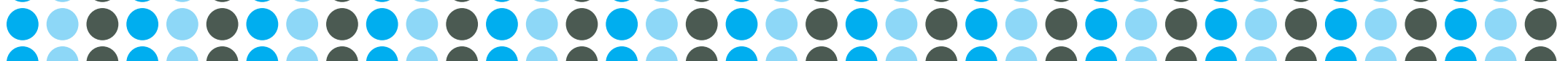
0 00000000000000000000000000000000009

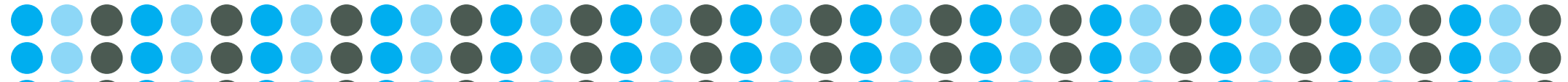
8 ८ ○

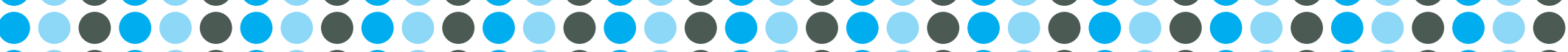

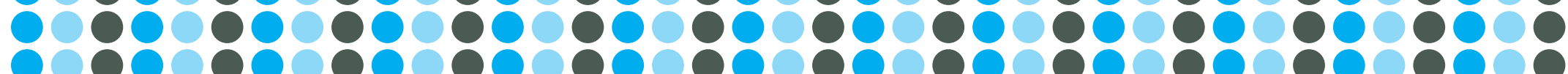

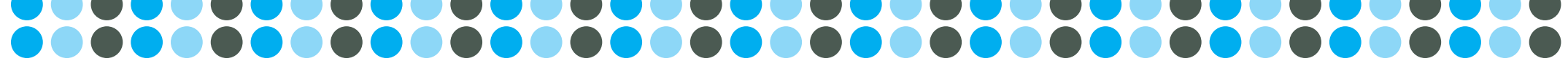

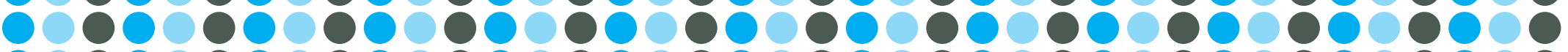

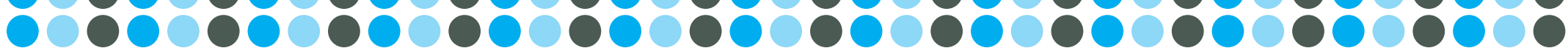
○0000000000000000000000000000000808

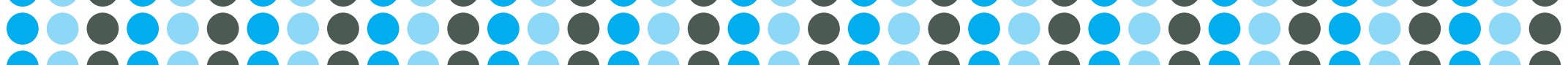
8

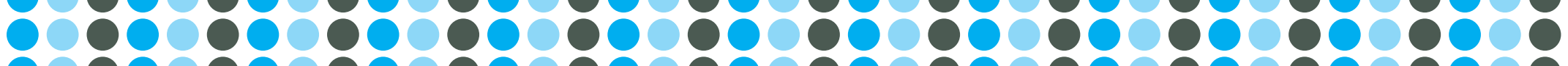

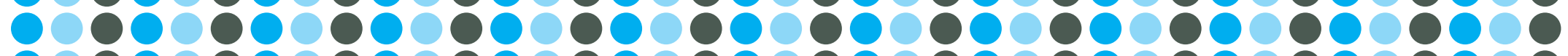

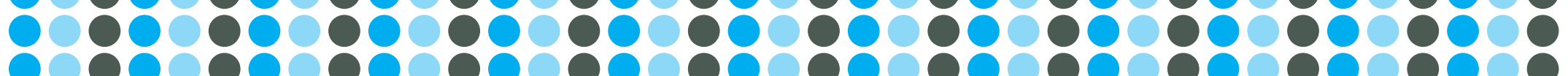

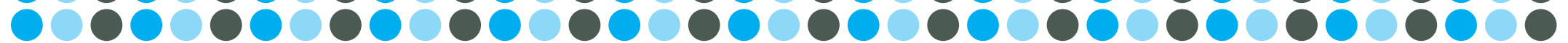
0000000000000000000000000000000000

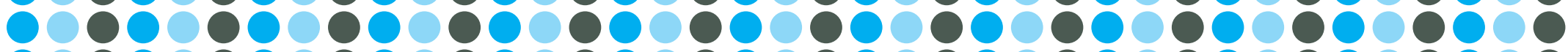

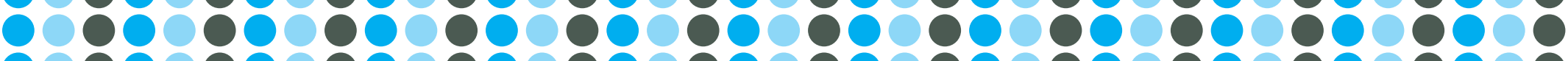

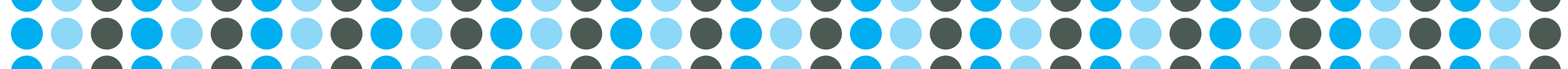
(2888

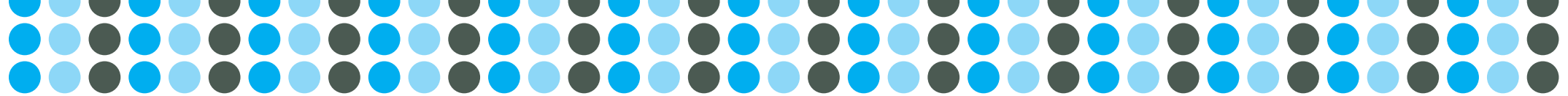




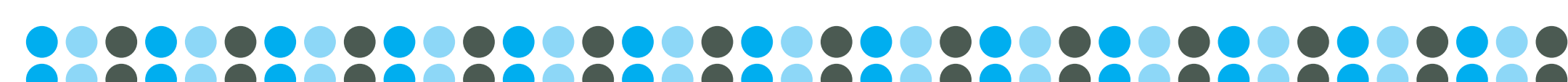

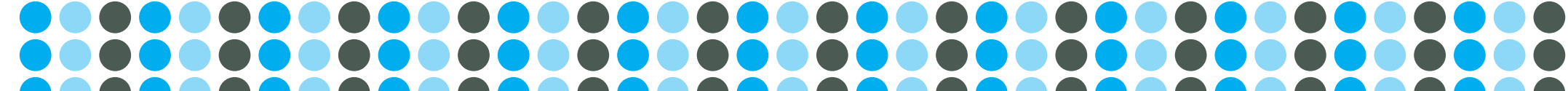

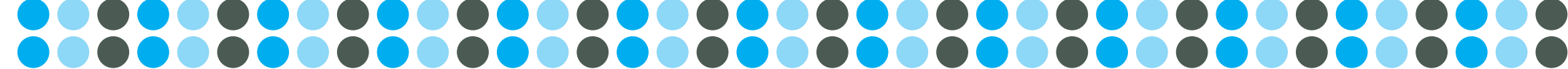
○

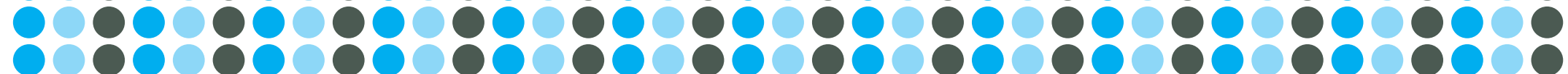

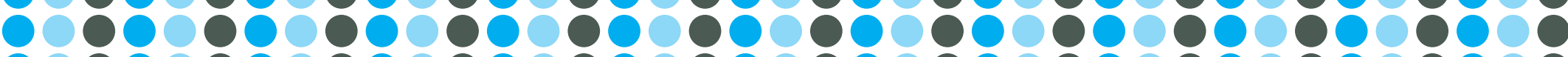

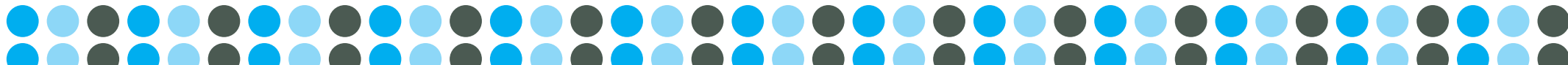

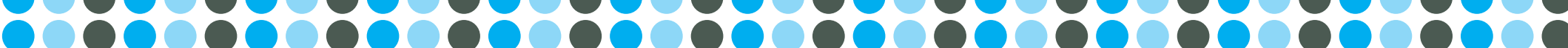

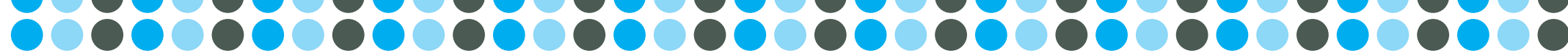
Q ○

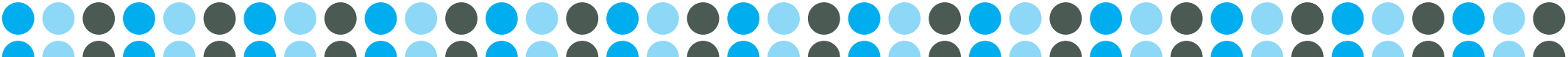
88808808808

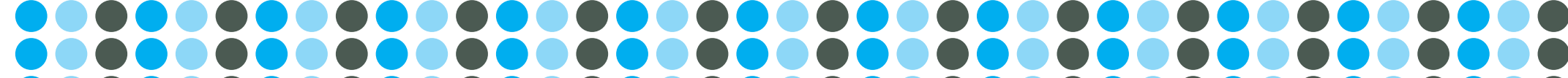

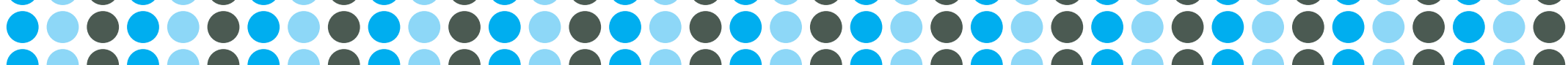
\&

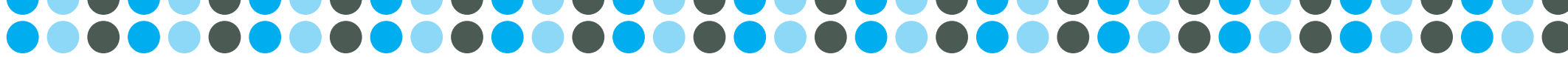

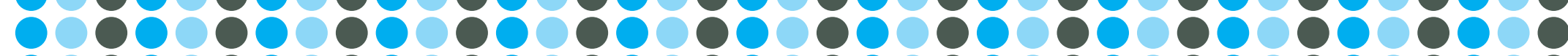
○

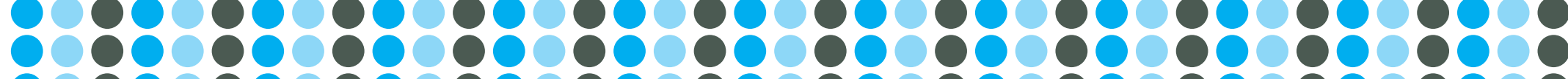
○

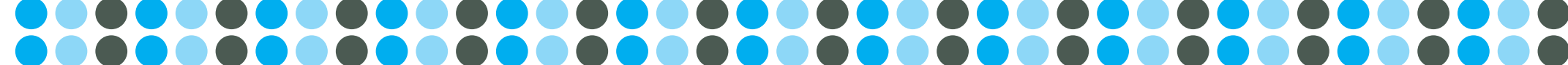
○ ○ \&888

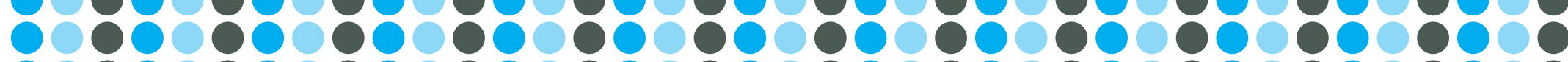
○

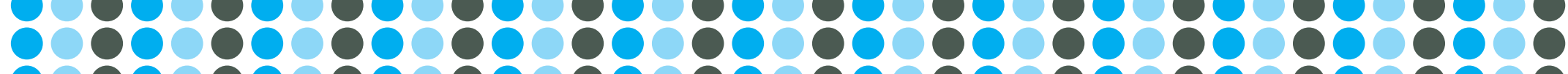

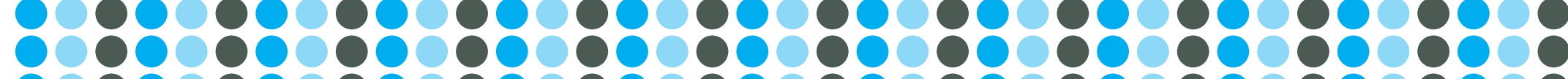

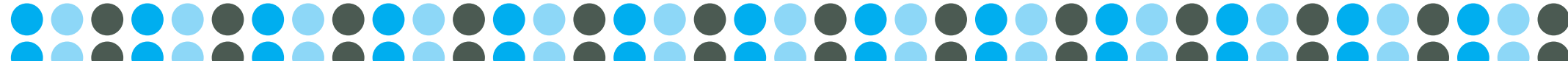

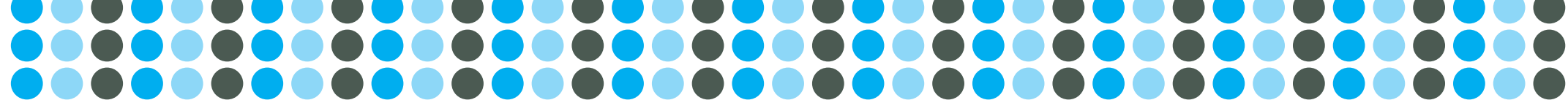

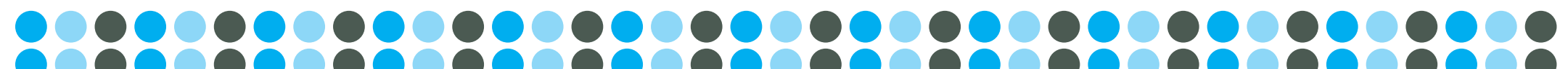

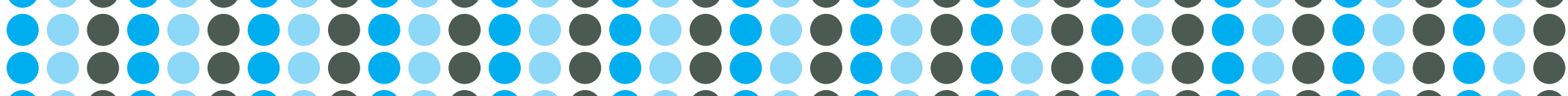

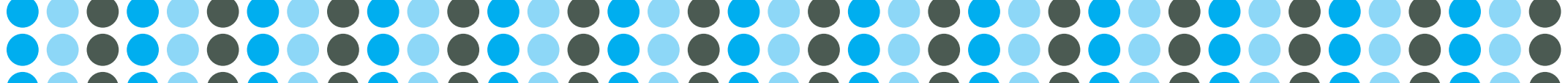

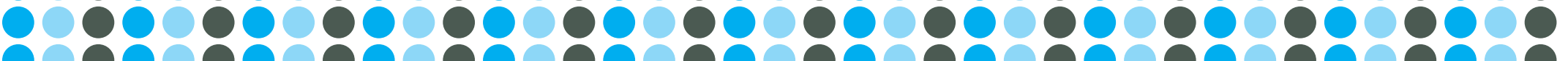
8 ○888 808888 ○88 ○

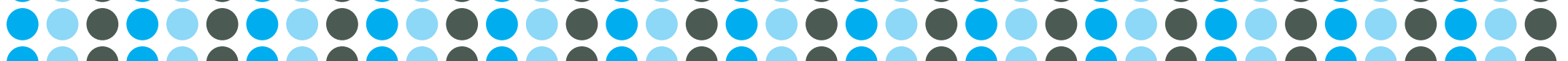
0 00000000000000000000000000000000009

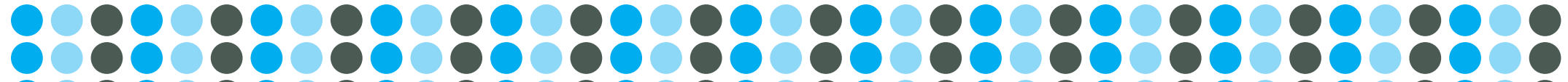
8 ८ ○

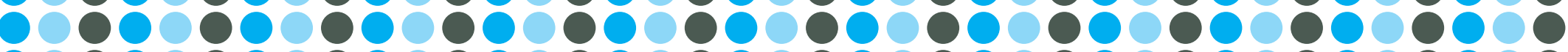

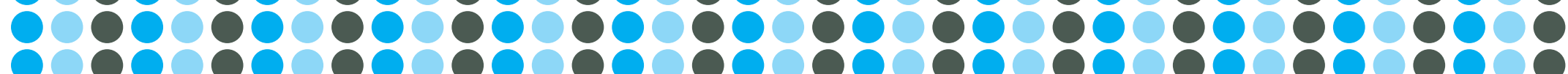

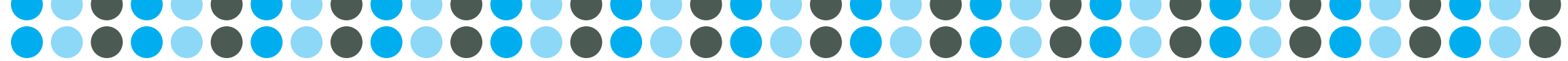

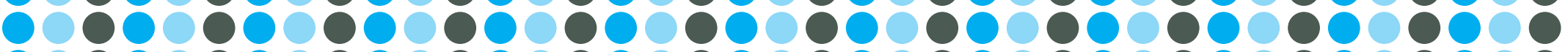

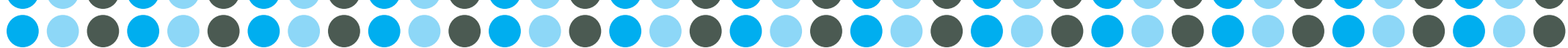
○0000000000000000000000000000000808

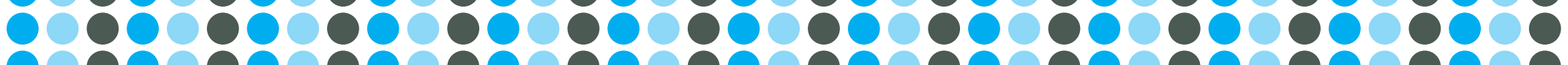
8

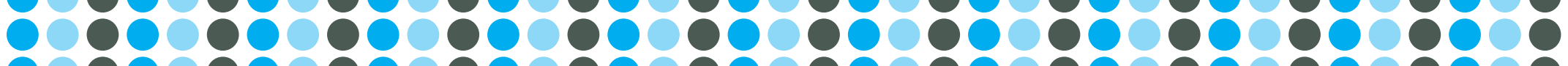

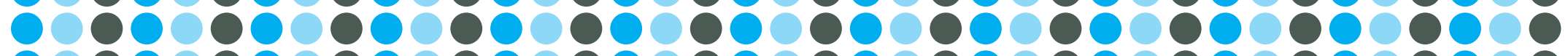

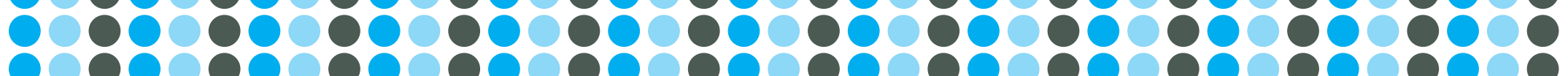

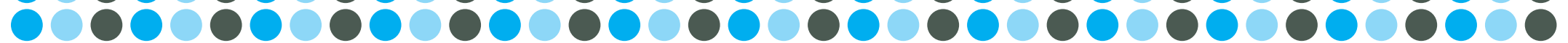
0000000000000000000000000000000000

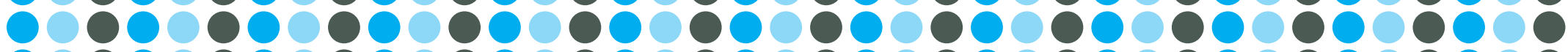

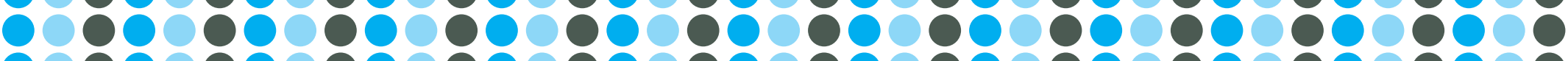

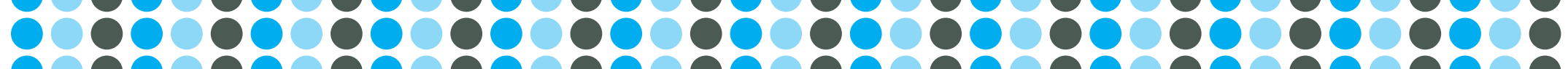
(2888

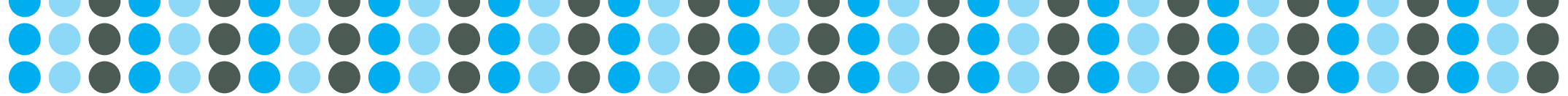




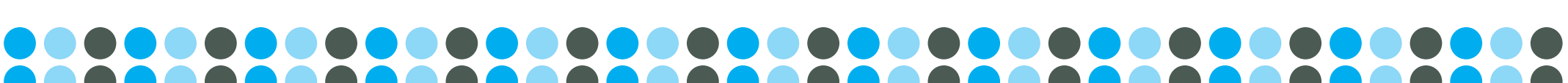

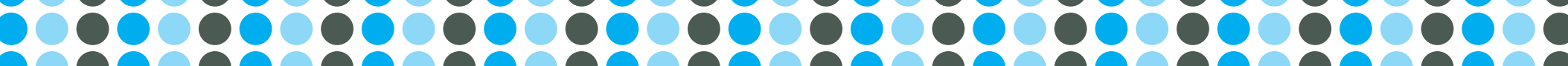

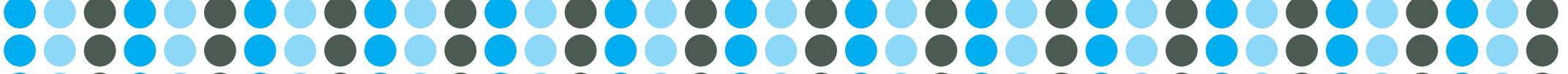

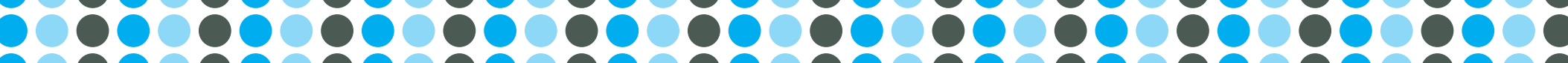

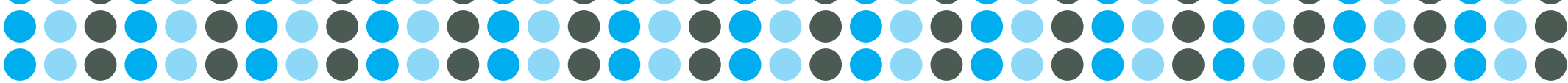

\section{AUTHOR BIOGRAPHIES}

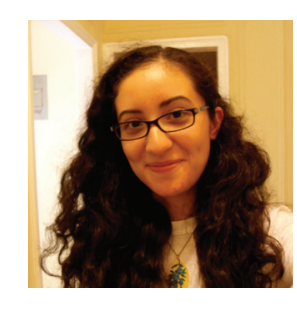

OSA MARIBEL COLORADO

is a member of the College of Arts and Sciences Class of 2oIr. As an undergraduate at Boston College, she

possible was a favorite endeavor for her. Her research published here was a final paper for the American Studies

edge Professor Richard Blake from the Film Studies Department for cultivating her interest in film and fil are

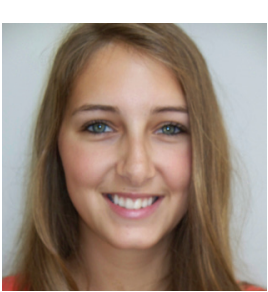

ENNA HOWARTH

S a member of the College of Arts \& Sciences class of 2014, majoring in English and minoring in Economics.

she graduates from Boston College. Jenna, a member of the College of Arts and Sciences Honors Program,

would like to thank Professor Timothy Duket and the students of his 20IO-20II Western Cultural Tradition classes for

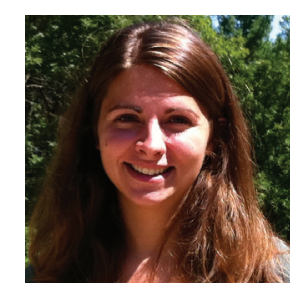

KAREN KOVAKA

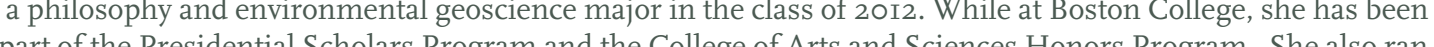

speaking and urban agriculture courses to middle school students through Citizen Schools. She has interned for

he International Water Management Institute in Bangalore, India and worked as a wilderness education in-

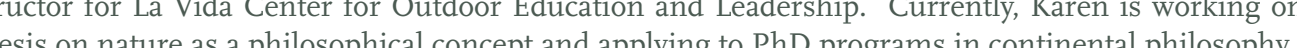

IPHAINE LEVERRIER

(tudied at Boston College as an exchange student from Institut d'Etudes Politiques in Paris ("Sciences Po")

specially took interest in theology and art courses. She wrote her featured article for a class about Frank Lloyd

Wright, taught by the wonderful Prof. Jeffery Howe. Tiphaine just finished her bachelor in political sciences and

specialize in human Rights law.

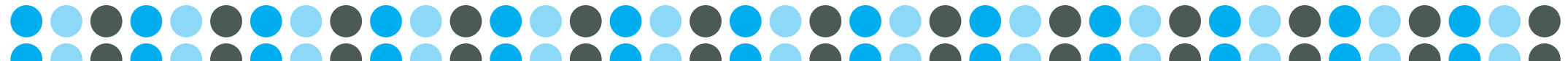
(2088 ○

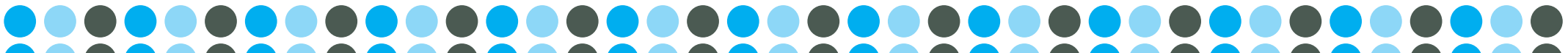
○○8

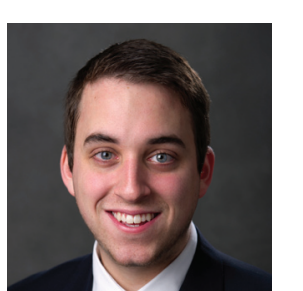

CACHART. MARTI

a recent College of Arts and Sciences graduate from the class of 20II. During his time at Boston College he

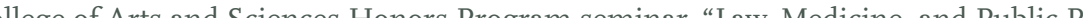
e took in the fall of his Senior year under Father John Paris. Zach was raised in Northern New Jersey, where his parents remain, and enjoys spend

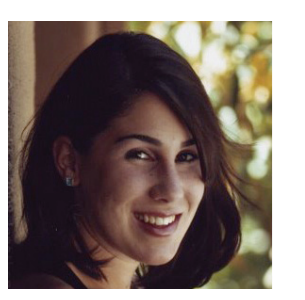

PHIA MORADIAN

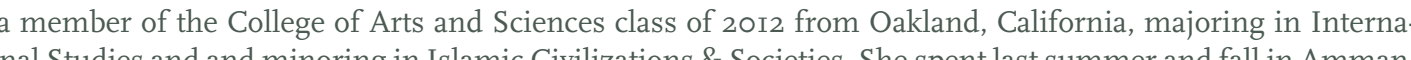
opment centers. Sophia plans to work internationally in the field of economic development and human rights.

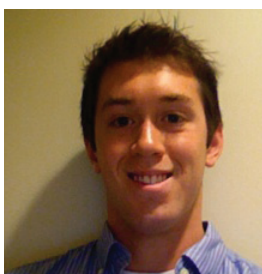

ANDREW ORR

is a former chemistry major in the Boston College Class of 201 and is now continuing his education at Robert Medicine, and Public Policy" seminar and was prompted by a search for how to best maintain the diennity of those who struggle with Alzheimer's disease.

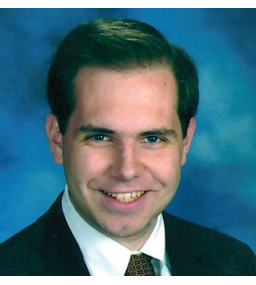

RIAN VARIAN

s a former Editor-in-chief of Elements who graduated summa cum laude in the class of 20 Ir from the Carroll

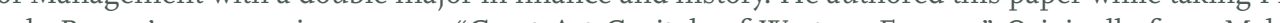
New York, Brian hopes to return to "the land of the bean and the cod" temporarily before pursuing a PhD in U.S. Economic History, with the goal of one day teaching at Boston College. 


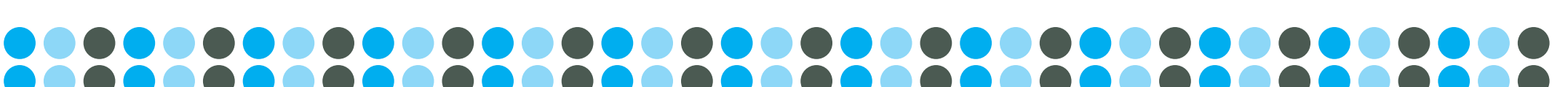

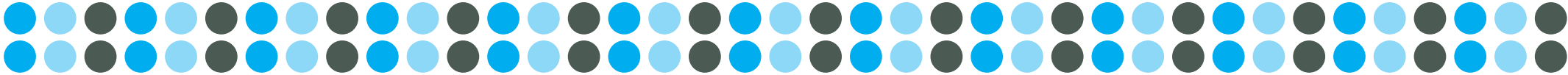
८ 0000090900900009000009000090000900

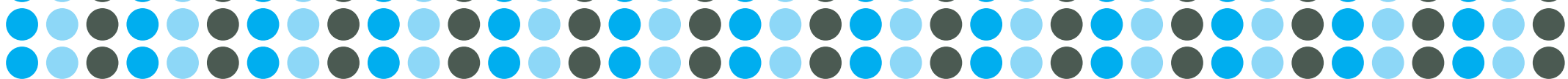
LIST OF ARTWORK

I5 WITHOUT MEMORY () Syldavia / iStockphoto

27 IRAQI IMMIGRANTS LEAVE JORDAN (D) Marco Di Lauro / Getty

TI IRAQI VICTIMS OF VIOLENCE RECEIVE EMERG ENCY CARE OUTSIDE OF IRAQ () Spencer Platt / Gety

36 mithras taurocton Scala / Art Resource, $N Y$

39 INTERIOR OF THE SYNAGOGUE OF DURA EUROPOS, 3RD CE. REPLICA. Erich Lessing / Art Resource, NY

48 COP STRUGgles WITH PROTESTER AT 1968 DEMOCRATIC NATIONAL () APA / Getty.

54 MADONNA AND CHILD OF JEANNE D'EVReuX (O) RéunNA AND CHILD OF JEANNE D'EVREUX

57 CHRIST'S DESCENT INTO LIMBO

() Réunion des Musées Nationau $/$ A

63 ORGAN DONOR () drbueller / iStockphoto.

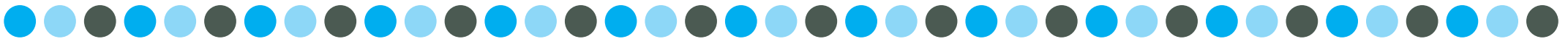

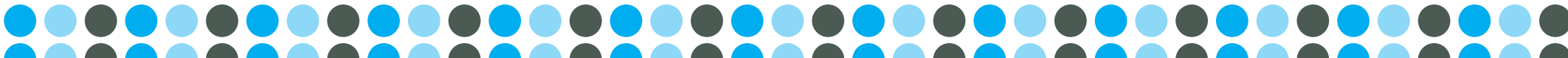
0

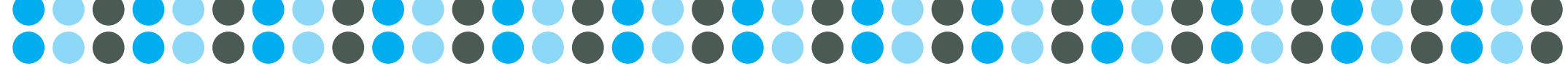

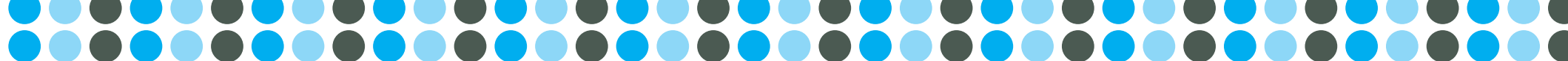
\$
66 HUMAN Heart () IngramPublishing / iStockphoto

75 FRANK LLOYD WRIGHT IN STUDIO AT TALIESIN, 1956 ( The Frank Lloyd Wright Foundation / Artists Rights Society, NY

77 WRIGHT, FRANK LLOYD (1867-1959) OThe Frank Lloyd Wright Foundation / Artists Rights Society, NY

84 maurice merleau-ponty (Thtp://www.philosophical-investigations.org/Users/PerigGouanvic/ur 86 WILHELM DILTHEY ๑ Atelier Dührkopp Berlin, around Igro 
S. 